Universidade de São Paulo

Instituto de Física

\title{
Estimativa das forças e torques articulares em seres humanos durante o andar em piscina com água rasa
}

\author{
Maria Isabel Veras Orselli \\ Orientador: Prof. Dr. Marcos Duarte
}

Dissertação de mestrado apresentada ao Instituto de Física para a obtenção do título de Mestre em Ciências.

Comissão Examinadora:

Profa. Dra. Emico Okuno (IF-USP)

Prof. Dr. Jefferson Fagundes Loss (EEF-UFRGS)

Prof. Dr. Marcos Duarte (EEFE-USP) 


\section{FICHA CATALOGRÁFICA}

\section{Preparada pelo Serviço de Biblioteca e Informação}

do Instituto de Física da Universidade de São Paulo

Orselli, Maria Isabel Veras

Estimativa das forças e torques articulares em seres humanos durante o andar em piscina com água rasa - São Paulo - 2008

Dissertação (Mestrado) - Universidade de São Paulo. Instituto de Fisica - Depto. de Fisica. Nuclear

Orientador: Prof. Dr. Marcos Duarte

Área de Concentração: Fisica.

Unitermos: 1. Biomecảnica; 2. Mecảnica dos Fluidos; 3. Locomoção; 4. Membros Inferiores; 5. Exercicio Fisico. 


\section{Agradecimentos}

Como eu demorei um longo tempo para finalizar o meu projeto de mestrado, deu tempo de inúmeras pessoas participarem deste processo. Algumas delas chegaram no meio do caminho, outras já faziam parte, há muito, da minha vida. Gostaria de não esquecer de ninguém neste agradecimento, mas os que me conhecem sabem que a memória não é meu forte, então, caso eu esqueça de alguém já peço desculpas antecipadamente. Queria então agradecer às seguintes pessoas:

Em primeiro lugar, ao Prof. Dr. Marcos Duarte, pela orientação durante estes quase quatro anos. Obrigada pelos ensinamentos e, principalmente, pela paciência. Aos meus colegas de laboratório, "atuais" e "antigos": Janina, Paulo, Reginaldo, Raquel, Thiago, Nadili, Bruno, Fernanda, Evandro, Cristina, André, Daniel Boari, Ana, Fernando, Wilson, Rogério, Beth, Rozy e Sandra. Agradeço muito pelo companheirismo, por todas as ajudas e por compartilharem comigo seus conhecimentos. Agradeço especialmente à Janina, ao Daniel Boari, ao Fernando, ao Rogério e ao Marcos pela força que me deram na coleta dos dados na piscina; ao Thiago e a Raquel pela ajuda na última prévia; e ao Wilson, meu companheiro nas disciplinas.

Agradeço a meus pais, Solange e Lourenço, por todo o cuidado e pelo esforço que fizeram para que eu pudesse chegar até aqui. Dedico este trabalho à vocês! Ao meu irmão Gabriel, pelo apoio e companheirismo. Ao Daniel, meu namorado, e sua família por todo carinho. E aos tios, primos e minha avó Livia por torcerem sempre por mim.

Aos meus amigos, todos, os que estão longe e os que estão mais perto. Obrigada por existirem e por compartilharem comigo as alegrias e tristezas. Em especial, agradeço à Laura, Gabi, Sabrina, Rê-Bia e Janina por me emprestarem a orelha e estarem sempre dispostas a ouvir e a ajudar. Ao meu time de Basquete, técnicos e meninas, vocês foram importantíssimos nestes anos! Aos colegas do Instituto de Física Silas, Rony e Diogo pela ajuda e atenção.

Agradeço à Profa. Dra. Elisangela Manffra e às amigas Claudiane, Gabi e Rê-Bia, pelas correções e sugestões sobre o texto da dissertação.

Agradeço à Professora Arlete, a tesourinha, por me apresentar à "Física"e à Marília, Camila e Cíntia, minhas companheiras na primeira investida no mundo da ciência. Vocês foram o 
começo de tudo! Agradeço à Berê por chamar minha atenção para a Biomecânica. Agradeço também ao Prof. Dr. Jorge Ernesto Horvath e ao Prof. Dr. Gustavo Medina Tanco, pela orientação durante a iniciação científica.

Agradeço finalmente a todos os voluntários que participaram dos experimentos, ao apoio financeiro do CNPq e aos funcionários da seção de pós-graduação Francisleine e Éber, por serem sempre gentis e prestativos. 


\section{Sumário}

$\begin{array}{ll}\text { Agradecimentos } & \text { i }\end{array}$

Lista de Figuras v

Lista de Tabelas $\quad$ viii

Resumo $\quad$ xi

Abstract $\quad$ xiii

1 Introdução 1

2 Revisão de Literatura $\quad 4$

2.1 A Análise do Andar Humano . . . . . . . . . . . . . . . . . . . 5

2.2 Diferenças Entre o Andar em Terra e em Água . . . . . . . . . . . . . . . . . . . . 9

2.3 Estimativas da Força de Arrasto . . . . . . . . . . . . . . . . 15

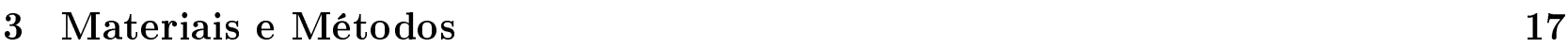

3.1 Dinâmica Inversa . . . . . . . . . . . . . . . . . . . . . . . . . . . . 17

3.2 O Modelo da Força de Arrasto . . . . . . . . . . . . . . . . . . . 23

3.3 Descrição Experimental . . . . . . . . . . . . . . . . . . . . . 31

3.3.1 A Aquisição de Dados em Piscina com Água Rasa . . . . . . . . . . . . . 32

3.3.2 A Aquisição de Dados no Laboratório . . . . . . . . . . . . . . . 35

3.4 Tratamento dos Dados . . . . . . . . . . . . . . . . . . 36

3.5 Análise Estatística . . . . . . . . . . . . . . . . . . . . . . . 38

$\begin{array}{lll}4 & \text { Resultados } & \mathbf{4 1}\end{array}$

4.1 Variáveis Cinemáticas . . . . . . . . . . . . . . . . . . . . 42

4.1 .1 Cinemática Descritiva . . . . . . . . . . . . . . . . 42

4.1 .2 Cinemática Angular e Segmentar . . . . . . . . . . . . . . . . . . . 43

4.2 Variáveis Cinéticas . . . . . . . . . . . . . . . . . . 56

4.2.1 Forças e Torques Externos . . . . . . . . . . . . 56

4.2 .2 Forças e Torques Internos . . . . . . . . . . . . . . . . . . . . 62

4.3 Relação entre a Força de Arrasto a Força de Reação do Solo Durante o Andar em Âgua . . . . . . . . . . . . . . . . . . . . . . . . . 73 
$\begin{array}{lll}5 & \text { Discussão } & \mathbf{7 7}\end{array}$

5.1 Cinemática do Andar em Ambiente Aquático . . . . . . . . . . . . . . . 78

5.1 .1 Cinemática Descritiva . . . . . . . . . . . . . . . 78

5.1 .2 Cinemática Articular e Segmentar . . . . . . . . . . . . . . . . . . 79

5.2 Cinética do Andar em Ambiente Aquático . . . . . . . . . . . . . . 82

5.2.1 Forças e Torques Externos . . . . . . . . . . . . . . 82

5.2 .2 Forças e Torques Internos . . . . . . . . . . . . . . . . . 85

5.2.3 O Papel da Força de Arrasto e do Empuxo nas Adaptações Realizadas Durante o Andar em Água . . . . . . . . . . . . . . . . . . . . . . . . . . . . . 90 90

5.2.4 Implicações e Estudos Futuros . . . . . . . . . . . . . . . . . . . . 91

6 Conclusão $\quad 93$

$\begin{array}{ll}\text { Anexo A Questionário de Anamnese Clínica } & 96\end{array}$

$\begin{array}{lll}\text { Anexo B } & \text { Termo de Consentimento Esclarecido } & 98\end{array}$

$\begin{array}{ll}\text { Referências Bibliográficas } & 101\end{array}$ 


\section{Lista de Figuras}

2.1 Ilustração caracterizando um passo, uma passada e as duas fases do ciclo do andar (adaptada de [1]). . . . . . . . . . . . . . . . . . . . . . .

2.2 Resultados obtidos por Barela [1] para : A)Ângulos articulares do tornozelo, joelho e quadril durante um ciclo do andar em ambiente aquático e terrestre. Nestes gráficos o sinal positivo representa dorsi-flexão para o tornozelo e flexão para o joelho e quadril; e B)Padrões das componentes de FRS também para os dois ambientes. A escala do eixo vertical esquerdo dá os valores de FRS normalizados pelo peso aparente em cada ambiente e o eixo vertical direito dá o valor das componentes obtidas em água, normalizadas pelo peso corporal. . .

2.3 Curvas típicas para os torques articulares sobre o tornozelo (ankle), joelho (knee) e quadril (hip) obtidas por Miyoshi e colaboradores [28] para a fase de apoio do andar (stance phase). O tempo está normalizado pelo período do apoio e os torques pelo produto entre o peso corporal e o comprimento do membro inferior $\left(P C * L_{m}\right) \ldots \ldots \ldots \ldots \ldots \ldots \ldots$

3.1 A)Modelo de segmentos rígidos usado para representar o corpo humano neste estudo. B)Representação dos ângulos segmentares do pé, perna, coxa e tronco (linhas pontilhadas) e ângulos articulares do tornozelo, joelho e quadril (linhas cheias). . . . . . . . . . . . . . . . . .

3.2 Diagrama de corpo livre para os segmentos pé, perna e coxa. O ponto de aplicação da força de reação do solo corresponde ao centro de pressão e o ponto de aplicação dos pesos e empuxos ao centro de massa. . . . . . . . . . . . . . .

3.3 Modelo geométrico do corpo humano proposto por Hanavan [25], onde a coxa e o pé são modelados por sólidos elípticos e a perna por um tronco de cone circular segundo os parâmetros descritos na tabela 3.2. . . . . . . . . . . . . . .

3.4 Representação da área da secção transversal perpendicular a sua velocidade de deslocamento $\left(d A_{\perp}\right)$, para uma faixa infinitesimal do sólido que modela o segmento corporal. Os eixos $x$ e $y$ representam o referencial do laboratório enquanto o eixo $z$ representa o referencial local (eixo longitudinal do segmento), que tem origem na articulação sobre a qual se deseja calcular o torque. . . . .

3.5 Arranjo experimental utilizado para aquisição de dados em ambiente aquático. Pode-se ver a plataforma de força inserida na passarela entre as duas faixas

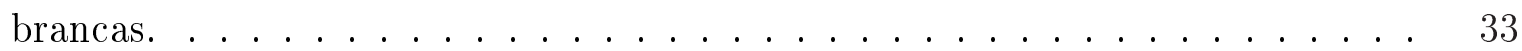

3.6 Vista frontal e lateral do posicionamento dos marcadores. . . . . . . . . . . . . 34

3.7 Quadro utilizado para a calibração do espaço em ambiente aquático. . . . . . . .

3.8 Calibração do espaço vista pela câmera posicionada no canto esquerdo do laboratório (na esquerda) e pela câmera posicionada no canto direito (na direita) . 
4.1 Ângulo articular do tornozelo $\left(\theta_{\mathrm{T}}\right)$, do joelho $\left(\theta_{\mathrm{J}}\right)$ e do quadril $\left(\theta_{\mathrm{Q}}\right)$ ao longo de uma passada. O tempo está normalizado pelo período do ciclo e as barras de incerteza representam o desvio padrão da média. As setas indicam os sentidos de rotação: flexão plantar (FP) e dorsi-flexão (DF) para o tornozelo; flexão (Flex) e extensão (Ext) para o joelho e o quadril.

4.2 A)Ângulo no contato inicial e B) Amplitude de movimentação das articulações do tornozelo, joelho e quadril. As barras de incerteza representam o desvio padrão $\mathrm{e}^{*}$ indica diferença entre os ambientes. . . . . . . . . . . . . . . .

4.3 Ângulos de dorsi-flexão e flexão plantar máximos, nas fases de apoio e balanço, para a articulação do tornozelo durante o andar em terra e em água. As barras de incerteza representam o desvio padrão e o * indica diferença entre os ambientes. 47

4.4 Ângulo de flexão máxima do joelho nos ambientes aquático e terrestre. As barras de incerteza representam o desvio padrão. . . . . . . . . . . . . . . . . .

4.5 Ângulo de máxima extensão ao longo do ciclo e de flexão máxima na fase de apoio, para a articulação do quadril, durante o andar em terra e água. As barras de incerteza representam o desvio padrão. . . . . . . . . . . . . . . . . .

4.6 Velocidades angulares do tornozelo $\left(\omega_{\mathrm{T}}\right)$, joelho $\left(\omega_{\mathrm{J}}\right)$ e quadril $\left(\omega_{\mathrm{Q}}\right)$ durante um ciclo completo do andar. As setas indicam os sentidos de rotação - flexão plantar (FP) e dorsi-flexão (DF) para o tornozelo, flexão (Flex) e extensão (Ext) para o joelho e o quadril - e as barras de incerteza representam o desvio padrão. . .

4.7 Comparação entre os ambientes dos valores representativos das velocidades angulares máximas do tornozelo e do joelho, nos dois sentidos de rotação, e da velocidade máxima de flexão e média (nos primeiros $50 \%$ do ciclo) de extensão para o quadril. $\mathrm{O} *$ indica diferença estatística significativa e as barras de incerteza representam o desvio padrão.

4.8 Comportamento das componentes horizontal (primeira coluna), vertical (coluna central) e do módulo (terceira coluna) do vetor velocidade do centro de massa dos segmentos pé, perna e coxa ao longo de uma passada. A barra de incerteza representa o desvio padrão. . . . . . . . . . . . . . . . . . .

4.9 Valores máximos da velocidade do centro de massa para os três segmentos. O * indica diferença entre os ambientes e a barra de incerteza o desvio padrão. . .

4.10 Componentes vertical $\left(F R S_{\mathrm{V}}\right)$ e ântero-posterior $\left(F R S_{\mathrm{AP}}\right)$ da força de reação do solo (FRS) para o andar em terra e água. As componentes de FRS estão em porcentagem do peso corporal e as barras de incerteza representam o desvio padrão. . . . . . . . . . . . . . . . . . . . .

4.11 Comportamento das componentes vertical e horizontal e do módulo do vetor força de arrasto durante uma passada realizada em ambiente aquático. A força é representada em porcentagem do peso corporal e as barras de incerteza fornecem o desvio padrão da média.

4.12 Torques produzidos pela força de arrasto no tornozelo, joelho e quadril durante um ciclo completo do andar em ambiente aquático. Os torques estão normalizados pelo produto entre o peso corporal e comprimento do membro inferior $\left(P C * L_{M}\right)$ e as barras de incerteza representam o desvio padrão. . . . . . . . . . .

4.13 Forças articulares que atuam no tornozelo, joelho e quadril durante uma passada. As forças estão reportadas em porcentagem do peso corporal e as barras de incerteza representam o desvio padrão. 
4.14 Valor máximo atingido pela força articular e suas componentes para as articulações do tornozelo joelho e quadril. $\mathrm{O} *$ indica diferença entre os valores encontrados para os dois ambientes e as barras de incerteza representam o desvio padrão. . . . . . . . . . . . . . . . . . . . .

4.15 Intensidade média, dada pela raiz quadrática média (RQM), da força de arrasto e de suas componentes durante a fase de apoio e balanço para as articulações do tornozelo, joelho e quadril. $\mathrm{O} *$ indica diferença estatística entre os valores encontrados para os dois ambientes e as barras de incerteza representam o desvio padrão. . . . . . . . . . . . . . . . . . . . . .

4.16 Torques internos resultantes que atuam nas articulações do tornozelo (gráfico superior), joelho (gráfico central) e quadril (gráfico inferior) durante um ciclo completo da marcha, para os dois ambientes. Os torques estão normalizados pelo produto entre o peso corporal e o comprimento do membro inferior $\left(P C * L_{m}\right)$ e as barras de incerteza representam o desvio padrão. . . . . . . . . . . .

4.17 Máximo torque articular dorsi-flexor $\left(\mathcal{T}_{\text {DFMax }}\right)$ e flexor plantar $\left(\mathcal{T}_{\text {FPMax }}\right)$ para o tornozelo e máximos torques flexores $\left(\mathcal{T}_{\text {FxMax }}\right)$ e extensores $\left(\mathcal{T}_{\text {ExMax }}\right)$ para o joelho e para o quadril. Os torques estão normalizados pelo produto entre o peso corporal e o comprimento do membro inferior $\left(P C * L_{m}\right)$ e as barras de incerteza representam o desvio padrão. $O *$ indica diferença entre os valores obtidos nos dois ambientes. . . . . . . . . . . . . . . . 88

Contribuição do torque da força de arrasto para o torque articular resultante no ambiente aquático. A curva em azul representa o inverso do torque da força de arrasto e a curva em vermelho o torque interno resultante. As barras de incerteza indicam o desvio padrão. . . . . . . . . . . . . . . . .

4.19 Potência articular (normalizada pelo peso corporal) do tornozelo, do joelho e do quadril, obtida durante o andar em ambiente terrestre (gráficos da primeira coluna) e durante o andar em ambiente aquático (gráficos da coluna central). Os gráficos da última coluna mostram a comparação em mesma escala das curvas nos dois ambientes. As barras de incerteza representam o desvio padrão. . . .

4.20 Componentes horizontal e vertical e módulo da força de arrasto que age sobre o tronco inferior (TI) e sobre o tronco médio (TM) durante um ciclo da marcha em ambiente aquático. . . . . . . . . . . . . . . .

4.21 A)Gráfico do impulso da componente horizontal de $F R S$ em função do impulso da componente horizontal do arrasto durante a fase de apoio único. A reta em vermelho representa o ajuste linear feito através do método dos mínimos quadrados. B) Gráfico de resíduo referente ao ajuste. . . . . . . . . . . . . . 


\section{Lista de Tabelas}

2.1 Resultado do estudo de Barela e colaboradores [3] para o período $\left(T_{p}\right)$, comprimento $\left(L_{p}\right)$ e velocidade $V_{p}$ da passada e para a duração da fase de apoio normalizada pelo período da passada $\left(T_{a_{\mathrm{NORM}}}\right)$, durante o andar em ambiente aquático e terrestre. . . . . . . . . . . . . . . . . . .

2.2 Valores médios para o impacto e para o primeiro e o segundo pico da força de reação do solo vertical, além do valor do impulso da componente ânteroposterior, obtidos por Barela e colaboradores para o ambiente terrestre e aquático (primeira e segunda colunas) [3]. Os valores apresentados na segunda coluna estão normalizados pelo peso aparente em água $(\dagger)$, já na terceira coluna são apresentados os valores re-normalizados pelo peso corporal. Esta re-normalização foi realizada a partir de dados dos autores. . . . . . . . . . . . . . . . . . .

3.1 Medidas necessárias à aplicação do modelo geométrico de Hanavan [25] . . . .

3.2 Representação dos segmentos corporais por sólidos geométricos segundo o modelo de Hanavan [23, 25]. A última coluna relaciona os parâmetros antropométricos do corpo do sujeito com as dimensões do sólido que melhor representa cada segmento. Nas equações, L representa o comprimento do sólido, a representa o raio da elipse na direção perpendicular ao pano sagital e e $\mathbf{b}$ o raio no plano sagital. Os índices $\mathbf{p}$ e $\mathbf{d}$ diferenciam as extremidades proximal e distal. . . . . . . . . . . . . . . .

4.1 Média (desvio padrão) do período da passada $\left(T_{p}\right)$, do período da fase de apoio absoluto $\left(T_{a}\right)$ e normalizado $\left(T_{a_{\mathrm{NORM}}}\right)$, do comprimento $\left(L_{p}\right)$ e da velocidade da passada $\left(V_{p}\right)$, obtidos durante o andar em terra e em água. As duas últimas colunas fornecem respectivamente o valor de p do teste de Shapiro-Wilk e do teste t. $\mathrm{O} *$ indica diferença entre os ambientes. . . . . . . . . . . . .

4.2 Amplitude média (desvio padrão) do deslocamento angular das articulações do membro inferior nos dois ambientes. As duas últimas colunas representam, respectivamente, o valor de $\mathrm{p}$ do teste de Shapiro-Wilk e do teste t. . . . . . . .

4.3 Ângulo articular médio (desvio padrão) no contato inicial (AI). As duas últimas colunas representam o valor de $\mathrm{p}$ do teste de Shapiro-Wilk e do teste t. $\mathrm{O} *$ indica diferença entre os ambientes. . . . . . . . . . . . . .

4.4 Valores representativos (média (desvio padrão)) para os ângulos de flexão plantar e dorsi-flexão máximos do tornozelo, nas fases de apoio e de balanço, e respectivos instantes de ocorrência (IO). Nas duas últimas colunas estão reportados os valores de p para o teste de Shapiro-Wilk e para o teste t, com o * indicando diferença entre os ambientes. . . . . . . . . . . . . . 
4.5 Valores médios (desvio padrão) dos ângulo de flexão máxima do joelho, da extensão máxima e da flexão máxima na fase de balanço para o quadril e os instantes em que ocorreram tais eventos (IO). Nas duas últimas colunas estão reportados os valores de p do teste de Shapiro-Wilk e do teste t. . . . . . . . . . . . .

4.6 Valores representativos da velocidade angular máxima, nos dois sentidos de rotação, para as articulações do membro inferior, com exceção do quadril para o qual esta reportada a velocidade média de extensão ao invés da máxima. Tais valores representativos consistem da média do grupo (desvio padrão) nos dois ambientes. Nas duas últimas colunas encontram-se os valores de $\mathrm{p}$ dos testes estatísticos e ${ }^{*}$ indica diferença entre os ambientes. . . . . . . . . . . .

4.7 Média do grupo (desvio padrão) dos valores máximos e mínimos alcançados pela componente horizontal da velocidade do centro de massa $\left(V C M_{\mathrm{H}}\right)$ de cada segmento, ao longo do ciclo, nos dois ambientes. As duas últimas colunas reportam o valor de $\mathrm{p}$ dos testes estatísticos e o ${ }^{*}$ indica diferença entre os valores obtidos nos dois ambientes. . . . . . . . . . . . . . . . .

4.8 Média do grupo (desvio padrão) da magnitude máxima da componente vertical da velocidade do centro de massa $\left(\left|V C M_{\mathrm{V}}\right|\right)$ de cada segmento em terra e em água. Nas últimas colunas estão reportados os valores de p dos testes estatísticos, com o* indicando diferença entre os valores obtidos nos dois ambientes. . . . .

4.9 Média (desvio padrão) dos valores máximos e mínimos do módulo da velocidade do CM de cada segmento, nos dois ambientes. Nas últimas colunas estão reportados os valores de $\mathrm{p}$ do teste de Shapiro-Wilk e do teste t. $\mathrm{O} *$ indica diferença significativa entre os ambientes. . . . . . . . . . . . . . .

4.10 Faixa de variação do Número de Reynolds de cada segmento nos dois ambientes. 55

4.11 Valor médio (desvio padrão) para o primeiro e para o segundo pico da componente vertical da força de reação do solo, para o valor máximo e o mínimo da componente ântero-posterior e para os respectivos instantes em que estes eventos ocorrem (IO). Nas duas últimas colunas estão reportados os valores de p dos testes estatísticos e o* indica diferença significativa entre os ambientes. . . . .

4.12 Média (desvio padrão) do valor máximo, em módulo, da componente horizontal, da componente vertical e do vetor força de arrasto, que age nos segmentos pé, perna e coxa durante o andar em ambiente aquático. São também reportados os instantes de ocorrência destes eventos (IO) em porcentagem do período do ciclo. . . . . . . . . . . . . . . . . . . .

4.13 Máximos torques da força de arrasto que atuam sobre as articulações do tornozelo, joelho e quadril durante o andar em terra e água. As duas últimas colunas mostram o valor de $\mathrm{p}$ dos testes estatísticos $\mathrm{e} *$ indica diferença significativa

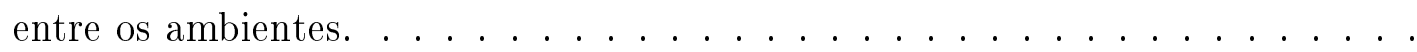

4.14 Média (desvio padrão) do valor máximo atingido pelo módulo do vetor força articular e por suas componentes, para o tornozelo, joelho e quadril. Nas duas últimas colunas estão reportados os valores de $\mathrm{p}$ dos testes estatísticos. $\mathrm{O}$ * representa diferença significativa entre os valores encontrados em cada ambiente. 
4.15 Valores representativos (média (desvio padrão)) da raiz quadrática média da componente vertical $\left(F_{\mathrm{V}}\right)$, da componente horizontal $\left(F_{\mathrm{H}}\right)$ e do módulo do vetor força articular, calculados para o tornozelo, para o joelho e para o quadril, durante as fases de apoio e balanço. As duas últimas colunas reportam o valor de $\mathrm{p}$ dos testes estatísticos. $\mathrm{O}$ sinal ${ }^{\sharp}$ indica não normalidade da amostra, $\dagger$ indica que foi usado o Teste de Wilcoxon (TW) ao invés do teste t (TT) e o * indica diferença entre os valores encontrados em terra e água. . . . . . . . . .

4.16 Média (desvio padrão) dos torques articulares no instante de contato inicial $\left(\tau_{\mathrm{CI}}\right)$, para o tornozelo, o joelho e o quadril. As duas últimas colunas reportam $\mathrm{o}$ valor de $\mathrm{p}$ dos testes estatísticos e $\mathrm{o}{ }^{*}$ indica diferença significativa entre os ambientes. . . . . . . . . . . . . . . . . .

4.17 Valores representativos (média(desvio padrão)) do máximo torque articular $\left(\mathcal{T}_{\text {MAx }}\right)$ dorsi-flexor e flexor plantar, que atua sobre o tornozelo, e do máximo torque flexor e extensor que atuam sobre o joelho e sobre o quadril. Nas duas últimas colunas estão reportados os valores de $\mathrm{p}$ dos testes estatísticos e o * indica diferença significativa entre os ambientes. . . . . . . . . . . . . .

4.18 Valores representativos (média(desvio padrão)) para a potência articular máxima e mínima do tornozelo, do joelho e do quadril nos dois ambientes. As duas últimas colunas reportam o valor de $\mathrm{p}$ dos testes estatísticos. O sinal ${ }^{\sharp}$ indica a não normalidade da amostra, † indica que foi usado o Teste de Wilcoxon (TW) ao invés do teste t (TT) e o * indica diferença significante entre os valores encontrados em terra e água. . . . . . . . . . . . . . . . . . . . 


\title{
Resumo
}

\section{Estimativa das forças e torques articulares em seres humanos durante o andar em piscina com água rasa}

\author{
Maria Isabel Veras Orselli \\ Orientador: Prof. Dr. Marcos Duarte
}

\begin{abstract}
O ambiente aquático é um recurso bastante utilizado na prática de atividade física, reabilitação e lazer. No entanto, apesar de seu amplo uso, pouco se sabe sobre a demanda mecânica a que nosso corpo está sujeito durante a atividade física neste ambiente. O conhecimento das cargas sobre o corpo durante exercícios em água poderá permitir uma melhor compreensão das adaptações realizadas pelo ser humano para se movimentar neste ambiente e, ainda, auxiliar na prescrição correta de atividades físicas. O objetivo deste trabalho foi, portanto, estimar as forças e torques articulares sobre o tornozelo, joelho e quadril de adultos jovens, saudáveis, durante o andar em ambiente terrestre e aquático (água rasa). Para tanto, conduzimos um experimento no qual 10 indivíduos caminharam com velocidade auto-selecionada nos dois ambientes. Durante o andar medimos as componentes da força de reação do solo, usando uma plataforma de força, e filmamos os movimentos, com auxílio um de sistema de aquisição de imagens. As forças e torques internos foram determinadas através da técnica da dinâmica inversa e de estimativas das forças de arrasto e respectivos torques, realizadas a partir da teoria das faixas ("strip theory"). Os resultados referentes à cinemática articular e descritiva e às forças de reação do solo foram, no geral, semelhantes aos resultados apresentados em estudos anteriores, indicando que não há mudanças na coordenação dos movimentos articulares nem re-organização temporal da passada durante o andar em água. Entretanto, foi possível perceber mudanças nos sentidos dos torques articulares durante o ciclo para o joelho e o quadril, sugerindo que, para manter a mesma coordenação articular sob a ação do empuxo e do arrasto, é necessário promover mudanças nos padrões dos torques internos nestas articulações. Com relação à articulação do tornozelo, os resultados mostram que há diminuição nos torques
\end{abstract}


articulares necessários para gerar a flexão plantar durante o apoio. A estimativa das forças de arrasto se mostrou adequada para descrever a situação experimental, o que indica que os valores apresentados neste estudo são adequados para descrever a carga mecânica no aparelho locomotor durante o andar em piscina com água rasa.

Palavras-chaves: biomecânica, mecânica dos fluidos, locomoção, membros inferiores, exercício físico. 


\begin{abstract}
Estimates of joint forces and torques during human walking in pool with shallow water

Maria Isabel Veras Orselli

Adviser: Prof. Dr. Marcos Duarte
\end{abstract}

The aquatic environment is a resource often used for the practice of physical activity, rehabilitation, and leisure. However, despite its extensive use, little is known about the mechanical demand that our body is subjected during physical activity in this environment. The knowledge of the load on the human body during water exercise will give us a greater understanding of the adaptations of the human being in water and assist the health professional to the correct prescription for physical activities. The goal of this work was, therefore, to estimate the internal joint forces and moments on the ankle, knee, and hip joints of young healthy adults during walking in the terrestrial and aquatic (shallow water) environments. For that, we conducted an experiment in which 10 subjects walked with self-selected speed in both environments. During the experiment, we measured the components of ground reaction forces, with a force plate, and recorded the subject's movements with a video analysis system. To find the forces and moments we used the inverse dynamics procedure and the calculation of drag forces and moments were based on the strip theory. The results concerning the joints and descriptive kinematics and the ground reaction forces were, in general, similar to the results presented in previous studies, indicating that there aren't changes in the coordination of joint movements or a re-organization of the stride during walking in water. Meanwhile, we were able to see changes in the directions of joint moments during the gait cycle for the knee and hip joints, suggesting that to keep the same joint coordination under the action of drag and buoyancy, it is necessary to promote changes in the patterns of internal moments in these joints. As for the ankle, the results showed that there is a decrease in joint moments necessary to generate the plantar flexion during the support phase. The estimation of the drag forces was adequate to 
describe the experimental situation, which suggests that the values presented here can describe correctly the mechanical load on the locomotor system during walking in shallow water.

Keywords: biomechanics, fluid mechanics, locomotion, lower limbs, physical exercise. 


\section{Capítulo 1}

\section{Introdução}

O ambiente aquático, por se tratar de um ambiente agradável e divertido para a maioria das pessoas, vem se popularizando como meio para prática de atividades físicas visando condicionamento, treinamento e reabilitação.

O uso da água para estes fins não é atual. Especificamente com relação a reabilitação, há registros de 2400 a.C. que sugerem que a cultura proto-indiana já usava a água com propósitos curativos. Em 500 a.C. os Romanos criaram os "banhos", centros onde eram realizadas atividades intelectuais, recreacionais, de saúde e higiene, que por volta de 339 d.C. passaram a ser usados para tratamento dos sintomas de doenças reumáticas, paralisias e efeitos posteriores a lesões. Já a prática da Hidroginástica é mais recente: passou a ser recomendada no final do século XIX, mas os exercícios apenas começaram a ser desenvolvidos na década de 1920. Após a segunda guerra mundial, o ambiente aquático se fortaleceu como meio para a prática de execícios e de manutenção do condicionamento físico [9].

No entanto, não é só o fato do ambiente aquático ser agradável que o torna atraente à prática de atividades físicas. Existem inúmeros benefícios de se exercitar dentro da água, e todos eles estão ligados às propriedades físicas deste meio, como a pressão, temperatura, densidade e viscosidade.

Do ponto de vista mecânico existem duas forças que atuam sobre um corpo imerso em movimento, são elas o arrasto e o empuxo. A força de arrasto se opõe ao deslocamento de qualquer corpo submerso e interfere nos movimento humanos em ambiente aquático de duas maneiras: modificando a velocidade de execução e a força muscular exercida para realizá-los. O empuxo age sempre na direção oposta à força gravitacional, como uma força de sustentação, proporcionando a sensação de redução do peso corporal e a diminuição da carga mecânica sobre as articulações [19].

Estas duas forças, tornam a piscina com água rasa um ambiente seguro à prática de atividades físicas no que diz respeito a lesões e a quedas. A menor velocidade de realização dos movimentos permite que eles sejam melhor controlados e que erros posturais possam ser detectados e corrigidos em tempo hábil [34]. Além disso, mesmo que a queda ocorra o risco de 
ferimento dentro da piscina é mínimo.

A segurança proporcionada por esse ambiente faz com que a hidroterapia e a hidroginástica sejam recomendadas a populações especiais, como por exemplo idosos, por trazer não só benefícios físicos, mas também psicológicos. Na água, esses indivíduos podem realizar atividades que em terra seriam difíceis ou mesmo impossíveis. Isso eleva sua confiança e moral de maneira que tais efeitos podem ser transferidos para as atividades em terra [9]. Ainda com relação a essa população, a atividade física em ambiente aquático é tão efetiva quanto em ambiente terrestre na melhora do equilíbrio [11] e é capaz de melhorar também aspectos relacionados ao condicionamento físico e a saúde [46].

Se exercitar em água também pode ser vantajoso para indivíduos que apresentem restrições ao exercício em terra, como portadores de artrite e dores na coluna ou aqueles que estão em processo de recuperação de lesões ou cirurgias ortopédicas [46]. Nestes casos a diminuição do impacto no contato com o solo, atribuído à redução do peso aparente e às baixas velocidades de execução dos exercícios, podem reduzir a dor local [48], pois a carga axial na coluna e nas articulações do membro inferior seriam reduzidas [19, 37]. Em adição, estudos mostram que o ambiente aquático é efetivo no ganho de força muscular e recuperação da mobilidade articular $[40,46,48]$. Isso faz com que os exercício em piscina possam ser prescritos visando uma volta antecipada à atividade para indivíduos que sofreram lesões no aparelho músculo-esquelético, evitando, desta forma, atrofia muscular, diminuição da mobilidade articular, possível aumento da dor local e auxiliando na manutenção do condicionamento do sistema cardio-respiratório [37].

Relatos também indicam que o exercício em meio aquático auxilia na circulação sanguínea e na diminuição de inchaços e edemas $[9,17,51]$. A esses relatos corrobora o fato da pressão hidrostática ser de aproximadamente $76 \mathrm{mmHg}$ a um metro de profundidade, sendo, portanto, maior que a pressão exercida por meias terapêuticas usadas no tratamento de problemas circulatórios (da ordem de $18.4 \mathrm{mmHg}$ a $59 \mathrm{mmHg}$ ) [12, 13].

A tarefa de caminhar ou correr em diferentes níveis de imersão, é indicada tanto em treinamento quanto em reabilitação. $\mathrm{O}$ andar, entretanto, é especialmente popular, pois não requer habilidades especiais e pode ser realizado por indivíduos de todas as idades e em diversas condições médicas [26].

$\mathrm{O}$ andar em ambiente aquático esteve presente em protocolos de reabilitação cuja eficiência foi comprovada [11, 46, 48], e ainda no campo da reabilitação, costuma ser usado para reintroduzir os mecanismos da marcha em pacientes que sofreram fraturas e lesões na coluna e membro inferior. A vantagem de realizar tal re-educação em ambiente aquático está relacionada à possibilidade de variação da carga na coluna e nas articulações do tornozelo, joelho e quadril com a profundidade de imersão [37] e também à redução dos riscos de ferimentos e lesões associados a quedas [17].

Entretanto, a piscina pode não ser sempre o ambiente ideal para restaurar os padrões da 
marcha. As propriedades físicas da água são diferentes e fazem com que a atividade muscular não seja a mesma em ambiente aquático e terrestre $[3,17]$. Isso mostra a necessidade de se comparar os aspectos biomecânicos do andar em ambiente aquático aos do andar em ambiente terrestre para uma melhor prescrição das atividades físicas na piscina.

A despeito da existência de trabalhos que comprovam a utilidade desta tarefa em treinamento e reabilitação, ainda existe uma escassez de estudos voltados para os aspectos biomecânicos do andar em água, mais especificamente no que diz respeito à carga sobre o aparelho locomotor nesta tarefa.

Os estudos existentes na literatura avaliaram a atividade elétrica dos músculos (eletromiografia) envolvidos na tarefa [2, 3, 26, 27], caracterizaram a cinemática da marcha para diferentes populações $[2,3,29]$ e reportaram as características das componentes vertical e ântero-posterior da força de reação do solo [1, 3, 19, 29, 43].

Contudo, apenas Miyoshi e colaboradores [28, 29, 30] quantificaram os torques nas articulações do tornozelo, joelho e quadril durante a fase de apoio e discutiram o papel desses torques no andar em piscina com água rasa. No entanto, esses trabalhos não reportam a magnitude das forças internas resultantes que agem nas articulações do membro inferior, nem as estimativas para os torques articulares na fase de balanço.

Um dos problemas na determinação das forças e torques internos durante os movimentos em ambiente aquático é a dificuldade de medir ou mesmo estimar a força de arrasto que age sobre os segmentos corporais durante o movimento. Em esportes como a natação, cujas características biomecânicas são bastante estudadas, ainda existem empecilhos na determinação das forças de arrasto [6, 16, 31, 35]. Mesmo Miyoshi e colaboradores [28, 29, 30] não calcularam esta força em sua estimativa dos torques articulares.

Este projeto teve como objetivo, portanto, preencher essa lacuna no conhecimento da marcha em ambiente aquático, fornecendo uma primeira estimativa dos valores das forças e torques articulares sobre o tornozelo, joelho e quadril durante um ciclo completo do andar; além de, fornecer uma solução razoavelmente simples para o problema da determinação da força de arrasto, calculando-a a partir de dados cinemáticos do andar e das características antropométricas dos indivíduos.

Os resultados referentes à marcha em ambiente aquático foram comparados com os resultados referentes à marcha em ambiente terrestre, visando uma melhor compreensão do papel da resistência, imposta pelo arrasto, e da sustentação, promovida pelo empuxo, na carga sobre o aparelho locomotor e na coordenação muscular durante o andar.

Pretendemos, desta forma, fornecer valores que possam auxiliar os profissionais da área de saúde como fisioterapeutas e profissionais de educação física na prescrição correta de atividades no ambiente aquático. 


\section{Capítulo 2}

\section{Revisão de Literatura}

O ser humano é capaz de se locomover de diferentes maneiras em ambientes distintos. Contudo, caminhar é a forma mais adotada por se tratar de uma maneira de locomoção eficiente (minimiza a fadiga) e segura (em termos de quedas e lesões associadas) [45]. Simoneu [45], cita Patla para expressar a importância da marcha para o ser humano: "Nada personifica mais um nível de independência e nossa percepção de uma qualidade de vida do que a capacidade de ir, independentemente com nossas próprias forças, de um lugar ao outro".

O andar é uma tarefa aprendida e cada indivíduo demonstra características comportamentais próprias ao andar. Contudo, existem padrões comuns à maioria dos indivíduos. Tais padrões podem ser alterados por fatores intrínsecos, como a faixa etária ou a presença de distúrbios no sistema motor, músculo-esquelético e/ou sensorial de quem se locomove, e extrínsecos, como as condições oferecidas pelo ambiente, a velocidade e a superfície de locomoção [1].

Dada a importância da deambulação para o ser humano, diversos estudos se preocuparam em determinar os padrões do andar considerando os inúmeros fatores que podem influenciá-los $[20,45,52]$.

Particularmente o andar de adultos saudáveis (que não possuem os distúrbios supracitados), realizado no ambiente terrestre, em superfície horizontal plana, com velocidade confortável e auto-selecionada é bem descrito na literatura [45, 52].

Já o andar em ambiente aquático realizado nas mesmas condições, apesar de sua aplicabilidade e crescente uso em reabilitação, condicionamento físico e treinamento de atletas, não tem suas características tão bem discutidas na literatura. Ainda existe uma carência de estudos, principalmente no que diz respeito à quantificação da carga sobre o aparelho locomotor. Isso deve-se à dificuldade de se realizar experimentos dentro da piscina e medir ou estimar a força de arrasto durante o movimento.

Dos estudos existentes na literatura, vários deles demonstraram a eficiência do exercício em ambiente aquático no ganho de força, mobilidade articular e melhoria do equilíbrio de idosos [11, 40, 46, 48]. Muitos desses protocolos envolveram o andar, o que faz com que um estudo 
detalhado dessa tarefa seja importante.

Entretanto, a maioria dos trabalhos na literatura que se referem ao andar em água, quantificou apenas os aspectos cinemáticos [3, 2, 29], eletromiográficos [2, 3, 26, 27] e as componentes da força de reação do solo [3, 4, 29, 19, 43], sem se preocupar com as cargas sobre as articulações do membro inferior. Apenas Miyoshi e colaboradores [28, 29, 30], usando o método da dinâmica inversa, quantificaram e analisaram o papel dos torques articulares no tornozelo, joelho e quadril na fase de apoio do andar, sem reportar, no entanto, o cálculo da força de arrasto durante este período.

O objetivo deste capítulo é, portanto, revisar conceitos fundamentais para a análise da marcha humana assim como apresentar resultados de estudos anteriores que compararam os padrões da marcha nos ambientes aquático e terrestre. Uma última seção irá discutir o problema da determinação das forças de arrasto sobre os segmentos corporais, essencial para a estimativa das forças e torques articulares durante o ciclo completo do andar.

\section{$2.1 \quad$ A Análise do Andar Humano}

Whittle [52] define o andar humano como "um método de locomoção envolvendo o uso das duas pernas, alternadamente, para promover suporte e propulsão". Ele se diferencia da corrida pelo fato de pelo menos um dos pés estar em contato com o solo em todos os momentos.

O andar é um evento cíclico, ou seja, quando examinamos os movimentos realizados principalmente pelos membros inferiores vemos que uma série de eventos se repetem a intervalos de tempos constantes. Define-se, desta forma, um ciclo do andar como a série de movimentos ocorridos entre duas repetições sucessivas de um determinado evento com relação a um mesmo membro inferior. Qualquer evento pode ser usado para demarcar o início de um ciclo, mas tipicamente é usado o toque do calcanhar com o solo.

Uma passada é equivalente a um ciclo completo do andar. Assim, considerando o toque do calcanhar no solo como evento inicial, a passada compreende todos os eventos ocorridos até que o mesmo calcanhar toque novamente o solo. Já um passo corresponde a aproximadamente meio ciclo (isto é, uma passada consiste de dois passos) e engloba os eventos ocorridos entre o toque do calcanhar com o solo e o sucessivo toque do calcanhar contralateral (ver figura 2.1).

O andar de um adulto saudável é de certa maneira simétrico: todos os eventos ocorridos com o membro direito se repetem no membro esquerdo, defasados de meio ciclo. Portanto, analisando apenas um lado do corpo humano ao andar, somos capazes de extrapolar os resultados para o lado oposto.

Como nem todas as pessoas caminham com a mesma velocidade, e nem todas as passadas de um mesmo indivíduo duram o mesmo tempo, ao analisar a marcha humana devemos normalizar cada instante com relação ao período do ciclo. O emprego deste procedimento permite, por exemplo, fazer comparações entre a marcha de diferentes sujeitos. 


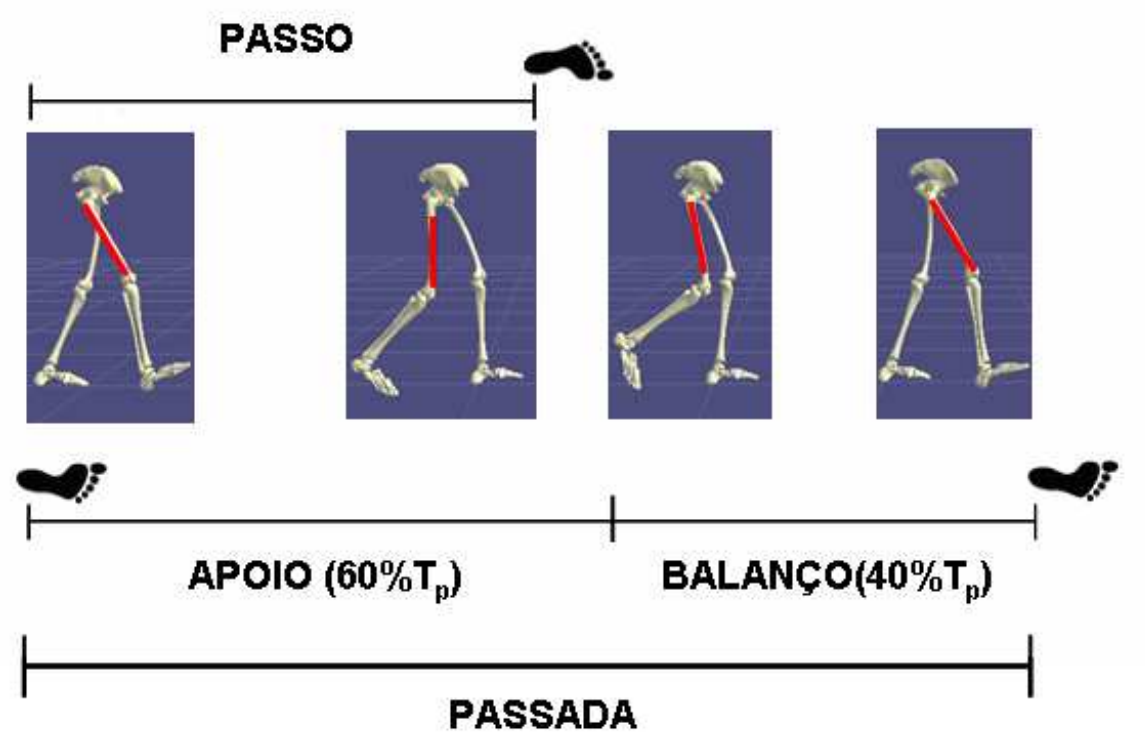

Figura 2.1: Ilustração caracterizando um passo, uma passada e as duas fases do ciclo do andar (adaptada de [1]).

Em uma passada existem duas fases: uma fase inicial de apoio, na qual o membro inferior contribui para a estabilidade da postura, sustentação do peso e propulsão do corpo, e uma fase final de balanço, na qual o membro inferior auxilia, essencialmente, na progressão do movimento e se prepara para iniciar um novo apoio [36]. A duração do apoio é de aproximadamente $60 \%$ do período do ciclo, enquanto os $40 \%$ restantes correspondem à fase de balanço, como está esquematizado na figura 2.1. Durante a fase de apoio existem períodos de apoio duplo (os dois pés estão em contato com o chão) e simples (apenas um pé toca o solo), sendo este último o mais duradouro (aproximadamente $40 \%$ do ciclo). Os períodos de apoio duplo ocorrem no início e no fim da fase de apoio enquanto a base, sobre a qual o corpo é equilibrado, é trocada de um pé para o outro [45, 52].

Uma análise completa do movimento humano envolve a descrição do movimento dos segmentos corporais e articulações envolvidas na tarefa (cinemática), das forças e torques que atuam sobre o corpo durante a realização da tarefa (cinética) e da atividade elétrica dos músculos solicitados durante o movimento (eletromiografia).

O estudo da atividade elétrica da musculatura envolvida no andar não faz parte dos objetivos deste projeto, pois esses dados podem ser encontrados na literatura para a marcha tanto em terra quanto em água $[2,3,26,27]$. O objetivo principal do trabalho aqui apresentado é estudar a cinética das articulações do membro inferior durante o andar em terra e água. No entanto, tais variáveis não poderiam ser calculadas sem uma primeira análise cinemática da marcha. Portanto, para fins de validação dos resultados, a cinemática do andar, bem como algumas variáveis que descrevem o ciclo como um todo, também serão aqui discutidas.

São denominadas variáveis cinemáticas descritivas aquelas que caracterizam espacial e/ou 
temporalmente um ciclo do andar. Utilizaremos aqui o comprimento $\left(L_{p}\right)$, o período $\left(T_{p}\right)$ e a velocidade $\left(V_{p}\right)$ da passada, além do período da fase de apoio $\left(T_{a}\right)$.

O comprimento da passada é a distância entre a posição onde ocorreu o contato inicial e a posição onde ocorreu o contato final do calcanhar. Para adultos saudáveis caminhando com velocidade confortável, o comprimento da passada é de aproximadamente 1,44m e dura pouco mais de um segundo. A velocidade média de uma passada apresenta valores próximos a $1,37 \mathrm{~m} / \mathrm{s}[45]$ e pode ser calculada por:

$$
V_{p}=\frac{L_{p}}{T_{p}}
$$

A marcha humana pode ser descrita através de uma análise bi ou tridimensional. A análise tridimensional da marcha é mais completa e descreve os movimentos ocorridos nos três planos de referência anatômica: sagital, aquele que divide o corpo em direita e esquerda; frontal, divide o corpo nas partes anterior e posterior; e plano transverso que delimita as metades inferior e superior. Porém, os movimentos do membro inferior e tronco ocorrem fundamentalmente no plano sagital e portanto uma análise bidimensional da marcha nesse plano nos fornece informações importantes. Obviamente a análise tridimensional pode revelar mais detalhes sobre o movimento e é empregada usualmente em ambiente terrestre. Contudo, essa análise em ambiente aquático seria muito mais complexa tanto do ponto de vista experimental quanto teórico. Como os parâmetros que pretendemos determinar são totalmente desconhecidos, uma análise bidimensional é adequada como primeira abordagem do problema.

A descrição cinemática do andar é feita principalmente em termos do comportamento ao longo do ciclo dos ângulos articulares, os quais consistem dos ângulos formados por dois segmentos adjacentes. No plano sagital, os ângulos do tornozelo, joelho e quadril são os ângulos formados, respectivamente, pelas projeções nesse plano dos segmentos pé e perna, perna e coxa e coxa e tronco, como está ilustrado na figura 3.1.

As forças e torques internos (ou articulares) quantificam a carga sobre uma determinada articulação. A determinação destas grandezas pode ser feita de duas maneiras: diretamente ou indiretamente.

Basicamente, a medida direta envolve a colocação de transdutores diretamente no tecido biológico, dentro do corpo humano, o que acarreta em desconforto ao sujeito de pesquisa [22]. Este método, além, de se tratar de um procedimento invasivo, possui diversas desvantagens: ele se limita a medidas em tendões mais superficiais e não é aplicável à área clínica, se limitando à medidas nas salas de cirurgias voltadas geralmente à pesquisa [14]. Por estes motivos, esta metodologia não é aplicada usualmente em estudos de caráter biomecânico.

Uma alternativa, a este procedimento é a estimativa indireta das forças e torques internos. Ela se baseia no fato de que é possível estimar as forças a partir da medição do efeito das suas 
ações (como por exemplo os movimentos dos segmentos corporais e as forças de reação do solo) [14]. A medida indireta requer, portanto, a elaboração de modelos mecânicos do corpo humano e medidas de variáveis externas, o que constitui um procedimento não invasivo [53, 56].

Existem inúmeras técnicas analíticas e experimentais que podem ser empregadas na determinação das forças e torques internos por métodos indiretos [14]. Um exemplo é a utilização de modelos computacionais do sistema músculo-esquelético "alimentados" com informações sobre a atividade elétrica de determinados grupos musculares. Outro método é resolver inversamente as equações do movimento dos segmentos corporais, a partir do conhecimento das forças externas e das características cinemáticas do movimento. Esta técnica é chamada de dinâmica inversa e será aplicada neste estudo (ver seção 3.1).

A força articular representa não apenas a força de contato entre os ossos (que ocorre indiretamente, pois entre eles há estruturas como cartilagem e líquidos para redução do atrito e do impacto), e sim uma somatória desta força com forças musculares e de tração exercidas por tendões e ligamentos. No entanto, nem todas as forças agem exatamente sobre o ponto articular, é o que acontece com as forças musculares, por exemplo. Tais forças geram, então, um torque, cuja somatória é representada pelo torque articular $[53,56]$. Os torques articulares, geralmente mais discutidos na literatura, podem ser extensores ou flexores e a convenção do sinal que os representa varia de autor para autor.

O papel dos torques articulares a cada instante durante o movimento pode ser melhor visualizado com o auxílio da potência articular. Existem diversas formas de se calcular a potência articular [55]. Neste caso, como se trata de uma análise bidimensional, podemos obtê-la ao multiplicar o torque interno resultante pela velocidade angular da articulação como na equação a seguir:

$$
P_{i}=\tau_{i} \omega_{i}=\tau_{i} \dot{\theta}_{i}
$$

onde $\tau_{i}$ representa o torque interno resultante, calculado a partir da dinâmica inversa (ver seção 3.1), sobre a articulação $i$ e $\omega_{i}$ a velocidade angular articular, dada pela derivação com relação ao tempo do ângulo articular (equação 3.3).

Uma potência positiva equivale a um torque resultante na direção do movimento, ou seja, equivale a uma força resultante agindo de forma a gerar movimento, o que implica em uma ação muscular concêntrica. A potência negativa indica que os torques estão sendo aplicados na direção oposta ao movimento articular, ou seja, que a resultante das forças age de modo a frear o movimento, sugerindo uma ação muscular excêntrica [18].

Para determinar as forças e torques articulares é essencial conhecer as componentes da força de reação do solo ao contato do pé de apoio $(F R S)$. A quantificação da $F R S$ não é só importante para o cálculo da cinética articular, os padrões das componentes durante o apoio 
têm papel crítico na análise da marcha tanto normal quanto patológica [45]. As componentes vertical $\left(F R S_{\mathrm{V}}\right)$ e ântero-posterior $\left(F R S_{\mathrm{AP}}\right)$ possuem um padrão bem definido e variam pouco entre os indivíduos caminhando com velocidades próximas. A componente médio-lateral, além de possuir magnitude pequena, é muito variável entre sujeitos, portanto é menos reportada na literatura.

\subsection{Diferenças Entre o Andar em Terra e em Água}

As variáveis descritas na seção 2.1 são bem conhecidas para um ciclo completo do andar em ambiente terrestre $[52,53]$. Para o andar em ambiente aquático há uma escassez de estudos que se referem às grandezas que quantificam a carga mecânica sobre as articulações do membro inferior [28, 29, 30]. Entretanto as variáveis cinemáticas e a força de reação do solo durante a fase de apoio já foram objetos de diversos estudos [2, 3, 19, 43].

As características cinemáticas do andar de adultos jovens em ambiente aquático foram reportadas nos estudos de Miyoshi e colaboradores [28, 29], Barela [1] e Barela e colaboradores $[3]$.

Miyoshi e colaboradores [28, 29], em seus estudos, reportaram os ângulos articulares apenas durante a fase de apoio do andar. Nos dois estudos os participantes caminharam com velocidade confortável nos dois ambientes e com água na altura das axilas e em [29] os participantes caminharam também com velocidade lenta e rápida nas mesmas condições de imersão. Nestes estudos, além dos ângulos articulares foram reportadas as velocidades médias de caminhada, as quais foram $0,55(9) \mathrm{m} / \mathrm{s}$ em água e de $1,05(7) \mathrm{m} / \mathrm{s}$ em terra na condição de velocidade confortável.

Barela e colaboradores [3] compararam, entre os ambientes, tanto os ângulos articulares quanto as variáveis descritivas para um ciclo completo do andar. Em seus experimentos os indivíduos caminharam com velocidade confortável e com água ao nível do processo xifóide (um pouco abaixo das axilas). Os resultados obtidos para as variáveis descritivas estão reportados na tabela 2.1 e as curvas típicas para os ângulos articulares do tornozelo, joelho e quadril nos gráficos da figura $2.2 \mathrm{~A}$.

Com relação a estas variáveis, Barela e colaboradores [3] observaram diferenças apenas entre a velocidade e o período da passada nos dois ambientes. Apesar dos participantes apresentarem um valor médio inferior para o comprimento da passada, o teste estatístico não indicou diferença significativa nesta variável e também não foi possível verificar diferenças entre a duração da fase de apoio quando normalizada por $T_{p}$. Estes resultados indicam que os participantes mantiveram a mesma organização temporal da passada em ambiente aquático apesar da redução na velocidade da marcha [1], o que é interessante pois em terra a duração da fase de apoio aumenta à medida que a velocidade da passada diminui [3].

Barela [1] observou ainda que os ângulos articulares apresentam comportamento similar nos 
Tabela 2.1: Resultado do estudo de Barela e colaboradores [3] para o período $\left(T_{p}\right)$, comprimento $\left(L_{p}\right)$ e velocidade $V_{p}$ da passada e para a duração da fase de apoio normalizada pelo período da passada $\left(T_{a_{\text {NORM }}}\right)$, durante o andar em ambiente aquático e terrestre.

\begin{tabular}{lcc}
\hline Variável & Terra & Água \\
\hline$T_{p}(s)$ & $0,95(1)$ & $2,41(25)$ \\
\hline$L_{p}(m)$ & $1,32(13)$ & $1,19(15)$ \\
\hline$V_{p}(m / s)$ & $1,39(14)$ & $0,50(7)$ \\
\hline$T_{a_{\mathrm{NORM}}}\left(\% T_{p}\right)$ & $61,9(19)$ & $60,4(22)$ \\
\hline
\end{tabular}

dois ambientes durante o ciclo. Entretanto percebeu diferença significativa entre os ambientes no ângulo do tornozelo no contato inicial: em terra a articulação inicia o ciclo em média com $4(5)^{\circ}$ de dorsi-flexão e em água com 3(5) ${ }^{\circ}$ de flexão plantar. Miyoshi e colaboradores também verificaram semelhanças nas curvas dos dois ambientes durante a fase de suporte, mas não investigaram os ângulos articulares do tornozelo no instante de contato inicial. Eles viram, porém, que o máximo ângulo de dorsi-flexão na fase de apoio era atingido antecipadamente no ambiente aquático (em 56,8(34)\% da fase de apoio no ambiente aquático e em 68,4(21)\% da fase de apoio no ambiente terrestre) [28, 29].

Tanto o estudo de Barela [1] quanto de Miyoshi e colaboradores [28, 29] reportaram que a articulação do joelho se manteve mais flexionada em ambiente terrestre do que em ambiente aquático no instante de início da fase de balanço. Eles verificaram, ainda, que o joelho se manteve mais flexionado em ambiente terrestre nos instantes iniciais da fase de apoio (o que pode ser visto no gráfico central da figura $2.2 \mathrm{~A}$ ).

No que diz respeito a amplitude de deslocamento articular durante um ciclo completo do andar, Barela e colaboradores [3] não constataram diferença entre os ambientes para as três articulações. Barela [1] também observou que não há diferença na amplitude de deslocamento articular do tornozelo, joelho e quadril na fase de apoio, já Miyoshi e colaboradores [28, 29] obtiveram resultados um pouco diferentes: estes autores observaram uma amplitude significativamente maior de deslocamento angular para o joelho no ambiente terrestre na fase de apoio.

Os estudos acima descritos investigaram também o comportamento das componentes ânteroposterior e vertical da $F R S[1,3,29]$. Além destes trabalhos podemos citar o estudo de Roesler e colaboradores [43] que também investigou estas duas componentes da $F R S$ durante o andar de adultos jovens em ambiente aquático. Nele os participantes foram divididos em três grupos distintos de acordo com o nível de imersão (ao nível do manúbrio, ao nível do processo xifóide e ao nível do ponto médio entre o manúbrio e o processo xifóide) e caminharam com velocidade lenta e rápida em duas situações diferentes: com os membros superiores dentro e fora d'água. 
A

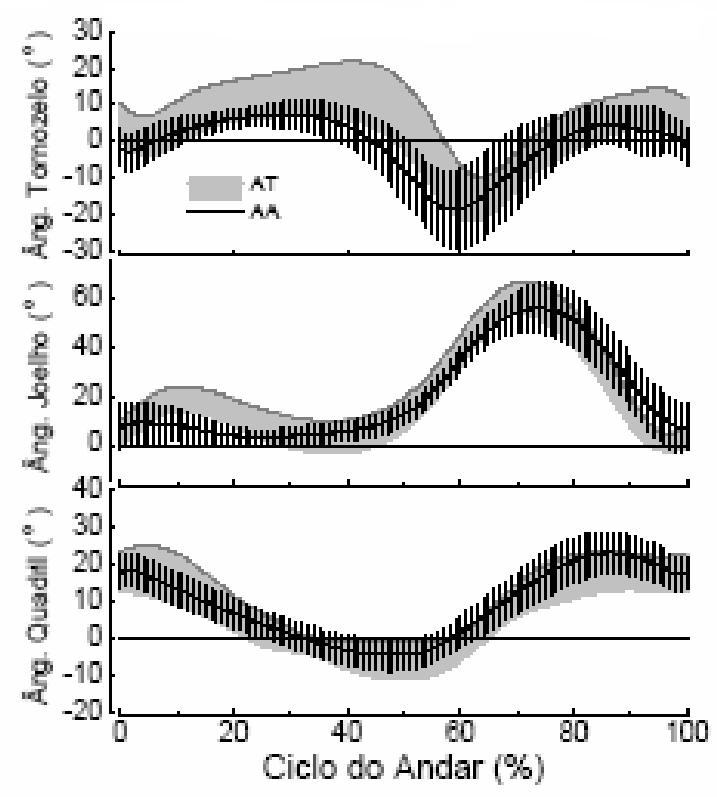

B
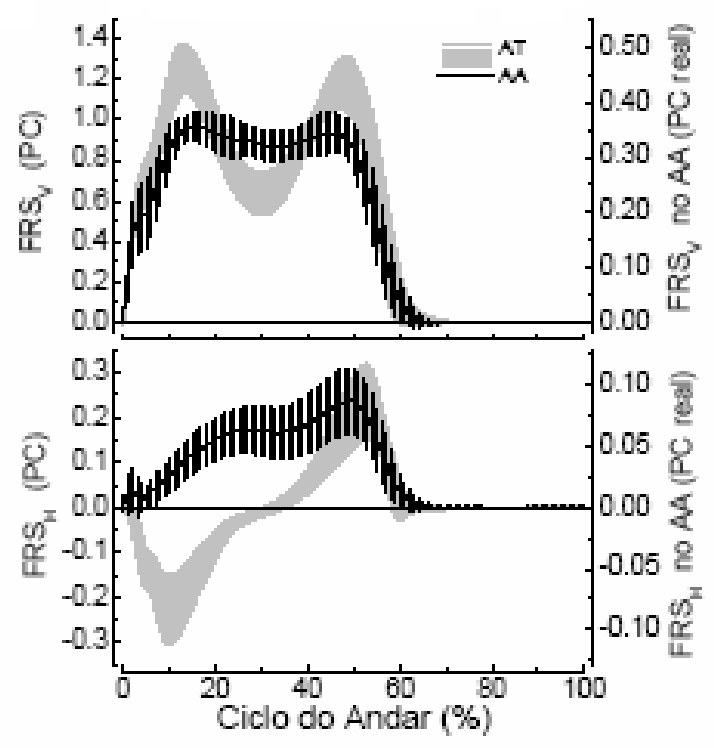

Figura 2.2: Resultados obtidos por Barela [1] para : A)Ângulos articulares do tornozelo, joelho e quadril durante um ciclo do andar em ambiente aquático e terrestre. Nestes gráficos o sinal positivo representa dorsi-flexão para o tornozelo e flexão para o joelho e quadril; e B)Padrões das componentes de FRS também para os dois ambientes. A escala do eixo vertical esquerdo dá os valores de FRS normalizados pelo peso aparente em cada ambiente e o eixo vertical direito dá o valor das componentes obtidas em água, normalizadas pelo peso corporal.

Os gráficos reportados na figura 2.2B representam o comportamento típico das componentes da força de reação do solo para um grupo de indivíduos caminhando com velocidade confortável, e foi retirada do trabalho de Barela [1].

Com relação a $F R S_{\mathrm{V}}$ os estudos [3, 29, 43] mostraram que apesar da curva obtida para o andar em água possuir um padrão similar àquele obtido em terra, ela é mais "achatada" e apresenta os dois picos e o vale menos pronunciados.

Em terra, o primeiro pico de $F R S_{\mathrm{V}}$ está associado à desaceleração do centro de massa (CM) que, nesta fase do ciclo, está em movimento descendente e se relaciona com a absorção de impacto. $\mathrm{O}$ vale ocorre quando o CM está sendo acelerado em seu movimento ascendente devido à elevação do membro contralateral. O segundo pico corresponde à nova desaceleração do centro de massa (novamente em movimento descendente) no final da fase de apoio [52].

Todos estes autores concordam que a redução da magnitude da componente vertical se deve principalmente ao empuxo [3, 29, 43], e esta dependência pode ser melhor vista a partir dos resultados de Roesler e colaboradores [43], os quais mostraram que os picos de $F R S_{\mathrm{V}}$ nas quatro condições são maiores para o grupo que caminhou com água ao nível do processo xifóide e nas situações em que os membros superiores não estavam imersos. Barela e colaboradores [3], porém, sugerem que a aparência mais "achatada" se deve principalmente à redução das 
velocidades de movimento devido à força de arrasto, e que a redução no impacto da força vertical se deve tanto à redução da velocidade do andar, quanto à redução do peso aparente.

Os resultados de Roesler e colaboradores [43], no que dizem respeito a influência da velocidade na componente vertical, mostraram que nas situações de maior velocidade houve um crescimento da $F R S_{\mathrm{v}}$, apesar desta diferença não ser significativa entre as condições de maior e menor velocidade.

Também foi constatado nos estudos supracitados que a componente ântero-posterior da força de reação do solo em ambiente aquático não possui uma fase em que aponta no sentido posterior e outra no sentido anterior, como é característico em terra. Em água, durante praticamente toda a fase de apoio ela aponta no sentido anterior.

Em terra, durante os instantes em que $F R S_{\mathrm{AP}}$ aponta no sentido posterior, ela freia o movimento progressivo da perna ao tocar o solo, e nos instantes em que aponta no sentido anterior, propulsiona a perna de apoio para a fase de balanço [52].

Miyoshi e colaboradores [29] constataram apenas a diferença entre os padrões desta componente nos dois ambientes, porém não procuraram discutir o motivo. Já Barela e colaboradores $[3,4]$ sugerem que mesmo para manter uma velocidade constante em água é necessário gerar um impulso horizontal para vencer o efeito resistivo da força de arrasto (ver tabela 2.2), e este seria o motivo da componente da força de reação do solo agir sempre no sentido anterior durante o andar em água.

Os resultados de Roesler e colaboradores [43] corroboram essa afirmação, pois indicam que o pico da componente horizontal cresce de forma significativa com o aumento da velocidade. Neste trabalho, os autores reportaram ainda um pequeno pico na direção posterior nos resultados de alguns sujeitos, com maior freqüência nas condições de menor velocidade e com maior magnitude para o grupo com menor volume submerso.

Os resultados de Barela e colaboradores [3] para os valores médios dos picos e impacto da força vertical nos dois ambientes, e também do impulso total da componente ântero-posterior durante o apoio, estão reportados na tabela 2.2. Como os resultados em ambiente aquático foram normalizados pelo peso aparente, foi necessário re-normalizar os resultados para que estes pudessem ser comparados com os resultados obtidos neste projeto. Para isso, cada valor foi multiplicado pela média do peso aparente e dividido pela média do peso corporal dos participantes do estudo (estes valores também se encontram na tabela 2.2).

Os torques internos que agem sobre as articulações do membro inferior durante a marcha em ambiente aquático, ao contrário dos torques em ambiente terrestre, não são conhecidos para um ciclo completo do andar. Apenas Miyoshi e colaboradores [28, 29, 30] investigaram o comportamento destas variáveis. Em seus estudos, os autores quantificaram e discutiram o papel dos torques articulares do tornozelo, joelho e quadril durante o andar em piscina com água ao nível das axilas, apenas durante a fase de apoio. Entretanto é importante ressaltar que os trabalhos não reportam a magnitude das forças articulares e nem o cálculo da força de 
Tabela 2.2: Valores médios para o impacto e para o primeiro e o segundo pico da força de reação do solo vertical, além do valor do impulso da componente ântero-posterior, obtidos por Barela e colaboradores para o ambiente terrestre e aquático (primeira e segunda colunas) [3]. Os valores apresentados na segunda coluna estão normalizados pelo peso aparente em água $(\dagger)$, já na terceira coluna são apresentados os valores re-normalizados pelo peso corporal. Esta re-normalização foi realizada a partir de dados dos autores.

\begin{tabular}{lccc}
\hline Variável & Terra & Água & $\begin{array}{c}\text { Água } \\
\text { (Ajustado) }\end{array}$ \\
\hline $1^{\text {o }}$ Pico $(\% P C)$ & $127(13)$ & $103(8) \dagger$ & $37(9)$ \\
\hline $2^{\text {o Pico }(\% P C)}$ & $120(14)$ & $101(10) \dagger$ & $37(9)$ \\
\hline Impacto $(P C / s)$ & $10,3(19)$ & $5,4(17) \dagger$ & $2,0(8)$ \\
\hline Impulso $(P C . s)$ & $0,00(1)$ & $0,20(6) \dagger$ & $0,07(3)$ \\
\hline
\end{tabular}

arrasto nos segmentos e respectivos torques sobre as articulações do membro inferior.

$\mathrm{Na}$ figura 2.3 está representado o comportamento típico dos torques na articulação do tornozelo, joelho e quadril obtido por Miyoshi e colaboradores [28] nos dois ambientes. Eles verificaram que, durante a fase de apoio do andar em ambiente aquático, os padrões dos torques articulares do tornozelo são semelhantes àqueles obtidos em ambiente terrestre. Entretanto as magnitudes destes torques são inferiores em ambiente aquático.

Ao manipular a velocidade de caminhada em seus experimentos e adicionando massa extra aos segmentos corporais dos participantes, os autores observaram que o pico do momento flexor plantar aumenta com o aumento da velocidade e com a adição de massa extra aos segmentos corporais em ambos os ambientes, sendo mais sensível ao aumento da massa [29, 30]. Eles sugerem, então, que a função do torque flexor plantar, o qual atua no tornozelo a partir de $10 \%$ do período do ciclo, é manter a estabilidade contra a gravidade ao invés de acelerar o corpo.

Com relação aos torques sobre o joelho, Miyoshi e colaboradores [28] perceberam que o momento era predominantemente flexor durante o andar em ambiente aquático e que, ao contrário do ambiente terrestre, não existiam os dois picos de momento extensor durante o apoio. Em água, ao invés do primeiro pico de torque extensor, eles constataram que o momento era flexor e que durante toda fase de apoio o joelho apresentava momentos de magnitude inferior em ambiente aquático. Quando manipularam a velocidade de caminhada perceberam que o primeiro pico de torque extensor, que não existia em velocidade confortável em água, começava a aparecer à medida que a velocidade aumentava [29, 30]. Os autores observaram este mesmo comportamento quando era acrescido peso adicional no membro inferior dos participantes, no entanto, a sensibilidade desta variação foi maior com a velocidade. Assim, concluíram que, 


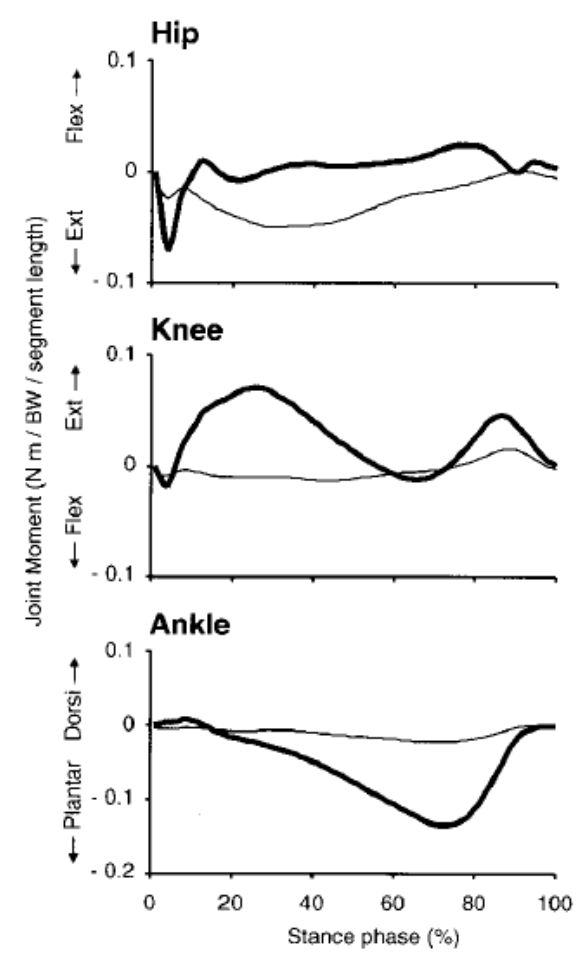

Figura 2.3: Curvas típicas para os torques articulares sobre o tornozelo (ankle), joelho (knee) e quadril (hip) obtidas por Miyoshi e colaboradores [28] para a fase de apoio do andar (stance phase). O tempo está normalizado pelo período do apoio e os torques pelo produto entre o peso corporal e o comprimento do membro inferior $\left(P C * L_{m}\right)$

como em terra, o torque no início da fase de apoio tem como função absorver o impacto e que sua redução ocorre devido à diminuição do impacto por causa da redução na velocidade e da existência do empuxo.

Já a articulação do quadril apresentou momento extensor durante toda a fase de apoio em ambiente aquático, enquanto em terra, possuía uma fase em que era extensor (no início do apoio), e uma fase em que era flexor (no final do apoio) [28]. Miyoshi e colaboradores $[29,30]$ perceberam que o torque extensor no quadril em ambiente aquático aumentava com a velocidade da passada, mas que não era influenciado significativamente pelo o aumento da massa dos segmentos. Como em terra eles observaram a situação inversa, sugeriram que poderia haver diferença entre as funções da articulação do quadril em terra e em água. Em terra, no início do ciclo, o torque extensor teria a função de controlar a aceleração da perna; no meio e fim do apoio o torque flexor teria a função de agir contra a gravidade para evitar o "colapso" do membro inferior, podendo ser uma fonte de propulsão do corpo. Já na água, devido a redução do peso aparente e a existência do arrasto, seria necessário uma força maior para se mover para frente [30]. Segundo os autores, estes resultados sugerem que a função do momento extensor em água é propulsionar o corpo para frente contra o arrasto durante todo o apoio.

Por fim, Miyoshi e colaboradores [28, 29, 30] concluíram que nas três articulações há uma 
redução na magnitude do momento no ambiente aquático em comparação com o ambiente terrestre, mas não só isso, há diferença na coordenação muscular entre as articulações durante a fase de apoio.

\subsection{Estimativas da Força de Arrasto}

A força de arrasto que atua sobre os corpos que se movem em um fluido tem um papel muito importante na biomecânica do movimento dentro d'água. A importância desta força está no fato de que ela possui uma ação contínua e resistiva, sempre se opondo a qualquer movimento por mais lento que ele seja.

Determinar a força de arrasto é essencial para podermos estimar as cargas sobre o sistema músculo esquelético durante a execução de exercícios físicos neste ambiente, principalmente quando estes exercícios são executados sem que os segmentos encostem diretamente no chão (como é o caso do "deep running").

Todavia, medir a força de arrasto não é uma tarefa simples pois ela possui diferentes intensidades em cada região de um mesmo segmento. Para determiná-la experimentalmente seriam necessários inúmeros sensores espalhados por toda área submersa do corpo e, mesmo assim, seria difícil determinar sua direção resultante.

Não bastasse isso, determinar o arrasto analiticamente não é menos complicado: em muitas situações é difícil modelar os efeitos inerciais e de turbulência, além disso, a falta de valores conclusivos para os coeficientes de arrasto dos segmentos corporais, muitas vezes impede que as estimativas sejam acuradas o bastante.

Por esses motivos existem poucos estudos relatando valores da força de arrasto nos segmentos corporais $[5,7,16,31,32,35,38]$ e até em áreas como a natação, na qual a compreensão das forças propulsivas e resistivas está diretamente ligada ao desempenho do atleta, estas dificuldades permanecem $[6,16,35,50]$.

Especificamente no que diz respeito às forças de arrasto no membro inferior, podemos citar os estudos de Pöyhönen e colaboradores [38], Bisarini e Ceruli [7] e de D. Newman [32]. Estes trabalhos reportaram técnicas diferentes para estimar o arrasto em ambiente aquático em duas tarefas distintas: flexão e extensão de joelho [7, 38] e durante o andar [32].

Dentre os estudos citados acima, apenas o de D. Newman [32] estimou a força de arrasto diretamente a partir do movimento humano. Ela utilizou um modelo geométrico do corpo humano, baseado nas características antropométricas do indivíduo cujo movimento está sendo estudado, e dados cinemáticos, obtidos experimentalmente através da filmagem do movimento. Aplicou, então, a teoria das faixas ${ }^{1}$ [33] para estimar a força de arrasto nos segmentos do membro inferior, durante o andar em esteira ergométrica submersa. Seu objetivo principal era

\footnotetext{
${ }^{1}$ Método usado em engenharia naval para o cálculo da força de arrasto em corpos extensos.
} 
calcular o gasto energético adicional para um ser humano se mover contra a força de arrasto e, portanto, calculou o trabalho desta força durante a marcha. O método adotado pela autora se mostrou bastante adequado para descrever o arrasto durante o andar em esteira ergométrica [32].

A mesma técnica de modelamento do arrasto foi utilizada por Bisarini e Ceruli [7]. Neste trabalho, os autores, usaram os dados de Pöyhönen e colaboradores [39] para determinar uma função que descrevesse a velocidade angular de flexão e extensão do joelho. Consideraram então o exercício de flexão e extensão dessa articulação sendo feito com um aparato resistivo de forma retangular preso à perna. Os autores aplicaram a teoria das faixas para determinar o arrasto aliada ao método da dinâmica inversa, e conseguiram simular as forças sobre a articulação do joelho durante este movimento.

Já o trabalho de Pöyhönen e colaboradores [38] foi bem diferente dos outros dois. Para este estudo os autores utilizaram uma prótese de perna humana coberta com borracha, imersa em um tanque com água e presa à um dinamômetro isocinético. $\mathrm{O}$ dinamômetro, gerava a rotação, com velocidade angular constante, do modelo de perna humana (simulando flexão e extensão de joelho) e, simultaneamente media a força necessária para isso. A partir destas medições eles determinaram a força de arrasto, que era igual a força necessária para mover o modelo, e construíram uma curva desta grandeza em função da velocidade de rotação. Através do ajuste de uma função aos dados experimentais, poderiam determinar o arrasto conhecendo a velocidade de rotação.

Comparando os métodos utilizados, nos estudos acima, para a determinação do arrasto, é possível concluir que a aplicação da teoria das faixas é o método vantajoso, já que para utilizá-lo só é preciso conhecer as características antropométricas do indivíduo estudado (as quais serão usadas para elaborar os modelos geométricos de seus segmentos) e a cinemática do movimento em questão, não havendo, portanto, a necessidade de construir uma prótese para modelar cada segmento. Além disso, como esta técnica leva em conta as características individuais de cada sujeito, diminuem os erros que surgem ao se atribuir a força de arrasto obtida para a prótese, a indivíduos com dimensões menores ou maiores. Por esses motivos a aplicação da teoria das faixas ao movimento humano vem se popularizando, e recentemente foi publicado um trabalho que visa aplicar esta técnica à analises voltadas para a natação [31].

A teoria das faixas foi também aplicada neste estudo e sua descrição detalhada pode ser vista na seção 3.2 . 


\section{Capítulo 3}

\section{Materiais e Métodos}

\subsection{Dinâmica Inversa}

Como discutido anteriormente (ver seção 2.1), a medida direta de forças e torques internos ao corpo humano constitui um procedimento invasivo, que acarreta desconforto ao sujeito de pesquisa e cujo emprego possui diversas limitações [14].

Uma alternativa, a este tipo de procedimento é a estimativa indireta destas forças e torques internos a partir da medição do efeito das suas ações (como por exemplo os movimentos dos segmentos corporais e as forças de reação do solo) [14]. A medida indireta requer, portanto, a elaboração de modelos mecânicos do corpo humano e medidas de variáveis externas, se tratando de um processo não invasivo $[53,56]$.

Existem inúmeras técnicas analíticas e experimentais que podem ser empregadas na determinação das forças e torques internos por métodos indiretos [14]. Neste estudo, no entanto, será usado o método da dinâmica inversa aliado a um modelo mecânico que considera os segmentos corporais como corpos rígidos.

A aplicação de tal metodologia consiste em construir um diagrama de corpo livre, para identificar as forças que agem em cada segmento corporal, determinar, para cada um deles, as equações diferenciais do movimento, as quais resultam da aplicação da segunda lei de Newton, e resolvê-las "inversamente".

Dizemos que as equações do movimento de um corpo são resolvidas inversamente quando as usamos para determinar as forças que geram o movimento ao invés de determinarmos sua trajetória $^{1}$.

A aplicação da segunda lei de Newton ao movimento bidimensional de corpos rígidos nos leva às seguintes equações:

\footnotetext{
${ }^{1}$ Segundo Zatsiorsky [56], o adjetivo "inverso" se refere ao fato de que forças causam mudanças no movimento, mas que o oposto não é verdadeiro.
} 


$$
\begin{aligned}
& \sum \vec{F}_{i}=m \vec{a}_{\mathrm{CM}} \\
& \sum \vec{\tau}_{i}=I \vec{\alpha}
\end{aligned}
$$

onde $\vec{F}_{i}$ e $\vec{\tau}_{i}$ são, respectivamente, as forças e torques que agem sobre o corpo rígido de massa $m$ e momento de inércia $I$, com relação ao eixo de rotação considerado, gerando uma aceleração linear $\vec{a}_{\mathrm{CM}}$ no centro de massa do corpo e uma aceleração angular $\vec{\alpha}$ em torno do eixo de rotação.

No caso do movimento humano, as incógnitas no problema da dinâmica inversa, ou problema inverso da dinâmica, são as forças e torques articulares, os quais são determinados a partir do conhecimento da cinemática (trajetórias, velocidades ou acelerações), das propriedades inerciais (massa, centro de massa e momentos de inércia), das características geométricas dos segmentos corporais e das forças e torques externos que agem sobre eles [56].

As propriedades inerciais são obtidas de estudos antropométricos que, em biomecânica, visam obter as características inerciais e geométricas de determinadas populações, de modo que estes dados possam ser usados na análise cinética do movimento humano.

Atualmente existem diversos estudos na literatura que foram conduzidos com o objetivo de determinar massa, centro de massa, momentos de inércia com relação aos três eixos anatômicos de referência, densidade e características geométricas dos segmentos corporais [41, 56].

A escolha do modelo antropométrico deve se basear entre outros fatores na idade e sexo da amostra [41]. Portanto, neste estudo, adotamos o modelo de Zatsiorsky e Seluyanov modificado por Paolo de Leva [10], no qual a idade média dos participantes foi de 23,6(62) para os homens e 19,0(40) anos para as mulheres. A escolha deste modelo também se deve ao fato deste estudo ter sido realizado em indivíduos vivos utilizando escaneamento por radiação gama de baixa intensidade, o que permitiu que o número da amostra fosse grande (100 homens e 15 mulheres fisicamente ativos). As modificações feitas por de Leva no modelo inicialmente proposto, consistem em mudanças nos acidentes anatômicos que delimitam os segmentos corporais e adequações dos parâmetros antropométricos a essas mudanças, visando viabilizar o posicionamento de marcadores durante os experimentos [10].

Seguindo a segmentação proposta pelo modelo antropométrico, foi construído um modelo mecânico simplificado do corpo humano (bi-dimensional), no qual os segmentos foram modelados por segmentos rígidos unidos por articulações do tipo dobradiça.

Como o objetivo era quantificar apenas as forças e torques articulares do membro inferior, não houve necessidade de considerar o movimento dos membros superiores. Portanto, fazem parte do modelo de segmentos rígidos o pé, a perna, a coxa e o tronco e as articulações do tornozelo, joelho e quadril como pode ser visto na figura 3.1A. 
Considerando este modelo os ângulos articulares do tornozelo $\left(\theta_{\mathrm{T}}\right)$, joelho $\left(\theta_{\mathrm{J}}\right)$ e quadril $\left(\theta_{\mathrm{Q}}\right)$ são definidos segundo as equações 3.3 , onde $\theta_{\text {spé }}, \theta_{\text {sperna }}, \theta_{\text {scoxa }}$ e $\theta_{\text {stronco }}$ são os ângulos que cada segmento forma com a horizontal (ângulos segmentares). Para uma melhor compreensão do movimento, os ângulos articulares são medidos a partir da posição neutra da articulação (denotada por $\theta_{o}$ ), a qual é obtida com o indivíduo em pé (posição ortostática).

$$
\begin{aligned}
\theta_{\mathrm{T}} & =\left(\pi-\theta_{\text {spé }}+\theta_{\text {sperna }}\right)-\theta_{\text {от }} \\
\theta_{\mathrm{J}} & =\left(\theta_{\text {sperna }}+\pi-\theta_{\text {scoxa }}\right)-\theta_{o \mathrm{~J}} \\
\theta_{\mathrm{Q}} & =\left(\pi-\theta_{\text {scoxa }}+\theta_{\text {stronco }}\right)-\theta_{o \mathrm{Q}}
\end{aligned}
$$

Assim, ângulos articulares negativos para o tornozelo indicam que a articulação está em dorsi-flexão e positivos em flexão plantar, já para o joelho e quadril ângulos negativos indicam que a articulação esta em flexão e positivos em hiper-extensão e extensão, respectivamente.
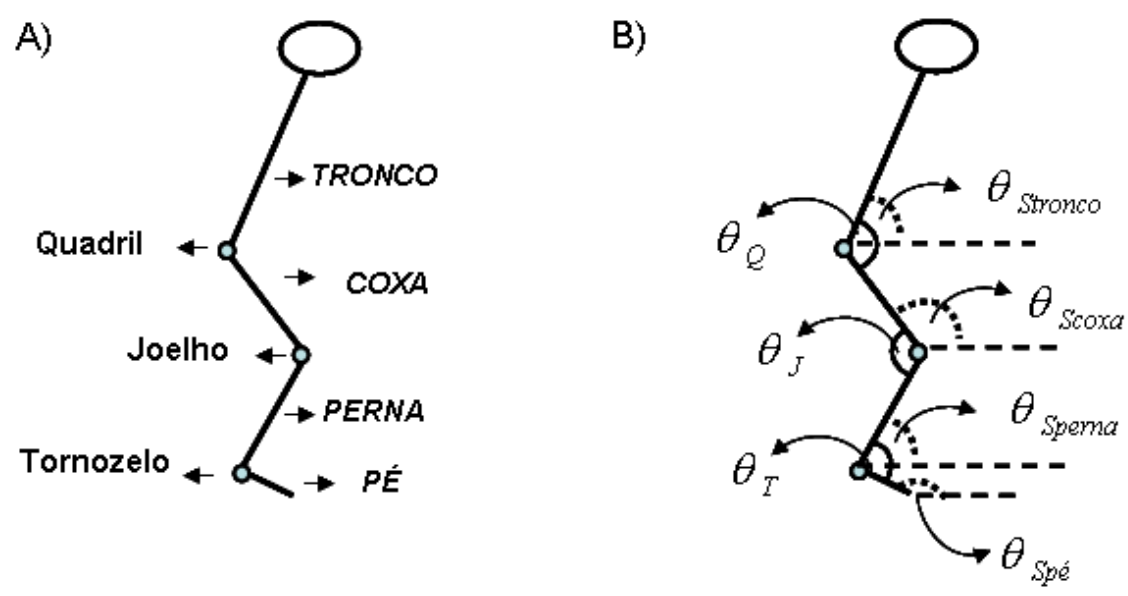

Figura 3.1: A)Modelo de segmentos rígidos usado para representar o corpo humano neste estudo. B)Representação dos ângulos segmentares do pé, perna, coxa e tronco (linhas pontilhadas) e ângulos articulares do tornozelo, joelho e quadril (linhas cheias).

Cada segmento rígido considerados no modelo mecânico, tem as mesmas características inerciais da parte do corpo do indivíduo que ele representa. Portanto, sua massa, seu centro de massa e momento de inércia são aqueles obtidos do modelo antropométrico ${ }^{2}$.

A determinação da posição do CM em função do tempo e do momento de inércia, assim como das velocidades e acelerações dependem do conhecimento prévio das posições no espaço das marcas anatômicas que delimitam os segmentos corporais. Para obtê-las utilizamos a técnica cinemetria [53], que consiste no posicionamento de marcadores nos acidentes anatômicos

\footnotetext{
${ }^{2}$ As formas geométricas dos segmentos e suas dimensões foram consideradas apenas no cálculo da força de arrasto.
} 
sugeridos pelo modelo antropométrico e na filmagem do movimento de interesse. Posteriormente digitalizamos a imagem e aplicamos o método da Transformação Linear Direta [24] para obter as coordenadas destes marcadores no referencial do laboratório.

$\mathrm{Na}$ cinemetria as velocidades e acelerações, necessárias à solução do problema da dinâmica inversa, podem ser obtidas da diferenciação numérica das trajetórias. Neste estudo utilizamos para isso o método Savitz-Golay de diferenciação [44], no qual é realizada uma regressão polinomial de quinta ordem ao redor de cada ponto (local), a partir do método dos mínimos quadrados. As derivadas são obtidas, então, dos coeficientes dos polinômios ajustados.

As forças externas que agem sobre o indivíduo que se move, dependem basicamente do movimento que está sendo executado e do ambiente em que ele ocorre. No caso do andar em terra, o peso $(\vec{P})$ dos segmentos e a força de reação do solo $\left(\vec{F}_{\mathrm{RS}}\right)$, aplicada sobre o pé na fase de apoio, são geralmente as únicas forças externas consideradas. Isso acontece pois, durante o andar em terra tanto o empuxo quanto a força arrasto podem ser desprezados.

Em ambiente terrestre o empuxo é aproximadamente 1000 vezes menor do que o peso corporal por que a densidade dos segmentos chega a ser 1000 vezes maior que a do ar $\left(\rho_{a r} \approx\right.$ $\left.1.2 \mathrm{~kg} / \mathrm{m}^{3}\right)$. Entretanto, o mesmo não acontece no ambiente aquático, no qual a densidade da água $\left(\rho_{\text {água }} \approx 1000 \mathrm{~kg} / \mathrm{m}^{3}\right)$ é da mesma ordem de grandeza da densidade dos segmentos corporais, proporcionando uma "redução aparente" no peso de cada segmento.

Portanto, durante o andar em água, além da força gravitacional, do arrasto e da força de reação do solo, devemos considerar que atua sobre cada segmento o empuxo $(\vec{E})$ que, para um corpo homogêneo, totalmente submerso, em um meio de densidade $\rho_{m}$ é dado pela equação 3.4 :

$$
\vec{E}=-\rho_{m} V \vec{g}
$$

onde $\vec{g}$ é a aceleração da gravidade e $V$ o volume de fluido deslocado que, neste caso, corresponde ao volume do corpo.

Para a aplicação da equação 3.4, o volume foi estimado através da razão entre a massa do segmento e sua densidade média. A densidade média foi utilizada pois os segmentos corporais não possuem densidade uniforme, contudo o modelo mecânico do corpo humano aqui considerado, aproxima os segmentos por corpos rígidos e de densidade homogênea, o que justifica essa simplificação. Também foram levadas em conta as diferenças nas densidades de cada segmento, já que cada um possui uma combinação particular de ossos, músculo, gordura e outros tecidos [53]. Entretanto, dada a dificuldade de se estimar a densidade média dos segmentos de cada indivíduo, foram adotados valores fixos para a densidades média de cada um, os quais foram $1100 \mathrm{~kg} / \mathrm{m}^{3}, 1090 \mathrm{~kg} / \mathrm{m}^{3}$ e $1050 \mathrm{~kg} / \mathrm{m}^{3}$, respectivamente, para o pé, a perna e a coxa [54].

O cálculo das forças de arrasto $\left(\vec{F}_{\mathrm{D}}\right)$ e seus respectivos torques $\left(\overrightarrow{\mathcal{\tau}}_{\mathrm{D}}\right)$ nos dois ambientes 
foi baseado no método proposto por D. Newman [32] e será cuidadosamente descrito na seção seguinte.

Conhecendo as forças e torques que agem sobre cada segmento podemos, a partir do diagrama de corpo livre (figura 3.2) e das equações 3.1 e 3.2, obter para os movimentos do pé as equações 3.5 e 3.6 , para os movimentos da perna as equações 3.7 e 3.8 e para os movimentos da coxa as equações 3.9 e 3.10 .

$$
\begin{aligned}
& \vec{F}_{\mathrm{T}}+\vec{F}_{\mathrm{RS}}+\vec{P}_{\mathrm{pé}}+\vec{E}_{\mathrm{pé}}+\vec{F}_{\mathrm{Dpé}}=m_{\mathrm{pé}} \vec{a}_{\mathrm{CM} \text { pé }} \\
& \vec{\tau}_{\mathrm{T}}+\vec{\tau}_{\mathrm{FRS}}+\vec{\tau}_{\mathrm{Ppé}}+\vec{\tau}_{\mathrm{Epé}}+\vec{\tau}_{\mathrm{Dpée}}=I_{\mathrm{pé}} \vec{\alpha}_{\mathrm{pé}} \\
& \vec{F}_{\mathrm{J}}-\vec{F}_{\mathrm{T}}+\vec{P}_{\text {perna }}+\vec{E}_{\text {perna }}+\vec{F}_{\text {Dperna }}=m_{\text {perna }} \vec{a}_{\text {CMperna }} \\
& \vec{\tau}_{\mathrm{J}}-\vec{\tau}_{\mathrm{T}}+\overrightarrow{\mathcal{\tau}}_{\text {Pperna }}+\vec{\tau}_{\text {Eperna }}+\vec{\tau}_{\text {Dperna }}+\vec{\tau}_{\mathrm{F}_{\mathrm{T}}}=I_{\text {perna }} \vec{\alpha}_{\text {perna }} \\
& \vec{F}_{\mathrm{Q}}-\vec{F}_{\mathrm{J}}+\vec{P}_{\text {coxa }}+\vec{E}_{\text {coxa }}+\vec{F}_{\text {Dcoxa }}=m_{\text {coxa }} \vec{a}_{\text {CMcoxa }} \\
& \vec{\tau}_{\mathrm{Q}}-\vec{\tau}_{\mathrm{J}}+\vec{\tau}_{\mathrm{Pcoxa}}+\vec{\tau}_{\mathrm{Ecoxa}}+\vec{\tau}_{\mathrm{Dcoxa}}+\vec{\tau}_{\mathrm{FJ}}=I_{\text {coxa }} \vec{\alpha}_{\text {coxa }}
\end{aligned}
$$

Nas equações 3.8 e $3.10, \vec{\tau}_{\mathrm{F}_{\mathrm{T}}}$ e $\vec{\tau}_{\mathrm{F} \text { J }}$ representam, respectivamente, o torque $-\vec{F}_{\mathrm{T}}$ com relação ao eixo que passa pela articulação do joelho (extremidade proximal da perna) e de $-\vec{F}_{\mathrm{J}}$ com relação ao eixo que passa pela articulação do quadril (na extremidade proximal da coxa).

A interação entre os segmentos adjacentes é representada no diagrama de corpo livre por uma força e um momento que resultam da aplicação da terceira lei de Newton ao sistema. Portanto, a interação entre pé e perna é representada por $\vec{F}_{\mathrm{T}}$ e $\vec{\tau}_{\mathrm{T}}$ atuando na extremidade proximal do pé e $-\vec{F}_{\mathrm{T}}$ e $-\vec{\tau}_{\mathrm{T}}$ atuando na extremidade distal da perna; a interação entre perna e coxa é representada por $\vec{F}_{\mathrm{J}}$ e $\vec{\tau}_{\mathrm{J}}$ que atuam na extremidade proximal da perna e $-\vec{F}_{\mathrm{J}}$ e $-\vec{\tau}_{\text {J }}$ na extremidade distal da coxa; e, por fim, a interação entre coxa e tronco é representada na extremidade proximal da coxa por $\vec{F}_{\mathrm{Q}}$ e $\vec{\tau}_{\mathrm{Q}}$. Estas forças e momentos são o que chamamos de forças e momentos articulares ou intersegmentares e são as incógnitas do problema.

As equações de 3.5 a 3.10 formam um sistema com seis equações e seis incógnitas, nas quais os torques são calculados com relação a um eixo perpendicular ao plano sagital e que passa pela articulação mais proximal (na extremidade) de cada segmento. O sistema pode ser 

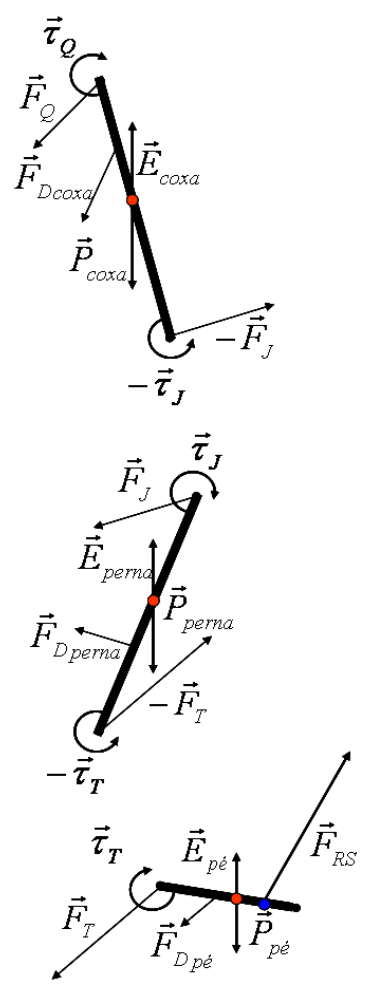

Figura 3.2: Diagrama de corpo livre para os segmentos pé, perna e coxa. O ponto de aplicação da força de reação do solo corresponde ao centro de pressão e o ponto de aplicação dos pesos e empuxos ao centro de massa.

solucionado se resolvermos estas equações na ordem em que estão listadas no texto.

Para calcular os torques dos pesos $\left(\overrightarrow{\mathcal{\tau}}_{\mathrm{P}}\right)$ e dos empuxos $\left(\overrightarrow{\mathcal{\tau}}_{\mathrm{E}}\right)$, consideramos que ambas as forças tinham como ponto de aplicação o centro de massa do segmento. Para o empuxo isso pôde ser feito, pois ao assumirmos que a densidade dos segmentos era homogênea, assumimos também que o centro de volume de cada segmento (ponto de aplicação do empuxo [12]), coincidia com o respectivo CM. Já a força de reação do solo tem como aplicação o centro de pressão (CP), que é o ponto sobre o qual o torque (no referencial da plataforma de força) da componente vertical da força de reação do solo é zero [56].

Assim, isolando as incógnitas e escrevendo explicitamente os torques, as equações 3.5 e 3.6 para o pé ficam:

$$
\begin{gathered}
\vec{F}_{\mathrm{T}}=m_{\mathrm{pé}} \vec{a}_{\mathrm{CM} \text { pé }}-\left(\vec{F}_{\mathrm{RS}}+\vec{P}_{\mathrm{pé}}+\vec{E}_{\mathrm{pé}}+\vec{F}_{\mathrm{D} \text { pé }}\right) \\
\vec{\tau}_{\mathrm{T}}=I_{\mathrm{pé}} \vec{\alpha}_{\mathrm{pé}}-\left(\left(\vec{r}_{\mathrm{CP}-\mathrm{T}} \times \vec{F}_{\mathrm{RS}}\right)+\left(\vec{r}_{\mathrm{CM}-\mathrm{T}} \times\left(\vec{P}_{\mathrm{pé}}+\vec{E}_{\mathrm{pé}}\right)\right)-\vec{\tau}_{\mathrm{Dpé}}\right)
\end{gathered}
$$

onde $\vec{r}_{\text {CP-T }}=\vec{r}_{\mathrm{CP}}-\vec{r}_{\mathrm{T}}$ representa o vetor posição do centro de pressão em relação a articulação do tornozelo e $\vec{r}_{\text {СM-т }}=\vec{r}_{\text {CM pé }}-\vec{r}_{\text {T }}$ representa a posição do centro de massas do pé 
com relação a essa mesma articulação.

Já para a perna as equações 3.7 e 3.8 ficam:

$$
\begin{gathered}
\vec{F}_{\mathrm{J}}=m_{\text {perna }} \vec{a}_{\text {CMperna }}-\left(\vec{P}_{\text {perna }}+\vec{E}_{\text {perna }}+\vec{F}_{\text {D perna }}-\vec{F}_{\mathrm{T}}\right) \\
\vec{\tau}_{\mathrm{J}}=I_{\text {perna }} \vec{\alpha}_{\text {perna }}-\left(\left(\vec{r}_{\text {CM-J }} \times\left(\vec{P}_{\text {perna }}+\vec{E}_{\text {perna }}\right)\right)-\left(\vec{r}_{\mathrm{T}-\mathrm{J}} \times \vec{F}_{\mathrm{T}}\right)+\vec{\tau}_{\text {Dperna }}-\vec{\tau}_{\mathrm{T}}\right)
\end{gathered}
$$

onde $\vec{r}_{\text {CM-J }}=\vec{r}_{\text {CMperna }}-\vec{r}_{\text {J }}$ representa a posição do centro de massas da perna com relação a articulação do joelho e $\vec{r}_{\mathrm{T}-\mathrm{J}}=\vec{r}_{\mathrm{T}}-\vec{r}_{\mathrm{J}}$, representa a posição do tornozelo com relação ao joelho.

E para a coxa as equações 3.9 e 3.10 ficam:

$$
\begin{gathered}
\vec{F}_{\mathrm{Q}}=m_{\text {coxa }} \vec{a}_{\mathrm{CMcoxa}}-\left(\vec{P}_{\text {coxa }}+\vec{E}_{\text {coxa }}+\vec{F}_{\text {Dcoxa }}-\vec{F}_{\mathrm{J}}\right) \\
\vec{\tau}_{\mathrm{Q}}=I_{\text {coxa }} \vec{\alpha}_{\text {coxa }}-\left(\left(\vec{r}_{\mathrm{CM}-\mathrm{Q}} \times\left(\vec{P}_{\text {coxa }}+\vec{E}_{\text {coxa }}\right)\right)-\left(\vec{r}_{\mathrm{J}-\mathrm{Q}} \times \vec{F}_{\mathrm{J}}\right)+\vec{\tau}_{\text {Dcoxa }}-\vec{\tau}_{\mathrm{J}}\right)
\end{gathered}
$$

onde $\vec{r}_{\mathrm{CM}-\mathrm{Q}}=\vec{r}_{\mathrm{Cmcoxa}}-\vec{r}_{\mathrm{Q}}$ representa a posição do centro de massas da coxa com relação a articulação do quadril e $\vec{r}_{\mathrm{J}-\mathrm{Q}}=\vec{r}_{\mathrm{J}}-\vec{r}_{\mathrm{Q}}$ representa a posição do joelho com relação ao quadril.

\subsection{O Modelo da Força de Arrasto}

Uma das dificuldades de se analisar a dinâmica do movimento humano em ambiente aquático está em determinar a força de arrasto que atua sobre o corpo do indivíduo (tanto experimentalmente quanto analiticamente). Este problema se estende inclusive (e principalmente) para a área da natação, na qual o conhecimento da resistência imposta pela água é importante para determinar as forças propulsivas e as resistivas [6, 16, 35, 50].

Atualmente estudos vêm sendo realizados visando determinar as forças de resistência impostas pelo ambiente aquático ao movimento humano em seu interior [5, 7, 16, 31, 32, 35, 38]. Em um deles, intitulado, "Human locomotion and energetics in simulated partial gravity"[32], D. Newman propôs o uso do meio aquático para realizar estudos sobre a locomoção humana em ambientes de gravidade reduzida. No entanto, era necessário verificar as diferenças no modo de locomoção do indivíduo e no gasto energético adicional devido a atuação da força de arrasto. 
A estimativa do gasto energético foi feita, então, através do cálculo do trabalho da força de arrasto [32].

D. Newman [32] utilizou a teoria das faixas (do inglês "strip theory") [33] para calcular a força de arrasto. Como o método proposto por ela se mostrou adequado para descrever a força nos membros inferiores durante o andar em esteira ergométrica, ele foi adotado neste estudo. Para a sua aplicação foram realizadas modificações no modelo geométrico utilizado para o corpo humano e houve também a necessidade de implementar o cálculo do torque da força de arrasto.

Antes de demonstrar o cálculo da força de resistência imposta, tanto pelo ar quanto pela água, ao andar humano devem ser esclarecidas as hipóteses feitas sobre o escoamento do fluido ao redor dos segmentos.

Neste estudo, mantivemos a aproximação feita por D. Newman [32] de fluxo estacionário e, portanto, desprezamos qualquer efeito não-inercial. Fazendo isso descartamos uma "força extra" necessária para acelerar a massa de fluido que se move ao redor do corpo, a qual é conhecida por massa adicional [8, 21, 33] (do inglês "added mass").

D. Newman [32] utilizou uma estimativa simplificada para quantificar o efeito desta força inercial na taxa metabólica total durante o caminhar em esteira ergométrica subaquática. Nela modelou o membro inferior como um único cilindro rígido e homogêneo e considerou apenas o movimento de rotação da perna ao redor do quadril, assumindo uma aceleração média de $0,208 \mathrm{~m} / \mathrm{s}^{2}$. Ela verificou que o gasto metabólico extra devido a esta força inercial era menor do que $3,6 \%$ do total [32], o que indica que sua magnitude é pequena e pode ser desprezada para esse movimento.

Contudo sabemos que para outros movimentos, como aqueles realizados em natação, os efeitos inerciais são importantes e o termo da força de arrasto que contém a massa adicional deve ser considerado [21]. Biscarini e Cerulli [7], em sua estimativa da carga sobre a articulação do joelho durante o exercício de extensão em água, adicionaram nos cálculos o efeito desta força no movimento da perna. Isso é um indício de que desprezar este efeito pode nos levar a subestimar a resistência imposta pelo fluido. Entretanto, este estudo se trata da primeira estimativa das forças e torques articulares no membro inferior durante um ciclo completo do andar e, levando em conta também a complexidade da estimativa dos efeitos não-inerciais [8, 33], optamos por não adicioná-los nesta primeira análise.

Ainda com relação ao escoamento, consideramos os efeitos de viscosidade apenas nas regiões de camada limite e de esteira. Nas outras regiões do campo foi considerada a hipótese de escoamento potencial. Levando em conta as dimensões e velocidades do problema, também foi possível tratar a água e o ar como fluidos incompressíveis ${ }^{3}$.

A resistência imposta pelo fluido ao movimento de um corpo nele imerso provém de duas fontes principais: do atrito entre a superfície do corpo e o fluido (atrito viscoso) e das diferenças

\footnotetext{
${ }^{3}$ Para número de mach menor que 0,2 a variação na pressão do ar é menor que $1 \%$ [15].
} 
de pressão ao longo do corpo que se move (arrasto de pressão). Em água ainda há uma terceira fonte de resistência que se deve à formação de ondas a medida que o corpo se move [50]. Sabese, no entanto, que durante o nado com velocidades próximas a $1 \mathrm{~m} / \mathrm{s}$ a contribuição deste tipo de resistência é de apenas $2 \%$ do arrasto total [47]. Como a velocidade confortável autoselecionada para o andar em ambiente aquático é, em média, $0,50(7) \mathrm{m} / \mathrm{s}$ (ver tabela 2.1) e os movimentos dos membros inferiores são realizados a uma profundidade maior, esta fonte não foi considerada.

A contribuição das outras duas fontes foi avaliada por D. Newman [32] através do número de Reynolds, o qual é dado pela equação 3.17 .

$$
R=\frac{|\vec{v}| \phi}{\nu}
$$

Nesta equação $|\vec{v}|$, representa o módulo da velocidade de deslocamento do corpo no fluido (ou do fluido ao redor do corpo), $\phi$ representa uma dimensão significativa do corpo, a qual depende da sua forma geométrica e posição em relação ao escoamento, e $\nu$ é a viscosidade cinemática do fluido.

D. Newman [32] constatou que os segmentos inferiores se moviam em água com números de Reynolds que variavam de $0,17 \times 10^{3}$ a $2,37 \times 10^{5}$. Nestas condições o regime de escoamento passa por laminar, parcialmente turbulento e turbulento e coexistem o arrasto viscoso e o arrasto de pressão. Contudo, ela verificou uma predominância do arrasto de pressão e do regime de escoamento parcialmente turbulento [32] e portanto desprezou o termo da força referente ao atrito entre a pele e o fluido. Essa aproximação foi mantida neste estudo.

Como será discutido adiante, os números de Reynolds aqui obtidos para os segmento do membro inferior, tanto para o andar em ambiente aquático quanto para o ambiente terrestre se encontram dentro desta faixa (tabela 4.10 na seção de resultados).

A força de arrasto $\left(\vec{F}_{\mathrm{D}}\right)$, quando há predominância do arrasto de pressão, é proporcional ao quadrado da velocidade do movimento do corpo $\left(v^{2}\right)$, à projeção da sua área frontal na direção perpendicular à velocidade $\left(A_{\perp}\right)$, à densidade do meio em que o corpo se encontra submerso $\left(\rho_{m}\right)$ e ao coeficiente de arrasto $\left(C_{\mathrm{D}}\right.$ - um número adimensional que depende apenas do formato do objeto em questão) e seu sentido é oposto ao de $\vec{v}$, como esta indicado na equação a seguir:

$$
\vec{F}_{\mathrm{D}}=-\frac{C_{\mathrm{D}} \rho_{m} A_{\perp} v^{2}}{2} \hat{v}
$$

onde $\hat{v}$ é um versor na direção da velocidade do movimento.

Para calcular a força que age sobre o corpo humano é necessário, inicialmente, modelar os 
segmentos por sólidos geométricos, para que seja possível determinar $A_{\perp}$. Adotamos, então, o modelo de Hanavan [23, 25], o qual aproxima os segmentos pelos sólidos indicados na figura 3.3 .

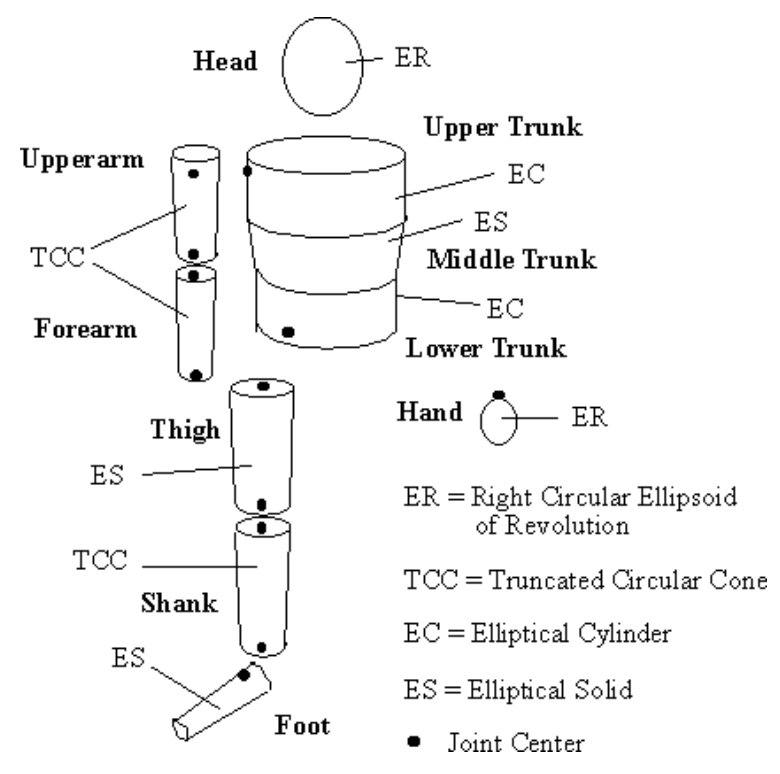

Figura 3.3: Modelo geométrico do corpo humano proposto por Hanavan [25], onde a coxa e o pé são modelados por sólidos elípticos e a perna por um tronco de cone circular segundo os parâmetros descritos na tabela 3.2 .

A principal modificação no modelo geométrico aqui adotado com relação àquele proposto por D. Newman [32], é que aqui os segmentos pé e perna foram tratados individualmente.

No modelo de Hanavan [25], as dimensões dos sólidos usados para representar o membro inferior e o tronco são calculadas a partir de parâmetros antropométricos medidos diretamente do corpo do participante [23]. As medidas necessárias à aplicação do modelo, bem como sua relação com as dimensões dos sólidos estão reportadas respectivamente nas tabelas 3.1 e 3.2 . Na tabela 3.2 a indica o diâmetro dos sólidos na direção perpendicular ao plano sagital e $b$ no plano sagital, L indica o comprimento do sólido e os índices p e d diferenciam as extremidades proximal e distal.

Poderíamos aplicar diretamente a equação 3.18 ao movimento de um corpo extenso se este apenas transladasse no espaço, o que não ocorre com os segmentos corporais durante o andar. Como o movimento estudado envolve translações e rotações simultâneas, pontos diferentes de um mesmo segmento possuem diferentes velocidades, o que implica que em cada pequena região age uma força diferente. Portanto, para computar a força de arrasto resultante e seu torque, devemos somar as forças que agem sobre cada região do segmento e os torques provocados por elas.

Realizamos o procedimento acima descrito aplicando a teoria das faixas ao cálculo da força de arrasto [33]. Assim, os sólidos que modelam cada segmento corporal foram divididos em secções transversais com relação ao seu eixo longitudinal e foi calculado para cada disco in- 
Tabela 3.1: Medidas necessárias à aplicação do modelo geométrico de Hanavan [25]

\begin{tabular}{|c|c|}
\hline Medida & Parâmetro Antropométrico \\
\hline M1 & Circunferência do pé \\
\hline M2 & Largura do pé \\
\hline M3 & Largura dos dedos \\
\hline M4 & Circunferência do metatarso \\
\hline M5 & Circunferência dos dedos \\
\hline M6 & Comprimento do pé \\
\hline M7 & Circunferência do joelho \\
\hline M8 & Circunferência do tornozelo \\
\hline M9 & Comprimento da perna \\
\hline M10 & Profundidade do quadril \\
\hline M11 & Circunferência da parte superior da coxa \\
\hline M12 & Comprimento da coxa \\
\hline M13 & Largura do tronco ao nível do umbigo \\
\hline M14 & Largura da articulação do quadril \\
\hline M15 & Comprimento do tronco inferior \\
\hline M16 & Circunferência do tronco ao nível do umbigo \\
\hline M17 & Circunferência da nádega \\
\hline M18 & $\begin{array}{l}\text { Largura do tronco ao nível do processo } \\
\text { xifóide }\end{array}$ \\
\hline M19 & $\begin{array}{l}\text { Circunferência do tronco ao nível do processo } \\
\text { xifóide }\end{array}$ \\
\hline M20 & Comprimento do tronco médio \\
\hline
\end{tabular}


Tabela 3.2: Representação dos segmentos corporais por sólidos geométricos segundo o modelo de Hanavan [23, 25]. A última coluna relaciona os parâmetros antropométricos do corpo do sujeito com as dimensões do sólido que melhor representa cada segmento. Nas equações, L representa o comprimento do sólido, a representa o raio da elipse na direção perpendicular ao pano sagital e e b o raio no plano sagital. Os índices $\mathbf{p}$ e $\mathbf{d}$ diferenciam as extremidades proximal e distal.

Segmento Formato Geométrico

Dimensões dos Sólidos em Função dos Parâmetros Antropométricos

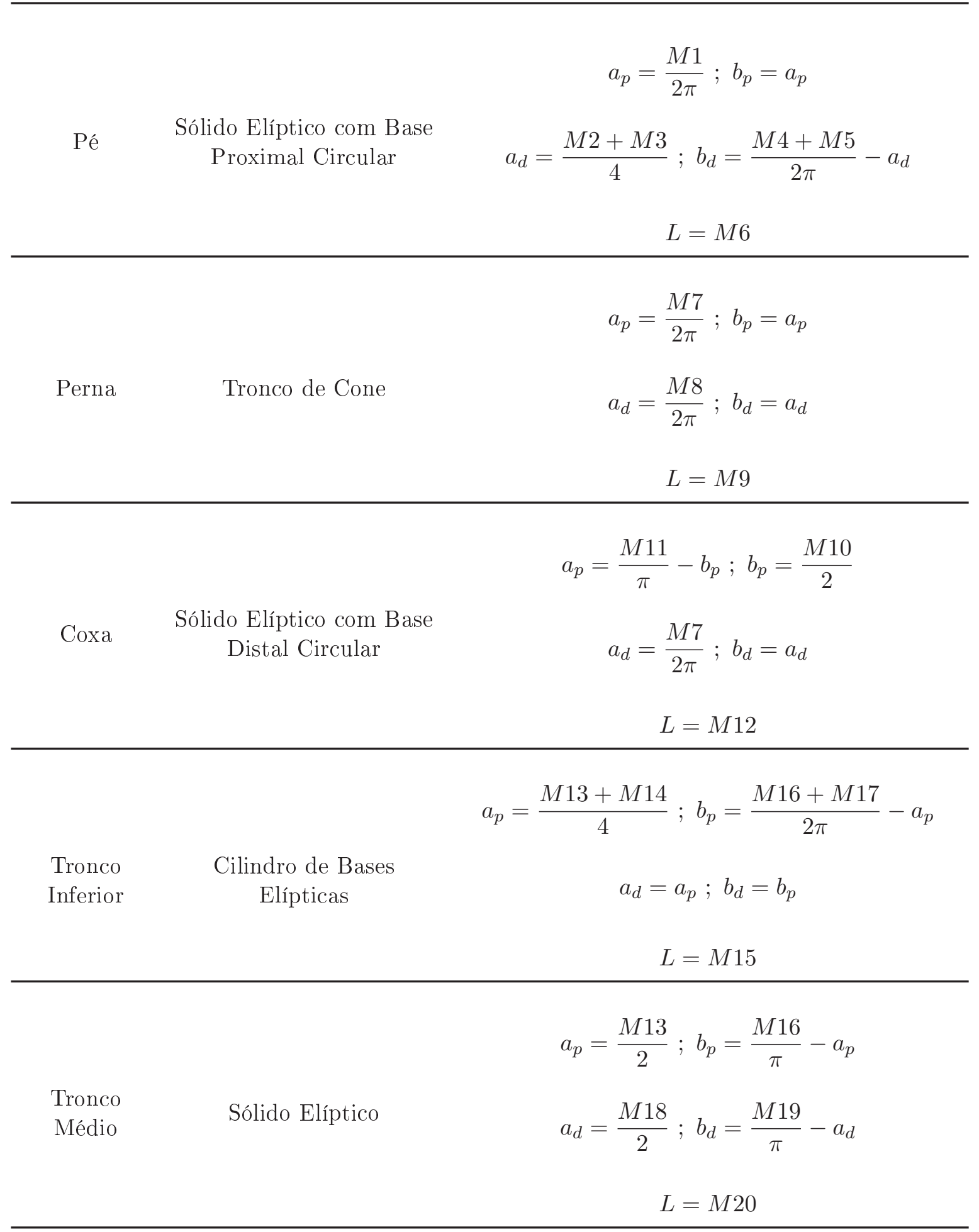




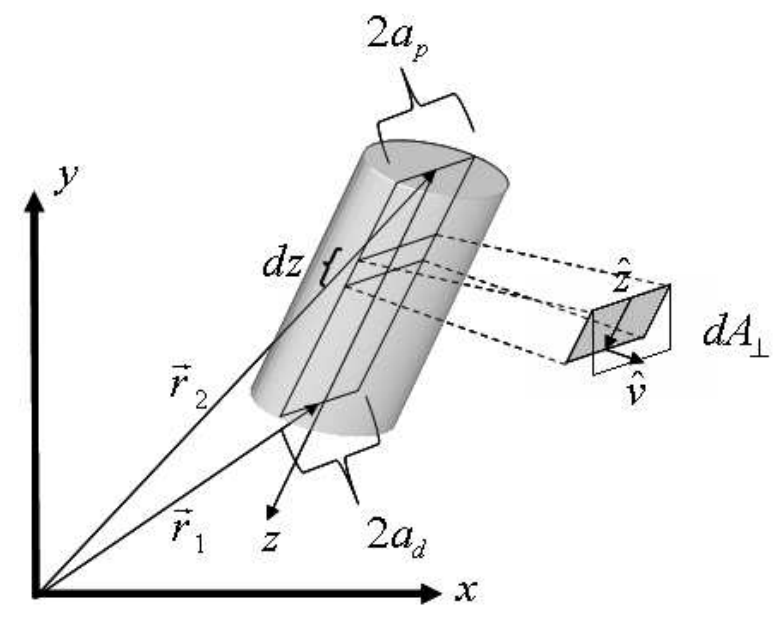

Figura 3.4: Representação da área da secção transversal perpendicular a sua velocidade de deslocamento $\left(d A_{\perp}\right)$, para uma faixa infinitesimal do sólido que modela o segmento corporal. Os eixos $x$ e $y$ representam o referencial do laboratório enquanto o eixo $z$ representa o referencial local (eixo longitudinal do segmento), que tem origem na articulação sobre a qual se deseja calcular o torque.

finitesimal, de área frontal $(d A)$, a força e seu torque com relação a articulação em questão. A força resultante é, portanto, a somatória de todas as forças infinitesimais $(d \vec{F})$ que agem sobre o segmento (equação 3.19).

$$
d \vec{F}_{\mathrm{D}}=-\frac{C_{\mathrm{D}} \rho_{m} v^{2}}{2} d A_{\perp} \hat{v}
$$

Foi utilizado para o cálculo das forças infinitesimais e seus respectivos torques um novo eixo de referência: o eixo longitudinal do segmento, $z$, com origem na articulação sobre a qual o torque deve ser calculado e apontando para a outra extremidade do segmento. O versor deste eixo $(\hat{z})$ orienta a posição do sólido no espaço e é dado pela equação 3.20 , onde $\vec{r}_{2}$ representa a coordenada da articulação mais proximal e $\vec{r}_{1}$ representa a coordenada da articulação na outra extremidade, ambas no referencial do laboratório (ver figura 3.4).

$$
\hat{z}=\frac{\vec{r}_{1}-\vec{r}_{2}}{\left|\vec{r}_{1}-\vec{r}_{2}\right|}
$$

A área frontal é a maior secção longitudinal do sólido perpendicular ao plano sagital e possui o formato de um trapézio de altura L e bases de largura $2 a_{p}$ e $2 a_{d}$ (ver tabela 3.2). Portanto um pedaço infinitesimal, formado por cortes transversais no segmento e posicionado a uma distância $z$ da articulação mais proximal, terá sua área frontal dada por: 


$$
d A(z)=2 a(z) d z=2\left[\frac{\left(a_{d}-a_{p}\right) z+a_{p} L}{L}\right] d z
$$

onde a $(z)$ é metade da largura do segmento a uma distância $z$ da articulação.

Já a velocidade em um ponto distante $z$ da articulação de referência é dada pela equação 3.22, na qual os índices 1 e 2 estão definidos como na equação 3.20:

$$
\vec{v}(z)=\frac{z \vec{v}_{1}+(L-z) \vec{v}_{2}}{L}
$$

Assumindo que a velocidade de cada disco infinitesimal é dada pela equação 3.22, a projeção da sua área frontal na direção do movimento pode ser calculada através do produto entre $d A$ e a magnitude do vetor determinado pelo produto vetorial entre o versor $\hat{z}$ e o versor que dá a direção de $\vec{v}(z)$ :

$$
d A_{\perp}(z)=d A\left|\hat{z} \times \frac{\vec{v}(z)}{|\vec{v}(z)|}\right|=2\left[\frac{\left(a_{d}-a_{p}\right) z+a_{p} L}{L}\right] \frac{|\hat{z} \times \vec{v}(z)|}{|\vec{v}(z)|} d z
$$

Substituindo, então, a equação 3.23 em 3.19 temos que a a força de arrasto é dada por:

$$
d \vec{F}_{\mathrm{D}}=-C_{\mathrm{D}} \rho_{m}\left[\frac{\left(a_{d}-a_{p}\right) z+a_{p} L}{L}\right]|\hat{z} \times \vec{v}(z)| \vec{v}(z) d z
$$

e o torque desta força com relação a articulação considerada é dado por:

$$
d \overrightarrow{\mathcal{T}}_{\mathrm{D}}=z \hat{z} \times d \vec{F}_{\mathrm{D}}=-C_{\mathrm{D}} \rho_{m} z\left[\frac{\left(a_{d}-a_{p}\right) z+a_{p} L}{L}\right]|\hat{z} \times \vec{v}(z)|(\hat{z} \times \vec{v}(z)) d z
$$

A força de arrasto e seu torque resultantes são obtidos a partir da integração das equações 3.24 e 3.25 no comprimento do segmento como esta representado nas equações 3.26 e 3.27.

$$
\begin{gathered}
\vec{F}_{\mathrm{D}}=-\int_{0}^{L} C_{\mathrm{D}} \rho_{m}\left[\frac{\left(a_{d}-a_{p}\right) z+a_{p} L}{L}\right]|\hat{z} \times \vec{v}(z)| \vec{v}(z) d z \\
\vec{\tau}_{\mathrm{D}}=-\int_{0}^{L} C_{\mathrm{D}} \rho_{m} z\left[\frac{\left(a_{d}-a_{p}\right) z+a_{p} L}{L}\right]|\hat{z} \times \vec{v}(z)|(\hat{z} \times \vec{v}(z)) d z
\end{gathered}
$$

Desta forma o modelo não leva em conta interações entre os fluxos ao redor dos segmentos 
adjacentes.

As integrais das equações 3.26 e 3.27 foram solucionadas numericamente, através de uma rotina construída em ambiente MATLAB, a partir da somatória do integrando, variando $z$ em passos de $0,01 \mathrm{~m}$.

Para o coeficiente adimensional $C_{\mathrm{D}}$ consideramos seu valor igual a 1 para todos os segmentos, por se tratar de um valor intermediário entre aqueles reportados na literatura [7, 32, 38]. Já a densidade do meio $\left(\rho_{m}\right)$ foi considerada $1000 \mathrm{~kg} / \mathrm{m}^{3}$ para a água e $1.2 \mathrm{~kg} / \mathrm{m}^{3}$ para o ar, e a viscosidade cinemática, usada na estimativa do número de Reynolds, $8,0 \times 10^{-7} \mathrm{~m}^{2} / \mathrm{s}$ na água e $1,5 \times 10^{-5} \mathrm{~m}^{2} / \mathrm{s}$ no ar $[15]$.

\subsection{Descrição Experimental}

O método da dinâmica inversa, como dito anteriormente, é um método não invasivo para determinar as forças e torques articulares. Esse método, contudo, exige o conhecimento das acelerações angulares e lineares dos segmentos corporais conectados pelas articulações, bem como as forças externas que agem sobre eles.

Com o objetivo de obter os dados cinemáticos e cinéticos para a determinação das forças e torques nas articulações do tornozelo, joelho e quadril durante o andar humano em ambiente aquático e terrestre, foi realizado um experimento, aprovado pelo Comitê de Ética da Escola de educação Física e Esporte da Universidade de São Paulo. Esse experimento contou com a participação de 23 voluntários, com idades entre 20 e 30 anos, que deveriam realizar a tarefa de caminhar em ambiente aquático (piscina com água rasa) e terrestre (laboratório de análise do movimento).

Os participantes assinaram um Termo de Consentimento Esclarecido (Anexo B), autorizando a utilização de seus dados no presente projeto, e responderam a um questionário de Anamnese Clínica (Anexo A), que avaliou se os indivíduos possuíam algum comprometimento músculo-esquelético ou neurológico que pudesse afetar a execução da marcha - a presença de um desses comprometimento excluía o indivíduo da amostra.

Durante as aquisições, tanto na piscina quanto no laboratório, os voluntários vestiram roupa de banho para que os marcadores circulares pudessem ser posicionados do lado direito do membro inferior e do tronco, de acordo com o modelo anatômico de Zatsiorsky modificado por De Leva [10]. Os sujeitos foram orientados a caminhar com uma velocidade confortável e tiveram tempo para se adaptar à tarefa antes que fosse iniciada a tomada de dados.

A aquisição de dados consistiu na filmagem do movimento do lado direito do corpo dos participantes, com câmeras digitais JVC (modelo DVR9800U) e na medição das componentes vertical e ântero-posterior da força de reação do solo, além do centro de pressão durante a fase de apoio do membro inferior direito, o que foi executado com plataformas de força da marca AMTI (modelo OR6WP em água e modelo OR62000 em terra). 
Após o tempo de adaptação, os sujeitos realizaram a tarefa 14 vezes (14 tentativas) e foram consideradas as tentativas nas quais apenas o calcanhar direito tocava a plataforma de força.

Como cada ambiente de coleta possuía diferentes limitações o mesmo arranjo experimental não pôde ser usado nas duas condições (estes serão descritos adiante mais especificamente) e a montagem e realização do experimento nos dois arranjos no mesmo dia tornaria o experimento muito longo. Além disso, havia restrições no tempo de uso da piscina, o que nos fez optar por realizar as duas fases do experimento em dias diferentes. Inicialmente os participantes realizaram a tarefa em ambiente aquático e voltaram ao laboratório em data posterior para participar da aquisição em ambiente terrestre.

Contudo, após a realização dos dois experimentos, foi verificado que apenas as imagens do andar de 10 sujeitos poderiam ser aproveitadas no estudo devido a problemas com o arranjo experimental em ambiente aquático.

Desta maneira, a amostra foi constituída de 10 indivíduos, 6 do gênero feminino e 4 do gênero masculino, que não apresentavam comprometimento neural e nem no sistema músculo esquelético, e possuíam idade, altura e massa médias respectivamente iguais a 24(3)anos, $1,68(7) \mathrm{m}$ e $63(8) \mathrm{kg}$. Todos os participantes eram fisicamente ativos e praticavam atividade físicas no mínimo duas vezes por semana.

\subsubsection{A Aquisição de Dados em Piscina com Água Rasa}

A aquisição de dados em ambiente aquático foi realizada na piscina aquecida da Escola de Educação Física e Esportes da Universidade de São Paulo (EEFE-USP), cujas dimensões são $12 m$ de largura, $25 \mathrm{~m}$ de comprimento e profundidade variável. Durante as coletas a temperatura da água foi mantida a $30^{\circ} \mathrm{C}$.

O fato do piso da piscina ser inclinada ao longo de seu comprimento, devido à diferença de profundidade, foi contornado com o uso de plataformas redutoras de profundidade (Aquática Slade Confecções, Ltda). Estas foram agrupadas de modo a formar uma passarela de aproximadamente $5 m$ de comprimento e $0,9 m$ de largura que, ao ser colocada na direção da largura da piscina, apresentava a superfície superior não inclinada.

O uso da passarela também era necessário para o nivelamento da plataforma de força em relação a superfície onde iria ocorrer o movimento. Diferente dos laboratórios, nos quais a plataforma fica inserida no piso de tal forma que a superfície de contato fica ao nível do solo, não há, na piscina, um "compartimento" para a colocação deste equipamento. Assim, um dos módulos da passarela foi construído de modo que a plataforma de força pudesse ser nele inserida, ficando com sua superfície no mesmo plano da superfície em que iria ocorrer o movimento.

O posicionamento da passarela na piscina foi ajustado de acordo com a altura do participante, o qual deveria caminhar sobre ela com água ao nível do processo xifóide, como pode 
ser visto na figura 3.5. Após ajustar a posição da passarela com relação a altura do sujeito, o experimentador verificava se a sua superfície estava realmente horizontal com a ajuda de um nível de bolha.

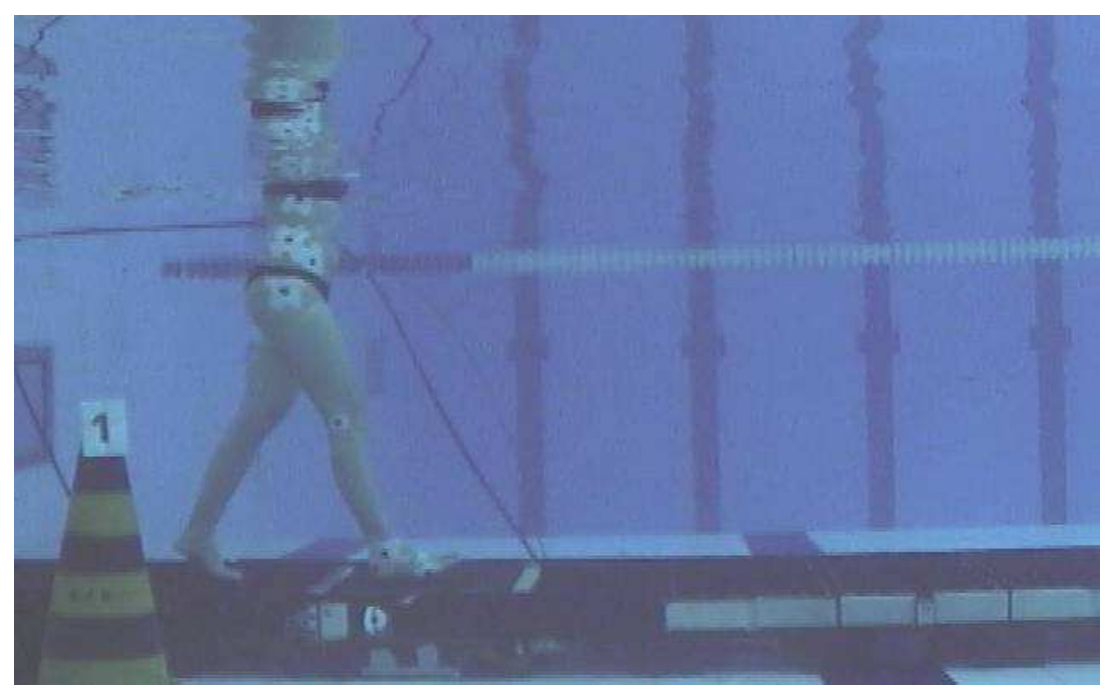

Figura 3.5: Arranjo experimental utilizado para aquisição de dados em ambiente aquático. Pode-se ver a plataforma de força inserida na passarela entre as duas faixas brancas.

As filmagens foram realizadas com apenas uma câmera colocada no interior de uma caixa estanque Ikelite própria para filmagens subaquáticas. A caixa foi fixada sobre um tripé e nele foram presos pesos adicionais para que o sistema não flutuasse. O conjunto era, então, posicionado de maneira que o eixo óptico da câmera ficasse perpendicular ao plano de movimento (aproximadamente o plano sagital) e a uma distância tal que conseguisse registrar uma passada iniciada com o calcanhar direito na plataforma de força. Ao lado do tripé foi colocada uma lâmpada a prova d'água com o objetivo de melhorar a iluminação local.

A aquisição dos dados da plataforma de força foi realizada com uma freqüência de amostragem de $200 \mathrm{~Hz}$ e a filmagem com freqüência $60 \mathrm{~Hz}$.

Antes de entrar na água eram feitas as medidas dos segmentos dos participantes, de acordo com a tabela 3.1. Estas medidas foram usadas no cálculo da força de arrasto. Foram afixados, então, sete marcadores circulares, usados para identificar os segmentos e articulações, nas seguintes posições anatômicas do membro inferior: cabeça do quinto metatarso, maléolo lateral, calcâneo, interlinha articular do joelho, trocanter maior e na porção lateral do tronco ao nível da cicatriz umbilical e ao nível do processo xifóide (marcadores de 1 a 7 da figura 3.6). Para fixá-los ao corpo do indivíduo foi utilizada fita Tegaderm, um tipo de adesivo transparente resistente a água usado na proteção de cicatrizes cirúrgicas.

Os marcadores circulares consistiam de um circulo branco, de aproximadamente 4,5cm de diâmetro, feito de um material resistente à água e com um adesivo circular preto, de aproximadamente $2,5 \mathrm{~cm}$ de diâmetro, colado concêntrico a ele. O circulo branco teve a função 


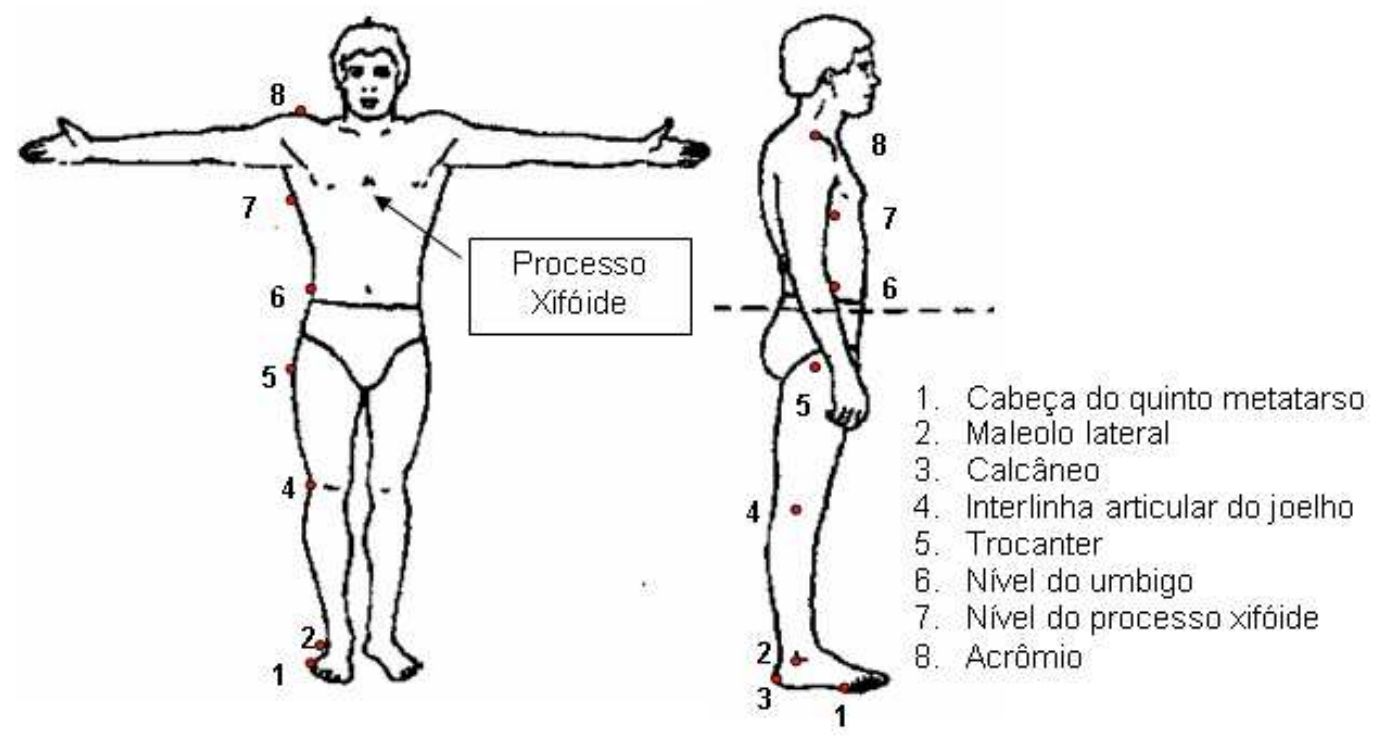

Figura 3.6: Vista frontal e lateral do posicionamento dos marcadores.

apenas de melhorar o contraste para que durante a digitalização das marcas fosse possível identificar o circulo preto, o qual efetivamente identificava a posição das marcas anatômicas.

O sujeito, então entrava na piscina, e após um tempo de adaptação à tarefa, era instruído a ficar parado sobre a plataforma de força, com os braços cruzados fora d'água. Ele era, então, filmado nesta posição, que serviu de referência para o cálculo dos ângulos articulares (equação 3.3), e simultaneamente foram adquiridos os dados da plataforma de força, através dos quais foi calculado o peso aparente do indivíduo em ambiente aquático.

Em seguida pedia-se ao participante que caminhasse sobre a passarela com velocidade confortável, sem mergulhar os braços na água, por 14 vezes. Após finalizada a aquisição, era feita a calibração do espaço com um quadro de acrílico $(120 \mathrm{~cm} \times 200 \mathrm{~cm})$ contendo 126 marcadores circulares pretos $(\approx 2,5 \mathrm{~cm}$ de diâmetro) distribuídos em 9 linhas e 14 colunas, espaçados igualmente de $12,0 \mathrm{~cm}$ (ver figura 3.7 ).

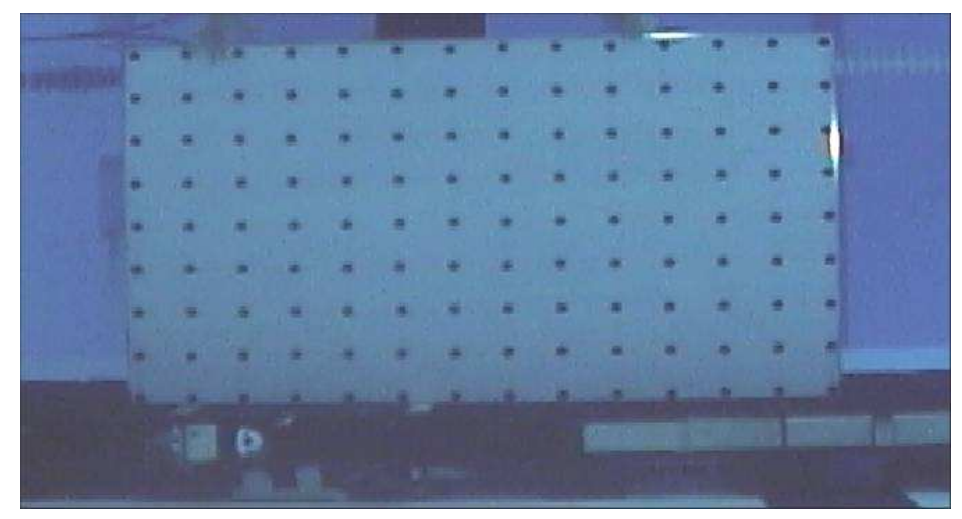

Figura 3.7: Quadro utilizado para a calibração do espaço em ambiente aquático. 


\subsubsection{A Aquisição de Dados no Laboratório}

A coleta em ambiente terrestre foi realizada no Laboratório de Biofísica na EEFE-USP, onde os indivíduos executaram a mesma tarefa realizada anteriormente em ambiente aquático.

Nessa parte do experimento não houve restrição com relação ao posicionamento dos braços e os participantes puderam caminhar como fazem em seu dia-a-dia.

Devido a limitações no espaço do laboratório, foi necessário o uso de duas câmeras digitais para que a passada iniciada com o pé direito na plataforma de força pudesse ser filmada do início ao fim. Estas câmeras foram fixadas no alto, em uma mesma lateral do laboratório, de modo a filmar o lado direito do participante.

Marcas feitas de esferas de isopor cobertas com fita retro-refletivas foram utilizadas para determinar os pontos anatômicos de referência. Elas foram afixadas à pele dos voluntários, com fita dupla face, nas seguintes posições anatômicas: cabeça do quinto metatarso, maléolo lateral, calcâneo, interlinha articular do joelho, trocanter maior e acrômio (figura 3.6).

Também foram adquiridos a imagem e os dados da plataforma de força com o indivíduo em pé parado sobre ela e com os braços cruzados a frente do corpo, para os fins descritos anteriormente.

A calibração do espaço foi feita com 20 marcas retro-refletivas posicionadas em quatro fios de prumo, presos ao teto do laboratório na região do espaço em que ocorreu o movimento. Essa calibração, diferente da realizada em ambiente aquático, foi feita em três dimensões, já que estávamos usando duas câmeras (ver figura 3.8).

As freqüências de amostragem das câmeras foram de $60 \mathrm{~Hz}$ e os dados referentes à plataforma de força foram adquiridos com freqüência de $100 \mathrm{~Hz}$.
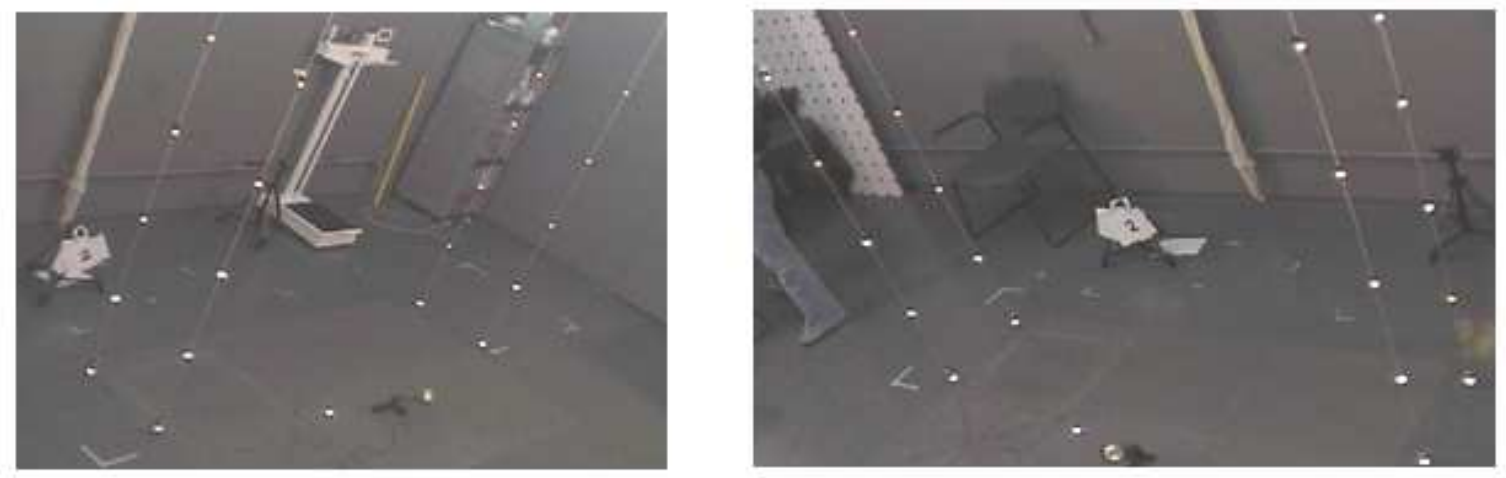

Figura 3.8: Calibração do espaço vista pela câmera posicionada no canto esquerdo do laboratório (na esquerda) e pela câmera posicionada no canto direito (na direita) 


\subsection{Tratamento dos Dados}

As imagens capturadas em ambiente aquático foram gravadas em fitas DV e precisaram ser digitalizadas, o que foi feito com o software Adobe Premiere. Não houve a necessidade de fazer o mesmo para as imagens adquiridos em ambiente terrestre, pois elas foram adquiridas com o auxílio do software APAS e salvas diretamente no computador.

Após a digitalização das imagens obtidas em água, foi verificado que apenas as imagens das tentativas de 10 sujeitos poderiam ser aproveitadas devido a iluminação insuficiente (em alguns momentos) no arranjo experimental no ambiente aquático. Portanto, apenas estes 10 indivíduos foram considerados nas análises. Devido a esse mesmo problema apenas 5 das 14 tentativas realizadas por cada indivíduo foram analisadas.

Com as imagens digitalizadas e o auxílio do software APAS, foram identificados, visualmente, em cada uma das 5 tentativa dos participantes, os quadros em que o sujeito tocava o calcanhar direito na plataforma de força (no inicio da passada) e quando voltava a encostar o calcanhar direito no solo (no fim da passada). As imagens foram cortadas 5 quadros adiante do toque inicial do calcanhar e 5 quadro seguintes ao toque final, com o objetivo de evitar distorções nos dados referentes ao início e ao fim da passada após a aplicação do filtro digital.

Utilizando novamente o software APAS, as posições dos marcadores foram digitalizadas, parte manualmente, pelo experimentador, parte automaticamente, por mecanismos do software. em seguida foi aplicado o algoritmo de Transformação Linear Direta, para que fossem obtidas as coordenadas dos marcadores no espaço. Estas foram armazenadas em arquivos de extensão ".3d" para serem analisadas em uma rotina criada em ambiente MATLAB.

A partir das posições dos marcadores foram calculadas, para cada tentativa de cada um dos participantes, as trajetórias: dos centros de massa dos segmentos, dos ângulos segmentares e dos ângulos articulares. Com o objetivo de reduzir ruídos, as curvas foram filtradas através do método proposto por Savitz e Golay [44] (descrito anteriormente na seção 3.1), ajustando aos dados polinômios locais de quinta ordem, com uma janela de 43 pontos para o ambiente aquático e 21 para o ambiente terrestre. Para isso, utilizamos a função "sgolay" fornecida pelo software MATLAB.

A função "sgolay" tem o seguinte incoveniente: ao ser aplicada são perdidos dados no início e no fim das curvas em número proporcional ao tamanho da janela utilizada. Para contornar este problema, além de digitalizar as posições dos marcadores em quadros extras, houve a necessidade de se adicionar mais pontos à curva antes do início e após o final do ciclo. Esta técnica se apóia no fato de que o andar é um evento cíclico e, portanto, nos permite inferir, a partir das informações de uma passada, o comportamento das variáveis na passada anterior e na seguinte [42]. Foram, então, adicionados dados em número suficiente para que, após a aplicação do filtro, fossem perdidos todos os dados extras e a curva fosse cortada exatamente nos instantes de contato inicial e final do calcanhar. Além das curvas citadas anteriormente as 
trajetórias dos marcadores também foram filtradas seguindo o mesmo procedimento.

Ainda utilizando a função "sgolay", foram calculadas as derivadas de primeira e segunda ordens com relação ao tempo da trajetória do centro de massa e das posições angulares do pé, da perna e da coxa. Das derivadas de primeira ordem, foram obtidas as velocidades do centro de massa e as velocidades angulares segmentares. Das derivadas de segunda ordem, as acelerações lineares e angulares necessárias cálculo da dinâmica inversa (equações de 3.11 a $3.16)$.

Seguindo o método de derivação descrito acima, foram calculadas para os dois ambientes: as velocidades angulares articulares do tornozelo, joelho e quadril, as quais foram usadas para determinar a potência articular (equação 2.2); e a velocidade de deslocamento dos marcadores posicionados no maléolo lateral, na interlinha articular do joelho e no trocanter. Somente para o ambiente aquático, foram calculadas as velocidades dos marcadores posicionados ao nível da cicatriz umbilical e do processo xifóide. As velocidades dos marcadores foram usadas na equação 3.22 no cálculo da força de arrasto.

Os dados da plataforma de força foram adquiridos com o software LabView e salvos em arquivos texto. Foram analisados os dados referentes à força de reação do solo nas direções vertical e ântero-posterior. Também foram necessárias, para o cálculo do $\mathrm{CP}$, as informações referentes à componente médio lateral e à componente vertical do momento de FRS com relação ao eixo de referência da plataforma. Assim como os dados cinemáticos, eles foram filtrados pelo método Savitz-Golay com polinômios de quinta ordem, mas desta vez, foi usada uma janela de 61 pontos para o ambiente aquático e 31 pontos para o ambiente terrestre. Não foi necessária a colocação de pontos extras antes da filtragem dos dados da plataforma de força, isso porque sua aquisição começou a ser feita antes do participante tocar a plataforma e continuou mesmo após o fim da fase de apoio.

A fase de apoio precisou ser identificada também nos dados da plataforma de força. Para essa tarefa foi utilizada como referência componente vertical, da qual foram considerados apenas os dados que fossem maior que um determinado limiar. Como todas as componentes da FRS e de seu momento com relação ao eixo da plataforma de força foram adquiridos simultaneamente, ao determinarmos o intervalo de dados que seriam usados nos cálculos para a componente vertical, estávamos determinado também para as outras variáveis.

O limiar adotado para a terra foi de $3 \%$ da diferença entre os valores máximo e mínimo obtido durante toda aquisição para a força de reação do solo e para água foi de $5 \%$ desta diferença. Os limiares adotados não foram similares pois a amplitude de variação da componente vertical de FRS era maior em ambiente terrestre do que em ambiente aquático.

Os dados da plataforma de força e da filmagem foram adquiridos com freqüências diferentes. Portanto, foi preciso sincronizar as curvas de todas as variáveis cinemáticas àquela obtidas com a plataforma. Para tanto, foram interpolados dados às curvas das variáveis cinemáticas de modo que a freqüência de amostragem passasse a ser igual àquela da plataforma de força. 
A interpolação foi feita por spline cúbico utilizando a função "interp1" do software MATLAB. As componentes de FRS e o CP foram considerados zero na fase de balanço.

Após a sincronização, as forças de arrasto e respectivos torques, as forças, os torques e as potência articulares foram calculados.

Para comparar as curvas das grandezas estudadas (dadas em função do tempo), obtidas por um determinado indivíduo, com as curvas obtidas pelos outros indivíduos do grupo, ou ainda, comparar as curvas obtidas nas diversas tentativas de um mesmo indivíduo, foi necessário normalizar o tempo pelo período da passada. O período da passada foi obtido subtraindo-se um do número de quadros presentes na imagem entre o instante de contato inicial do calcanhar e o instante do contato final e, multiplicando esse número pelo período de aquisição da imagem. A normalização foi feita através de uma nova interpolação por spline cúbicos. Desta maneira, todas as curvas passaram a ter o mesmo número de dados que correspondem aos instantes de 0 a $100 \% T_{p}$ incrementados de $0,1 \% T_{p}$.

Ainda para fins de comparação entre as diversas tentativas do indivíduo, entre o indivíduo e o grupo e entre o grupo e os valores reportados na literatura, todas as variáveis referentes a forças foram normalizadas em relação ao peso corporal do indivíduo $(P C)$ e reportadas em porcentagem deste. Já os torques, foram normalizados pelo produto entre o peso corporal do sujeito e o comprimento de seu membro inferior $\left(L_{m}\right)$, o qual foi estimado a partir da distância média entre o marcador do trocanter e do maléolo lateral na posição ortostática. As potências foram normalizadas pela massa corporal do indivíduo, sendo, então, reportadas em $\mathrm{W} / \mathrm{kg}$. Os ângulos e velocidades angulares articulares foram reportados respectivamente em graus e em graus por segundo.

Após as normalizações e ajustes de unidades foi analisado o comportamento das seguintes variáveis nos dois ambientes: ângulo, velocidade angular, força, torque e potência articular do tornozelo, do joelho e do quadril, além da velocidade do centro de massa e da força de arrasto e respectivo torque para os segmentos pé, perna e coxa.

Também foram comparados entre os ambientes comprimento, período e velocidade da passada e os períodos absoluto e normalizado da fase de apoio.

Com o objetivo de verificar a validade do modelo para o cálculo da força de arrasto, ainda verificamos a relação entre o impulso da componente horizontal desta força e o impulso da componente horizontal da força de reação do solo durante a fase de apoio simples da passada.

\subsection{Análise Estatística}

A análise das variáveis de interesse consistiu inicialmente em determinar, para cada grandeza, a curva que melhor representa o comportamento do grupo e uma estimativa da variação deste conjunto. Esta curva foi, então, determinada a partir das curvas representativas de cada indivíduo através do procedimento descrito a seguir. 
A cada grandeza monitorada, a curva que melhor representa o comportamento de um determinado sujeito k é dada pela equação 3.28 e consiste na média, instante-a-instante, da grandeza em cada uma das 5 tentativas realizadas por ele. A curva representativa do grupo é, portanto, dada pela média (equação 3.29) e respectivo desvio padrão (equação 3.30), calculados, instante-a-instante, a partir das curvas representativas dos $\mathrm{N}$ sujeitos considerados na análise da grandeza.

$$
\begin{gathered}
\bar{m}_{k}\left(t_{i}\right)=\frac{1}{5} \sum_{j=1}^{5} m_{k j}\left(t_{i}\right) \\
\bar{M}\left(t_{i}\right)=\frac{1}{N} \sum_{k=1}^{N} \bar{m}_{k}\left(t_{i}\right) \\
S_{\bar{M}}\left(t_{i}\right)=\sqrt{\frac{\sum_{k=1}^{N}\left(\bar{m}_{k}\left(t_{i}\right)-\bar{M}\left(t_{i}\right)\right)^{2}}{(N-1)}}
\end{gathered}
$$

Alguns eventos de cada curva foram selecionados para serem comparados entre os ambientes, como por exemplo máximos e mínimos ao longo do ciclo. Os valores representativos destes eventos foram obtidos seguindo um procedimento semelhante ao descrito acima: eles foram calculados para as 5 tentativas de cada sujeito nos dois ambientes; para cada ambiente foi obtido um valor representativo por indivíduo, o qual consistiu da média dos valores obtidos nas 5 tentativas; e, finalmente, o valor representativo para o grupo, em um determinado ambiente, e sua variabilidade (desvio padrão), foram estimados a partir da média dos 10 indivíduos participantes.

Este procedimento também foi seguido na determinação dos valores médios em cada ambiente e respectivos desvios padrões das variáveis descritivas 2.1.

As grandezas obtidas em terra e em água foram comparadas através do teste t para medidas pareadas, cuja aplicação está condicionada à normalidade da amostra que se quer testar, no caso, o conjunto das diferenças dos valores representativos obtidos para uma determinada variável em terra e água, para um mesmo sujeito. Por esse motivo o teste t foi antecedido do teste de Shapiro-Wilk, que verifica a normalidade da amostra. A hipótese nula do teste t $\left(H_{o}\right)$ postulava a igualdade entre o valor obtido em terra e em água e do teste de Shapiro-Wilk, a normalidade do conjunto de dados. Nas situações em que a condição de normalidade não foi atingida, foi aplicado o teste de Wilcoxon para medidas pareadas. Neste teste a hipótese nula também postulava a igualdade entre o valor obtido em terra e em água.

O nível de significância adotado neste estudo foi de 0,01 . Todas as análises estatísticas, 
com exceção do teste de Shapiro-Wilk, foram realizadas em ambiente MATLAB, apenas o teste de normalidade foi realizado com a ferramenta fornecida pelo software ORIGIN. 


\section{Capítulo 4}

\section{Resultados}

Para uma melhor compreensão dos resultados obtidos neste estudo as variáveis quantificadas foram agrupadas em cinemáticas e cinéticas. As variáveis cinemáticas foram divididas em duas seções: Cinemática Descritiva (seção 4.1.1) e Cinemática Angular e Segmentar (seção 4.1.2); e as variáveis cinéticas em outras duas: Forças e Torques Externos (seção 4.2.1) e Forças e Torques Internos (seção 4.2.2).

Na seção 4.1.1 estão reportadas as análises referentes aos períodos da passada $\left(T_{p}\right)$ e da fase de apoio $\left(T_{a}\right)$ e ao comprimento $\left(L_{p}\right)$ e à velocidade $\left(V_{p}\right)$ da passada. Na seção seguinte encontram-se as análises dos ângulos das velocidades angulares articulares para o tornozelo, joelho e quadril, assim como das velocidades lineares dos centros de massa dos segmentos pé, perna e coxa durante o ciclo.

A análise das variáveis cinemáticas é importante não só para auxiliar na compreensão dos padrões das forças e torques internos resultantes, mas também para avaliar o modelo adotado para a força de arrasto.

Com relação às variáveis cinéticas, na seção 4.2.1 foram descritos os resultados referentes às análises das componentes da força de reação do solo, das forças de arrasto e dos torques gerados pelas forças de arrasto ao longo do ciclo. Já na seção 4.2 .2 foram descritos os resultados das análises das forças e torques articulares que agem sobro o tornozelo o joelho e o quadril. Nessa seção também são reportadas as potências das três articulações, com o objetivo de auxiliar na compreensão dos torques articulares durante o ciclo.

Em uma última seção (seção 4.3) estão reportados os resultados das análises que verificam a relação entre a mudança na componente ântero-posterior da FRS e a existência do arrasto. 


\subsection{Variáveis Cinemáticas}

\subsubsection{Cinemática Descritiva}

Após o processo de digitalização das imagens e filtragem dos dados foi possível quantificar, para cada vídeo, o número de quadros que correspondiam a uma passada. O período do ciclo foi calculado, através do produto do número de quadros menos um, pelo período de aquisição da câmera de vídeo $\left(\frac{1}{60} s\right)$. Já o cálculo do período da fase de apoio foi realizado a partir dos dados referentes à força de reação do solo na direção vertical $\left(F R S_{V}\right)$. Seguindo o processo de sincronização descrito na seção 3.4, foi possível computar o número de dados adquiridos pela plataforma de força durante a fase de apoio. O período desta fase foi obtido, então, do produto entre o número de dados adquiridos no apoio menos um e o período de aquisição da plataforma (0,01s para aquisição em terra e 0,005 para aquisição em água).

Foi calculada a média individual de cada sujeito, tanto para $T_{p}$ quanto para $T_{a}$, e em seguida a média do grupo. Estes valores, assim como os das outras variáveis descritivas, se encontram na tabela 4.1.

Tabela 4.1: Média (desvio padrão) do período da passada $\left(T_{p}\right)$, do período da fase de apoio absoluto $\left(T_{a}\right)$ e normalizado $\left(T_{a_{\mathrm{NORM}}}\right)$, do comprimento $\left(L_{p}\right)$ e da velocidade da passada $\left(V_{p}\right)$, obtidos durante o andar em terra e em água. As duas últimas colunas fornecem respectivamente o valor de p do teste de Shapiro-Wilk e do teste t. $\mathrm{O} *$ indica diferença entre os ambientes.

\begin{tabular}{ccccc}
\hline \multirow{2}{*}{$\begin{array}{c}\text { Variáveis } \\
\text { Descritivas }\end{array}$} & Terra & Água & \multicolumn{2}{c}{ Testes Estatísticos } \\
\cline { 4 - 5 } & & & Shapiro-Wilk & teste t \\
\hline$T_{p}(s)$ & $1,12(8)$ & $2,79(30)$ & 0,97 & $<0,0001 *$ \\
\hline$T_{a}(s)$ & $0,71(5)$ & $1,60(18)$ & 0,21 & $<0,0001 *$ \\
\hline$T_{a \mathrm{NORM}}\left(\% T_{p}\right)$ & $63,1(10)$ & $57,6(33)$ & 0,84 & $<0,0001 *$ \\
\hline$L_{p}(m)$ & $1,38(8)$ & $1,39(18)$ & 0,84 & 0,71 \\
\hline$V_{p}(m / s)$ & $1,23(10)$ & $0,50(4)$ & 0,43 & $<0,0001 *$ \\
\hline
\end{tabular}

Comparando os resultados obtidos para os dois ambientes vemos que tanto o período da passada, quanto o período da fase de apoio, são diferentes e maiores no ambiente aquático.

Normalizando a duração da fase de apoio pelo período do ciclo, ou seja dividindo $T_{a}$ por $T_{p}$, obtemos que em terra a fase de apoio correspondeu à $63,1(10) \% T_{p}$, enquanto em água correspondeu a 57,6(33)\% $T_{p}$. Mesmo após ser feita a normalização, o período da fase de suporte foi diferente entre os ambientes, sendo aproximadamente $5 \%$ maior durante o movimento em terra (ver tabela 4.1 ). 
O comprimento da passada, obtido da diferença da coordenada horizontal da marca do calcanhar entre os instantes inicial e final do ciclo, não apresentou diferença entre os dois ambientes, o que levou a velocidade da passada a ser maior no ambiente terrestre (aproximadamente 2,4 vezes a velocidade em água), como está reportado na tabela 4.1.

\subsubsection{Cinemática Angular e Segmentar}

Os gráficos da figura 4.1 representam os deslocamentos angulares das articulações do tornozelo, joelho e quadril (equações 3.3) para um ciclo completo do andar.
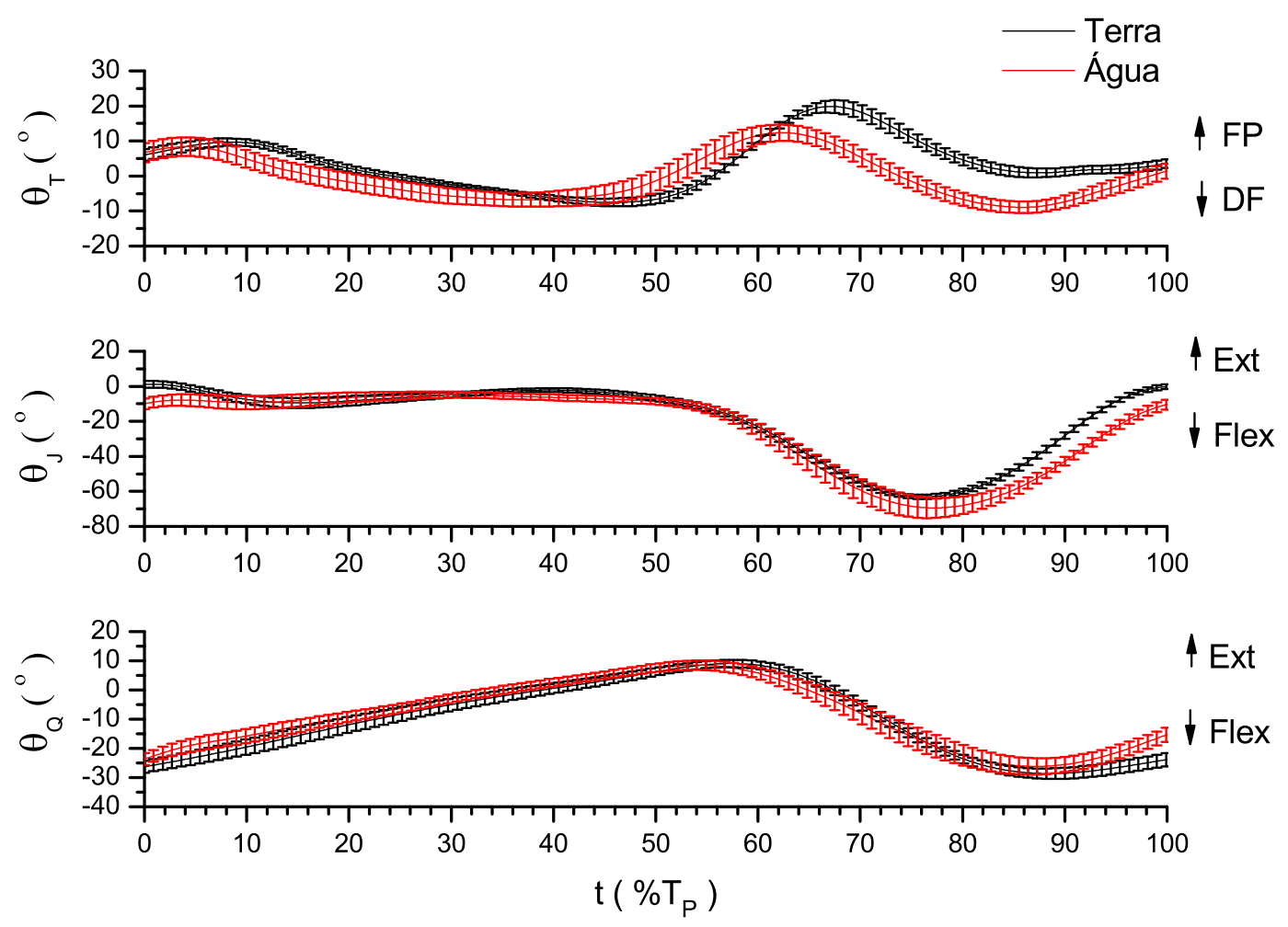

Figura 4.1: Ângulo articular do tornozelo $\left(\theta_{\mathrm{T}}\right)$, do joelho $\left(\theta_{\mathrm{J}}\right)$ e do quadril $\left(\theta_{\mathrm{Q}}\right)$ ao longo de uma passada. O tempo está normalizado pelo período do ciclo e as barras de incerteza representam o desvio padrão da média. As setas indicam os sentidos de rotação: flexão plantar (FP) e dorsi-flexão (DF) para o tornozelo; flexão (Flex) e extensão (Ext) para o joelho e o quadril.

Nessas curvas o sentido positivo indica flexão plantar para o tornozelo e extensão para o joelho e o quadril. As barras de incerteza representam o desvio padrão da média ${ }^{1}$ apenas para facilitar a visualização, já que os desvios padrões dos ângulos articulares apresentaram valores muito elevados, principalmente no ambiente aquático, no qual problemas na iluminação levaram

\footnotetext{
${ }^{1} S_{\bar{M}}\left(t_{i}\right) \div \sqrt{N}$, onde $\mathrm{N}$ é o número de sujeitos considerados
} 
a dificuldades na identificação dos marcadores durante o processo de digitalização. Além disso, no cálculo dos ângulos articulares foram considerados apenas os dados de 7 indivíduos ${ }^{2}$, pois os arquivos das imagens na posição ortostática de três dos participantes, em ambiente terrestre, estavam corrompidos. Portanto, para fins de comparação estes mesmos três indivíduos foram excluídos da análise em ambiente aquático.

Observando o comportamento dos ângulos articulares em função do tempo, pode-se perceber um padrão semelhante no deslocamento angular das articulações do tornozelo, joelho e quadril em terra e em água. Contudo, os picos de dorsi-flexão e flexão plantar do tornozelo parecem diferir em magnitude e no instante de ocorrência. Além disso, o ângulo de flexão máxima do joelho parece ser maior.

Com o objetivo de compreender melhor o comportamento das curvas, foram comparadas entre os ambientes as seguintes variáveis: amplitude de movimentação articular e ângulo articular no contato inicial (AI), para as três articulações. Os dados referentes a essas variáveis se encontram nas tabelas 4.2 e 4.3 e podem ser melhor visualizados nos gráficos da figura 4.2 .

Tabela 4.2: Amplitude média (desvio padrão) do deslocamento angular das articulações do membro inferior nos dois ambientes. As duas últimas colunas representam, respectivamente, o valor de $\mathrm{p}$ do teste de Shapiro-Wilk e do teste t.

\begin{tabular}{lcccc}
\hline \multirow{2}{*}{ Articulações } & \multicolumn{2}{c}{ Amplitude Articular $\left(^{\circ}\right)$} & \multicolumn{2}{c}{ Testes Estatísticos } \\
\cline { 2 - 5 } & Terra & Água & Shapiro-Wilk & teste t \\
\hline Tornozelo & $28,2(45)$ & $27,7(34)$ & 0,71 & 0,68 \\
\hline Joelho & $66,0(33)$ & $70(17)$ & 0,55 & 0,60 \\
\hline Quadril & $38,4(34)$ & $38,9(61)$ & 0,51 & 0,80 \\
\hline
\end{tabular}

Tabela 4.3: Ângulo articular médio (desvio padrão) no contato inicial (AI). As duas últimas colunas representam o valor de p do teste de Shapiro-Wilk e do teste t. O * indica diferença entre os ambientes.

\begin{tabular}{lcccc}
\hline \multirow{2}{*}{ Articulações } & \multicolumn{2}{c}{ AI $\left(^{\circ}\right)$} & \multicolumn{2}{c}{ Testes Estatísticos } \\
\cline { 2 - 5 } & Terra & Água & Shapiro-Wilk & teste t \\
\hline Tornozelo & $6,1(44)$ & $6,6(73)$ & 0,24 & 0,78 \\
\hline Joelho & $1,1(53)$ & $-10,0(79)$ & 0,27 & $<0,01 *$ \\
\hline Quadril & $-26,3(54)$ & $-23,6(54)$ & 0,58 & 0,22 \\
\hline
\end{tabular}

\footnotetext{
${ }^{2} \mathrm{Na}$ análise das outras variáveis cinemáticas não foi excluído nenhum sujeito da análise.
} 


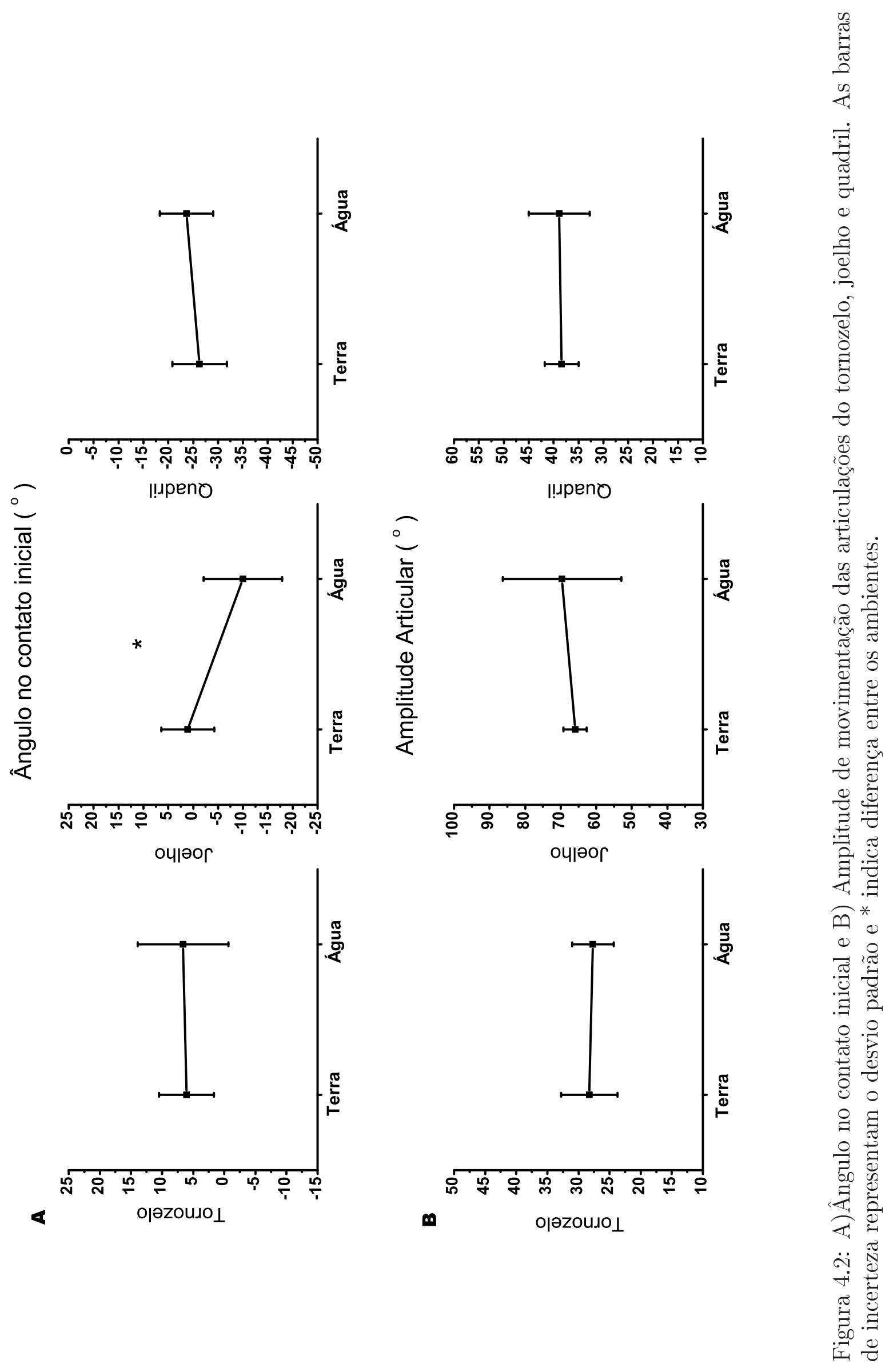


Para cada articulação ainda foram comparados alguns eventos específicos e seus instantes de ocorrência (IO). Do tornozelo foram quantificados os ângulos de dorsi-flexão e flexão plantar máximos nas fases de apoio e balanço (tabela 4.4); do joelho o ângulo de flexão máxima e do quadril o ângulo de máxima extensão durante o ciclo e o de flexão máxima na fase de balanço (tabela 4.5).

Não foi possível perceber diferenças significativas entre os ambientes com relação à amplitude das três articulações, como pode ser visto na figura 4.2B e na tabela 4.2. Ao confrontarmos os valores de AI, no entanto, verifica-se que para a articulação do joelho não há semelhança entre os valores obtidos em terra e e em água: em média o joelho se encontra próximo da posição neutra em terra $\left(1(5)^{\circ}\right)$ e ligeiramente flexionado $\left(-10(8)^{\circ}\right)$ em água. Tornozelo e quadril não apresentaram diferença entre os ambientes nos ângulo no contato inicial.

Dos ângulos máximos de dorsi-flexão e flexão plantar do tornozelo, nas fases de apoio e balanço, e respectivos instantes de ocorrência, apenas foi constatada diferença entre água e terra na magnitude do ângulo de dorsi-flexão máxima ocorrido na fase de balanço. Os ângulos médios e instantes em que ocorreram, assim como os resultados do teste t, estão reportados na tabela 4.4 e podem ser melhor examinados nos gráficos da figura 4.3.

Tabela 4.4: Valores representativos (média (desvio padrão)) para os ângulos de flexão plantar e dorsi-flexão máximos do tornozelo, nas fases de apoio e de balanço, e respectivos instantes de ocorrência (IO). Nas duas últimas colunas estão reportados os valores de p para o teste de Shapiro-Wilk e para o teste t, com o ${ }^{*}$ indicando diferença entre os ambientes.

\begin{tabular}{|c|c|c|c|c|c|}
\hline \multirow{2}{*}{ Eventos } & \multirow{2}{*}{ Variáveis } & \multirow{2}{*}{ Água } & \multirow{2}{*}{ Terra } & \multicolumn{2}{|c|}{ Testes Estatísticos } \\
\hline & & & & Shapiro-Wilk & teste $\mathrm{t}$ \\
\hline \multirow{2}{*}{$\begin{array}{l}\text { Flexão Plantar } \\
\text { Máxima - FB }\end{array}$} & Ângulo $\left(^{\circ}\right)$ & $15,4(44)$ & $20,4(45)$ & 0,10 & 0,09 \\
\hline & $I O\left(\% T_{p}\right)$ & $63,0(58)$ & $67,0(13)$ & 0,51 & 0,10 \\
\hline \multirow{2}{*}{$\begin{array}{l}\text { Flexão Plantar } \\
\text { Máxima - FA }\end{array}$} & Ângulo $\left(^{\circ}\right)$ & $9,4(75)$ & $10,5(27)$ & 0,41 & 0,62 \\
\hline & $I O\left(\% T_{p}\right)$ & $4,2(21)$ & $7,7(39)$ & 0,02 & 0,03 \\
\hline \multirow{2}{*}{$\begin{array}{l}\text { Dorsi Flexão } \\
\text { Máxima - FB }\end{array}$} & Ângulo $\left(^{\circ}\right)$ & $-9,7(46)$ & $-1,1(28)$ & 0,97 & $<0,001 *$ \\
\hline & $I O\left(\% T_{p}\right)$ & $85,7(18)$ & $91,4(57)$ & 0,93 & 0,02 \\
\hline \multirow{2}{*}{$\begin{array}{l}\text { Dorsi Flexão } \\
\text { Máxima - FA }\end{array}$} & Ângulo $\left(^{\circ}\right)$ & $-9,6(54)$ & $-7,8(29)$ & 0,27 & 0,35 \\
\hline & $I O\left(\% T_{p}\right)$ & $38,1(78)$ & $44,7(35)$ & 0,31 & 0,05 \\
\hline
\end{tabular}

Também não houve diferença entre os ambientes nos ângulos de flexão máxima do joelho, extensão máxima do quadril e flexão máxima do quadril na fase de balanço, e nem nos instantes em que esses eventos ocorreram (ver tabela 4.5 e gráficos das figuras 4.4 e 4.5). 
Tabela 4.5: Valores médios (desvio padrão) dos ângulo de flexão máxima do joelho, da extensão máxima e da flexão máxima na fase de balanço para o quadril e os instantes em que ocorreram tais eventos (IO). Nas duas últimas colunas estão reportados os valores de $\mathrm{p}$ do teste de Shapiro-Wilk e do teste t.

\begin{tabular}{|c|c|c|c|c|c|}
\hline \multirow{2}{*}{ Eventos } & \multirow{2}{*}{ Variáveis } & \multirow{2}{*}{ Água } & \multirow{2}{*}{ Terra } & \multicolumn{2}{|c|}{ Testes Estatísticos } \\
\hline & & & & Shapiro-Wilk & teste $\mathrm{t}$ \\
\hline \multirow{2}{*}{$\begin{array}{c}\text { Flexão Máxima do } \\
\text { Joelho }\end{array}$} & Ângulo $\left({ }^{\circ}\right)$ & $-71(15)$ & $-63,6(34)$ & 0,21 & 0,19 \\
\hline & $\mathrm{IO}\left(\% T_{p}\right)$ & $77,6(28)$ & $75,9(14)$ & 0,10 & 0,22 \\
\hline \multirow{2}{*}{$\begin{array}{c}\text { Extensão Máxima do } \\
\text { Quadril }\end{array}$} & Ângulo ( $\left.{ }^{\circ}\right)$ & $9,7(35)$ & $9,4(34)$ & 0,95 & 0,80 \\
\hline & $\mathrm{IO}\left(\% T_{p}\right)$ & $54,2(22)$ & $57,3(35)$ & 0,72 & 0,03 \\
\hline \multirow{2}{*}{$\begin{array}{c}\text { Flexão Máxima do } \\
\text { Quadril (FB) }\end{array}$} & Ângulo $\left(^{\circ}\right)$ & $-28,0(74)$ & $-8,9(46)$ & 0,24 & 0,73 \\
\hline & $\mathrm{IO}\left(\% T_{p}\right)$ & $87,2(40)$ & $88,4(18)$ & 0,43 & 0,51 \\
\hline
\end{tabular}
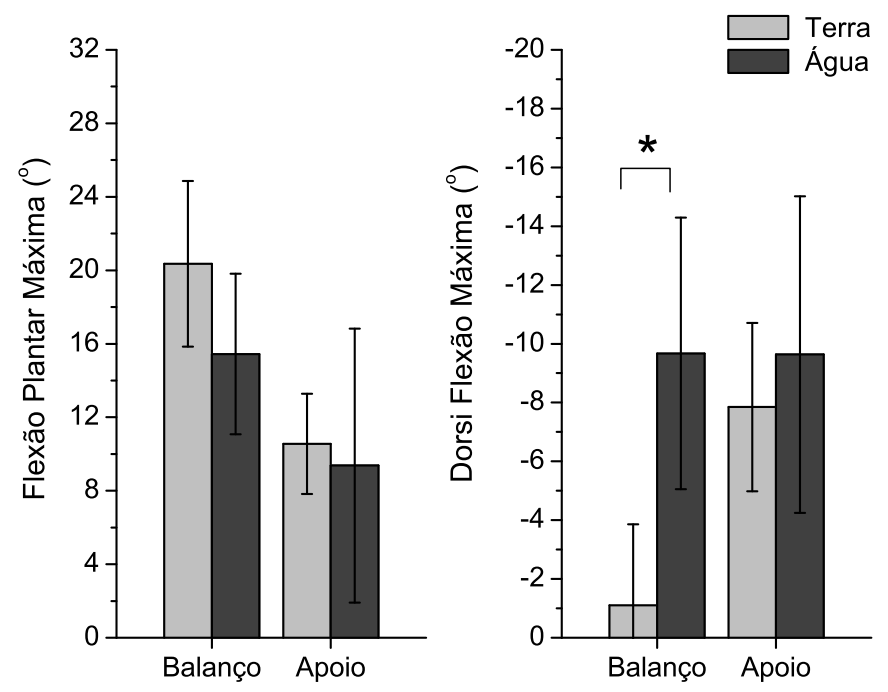

Figura 4.3: Ângulos de dorsi-flexão e flexão plantar máximos, nas fases de apoio e balanço, para a articulação do tornozelo durante o andar em terra e em água. As barras de incerteza representam o desvio padrão e o ${ }^{*}$ indica diferença entre os ambientes. 


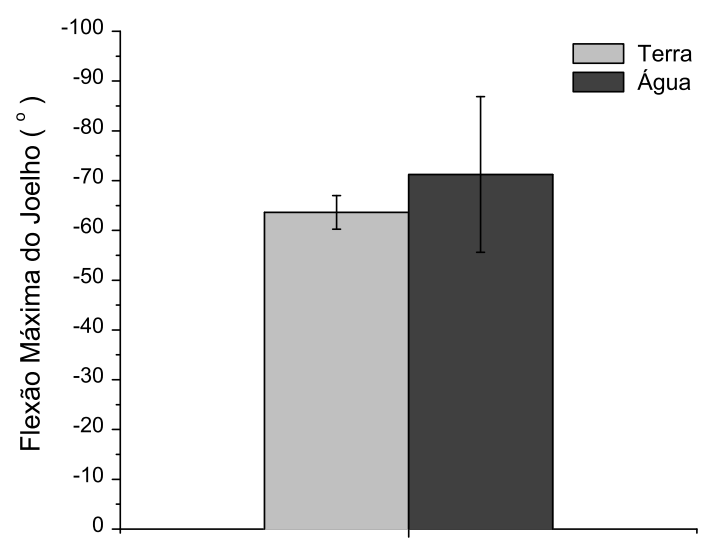

Figura 4.4: Ângulo de flexão máxima do joelho nos ambientes aquático e terrestre. As barras de incerteza representam o desvio padrão.
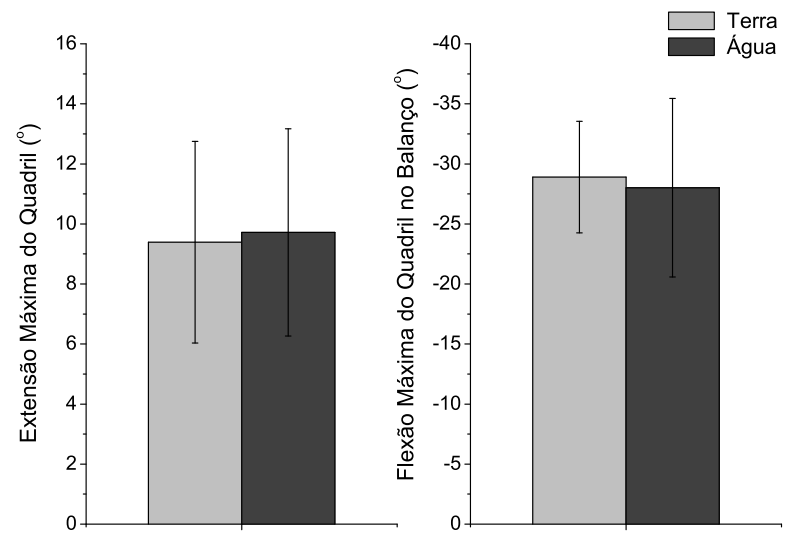

Figura 4.5: Ângulo de máxima extensão ao longo do ciclo e de flexão máxima na fase de apoio, para a articulação do quadril, durante o andar em terra e água. As barras de incerteza representam o desvio padrão.

A partir da derivação numérica dos dados referentes aos ângulos articulares do tornozelo, joelho e quadril, obtivemos as velocidades angulares ao longo da passada. As curvas que representam a média do grupo podem ser vistas na figura 4.6. Nelas o sentido positivo corresponde a flexão plantar, para o tornozelo, e a extensão, para o joelho e o quadril.

Na figura 4.6, podemos ver que as velocidades das três articulações são menores em magnitude no ambiente aquático, porém elas apresentam padrões semelhantes àqueles observados no ambiente terrestre, com a diferença de que as mudanças no sentido de rotação das articulações parecem acontecer, na maioria das vezes, antecipadamente no ambiente aquático.

No tornozelo, é possível identificar quatro mudanças de sentido ao longo do ciclo, o que 

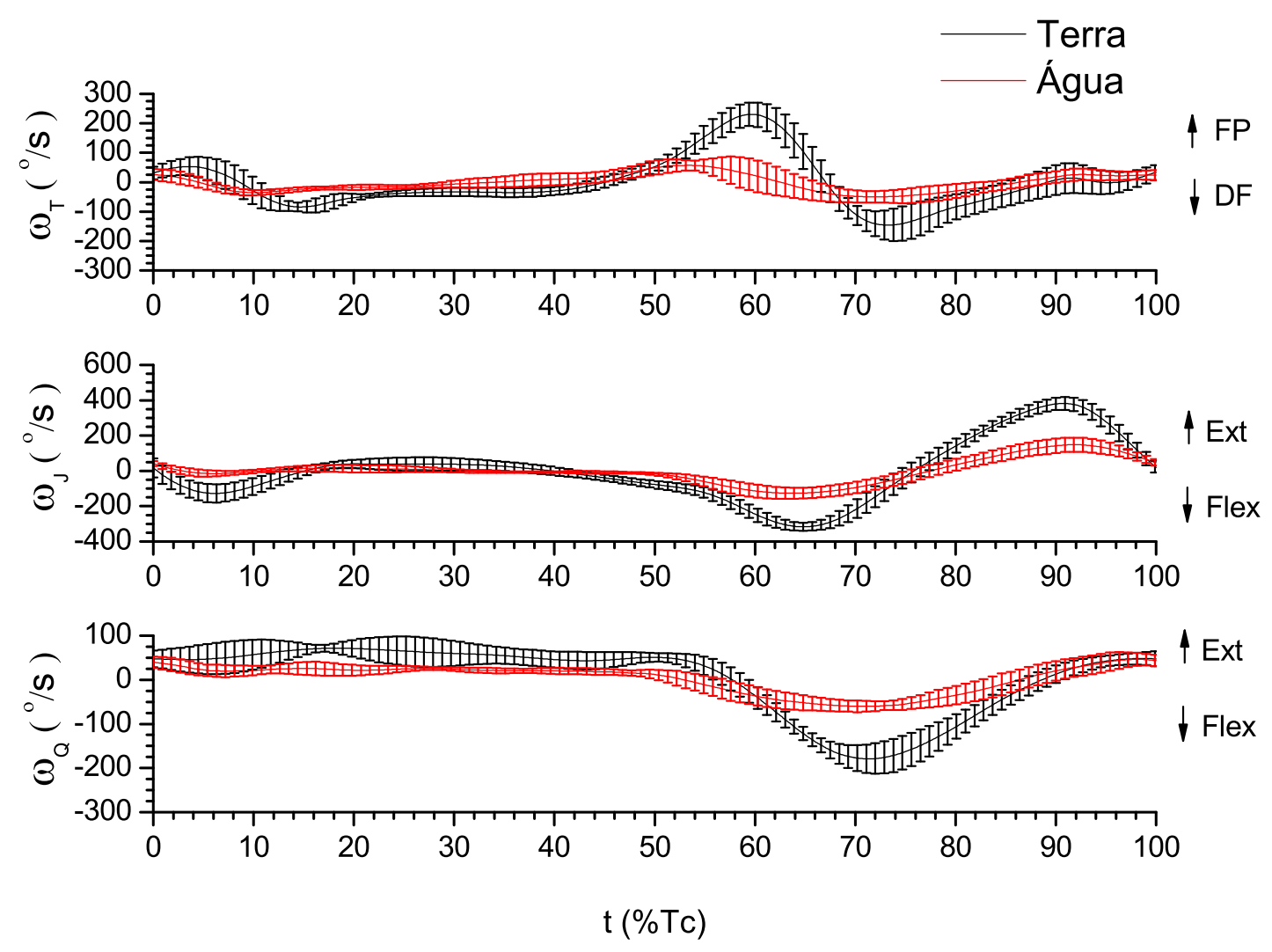

Figura 4.6: Velocidades angulares do tornozelo $\left(\omega_{\mathrm{T}}\right)$, joelho $\left(\omega_{\mathrm{J}}\right)$ e quadril $\left(\omega_{\mathrm{Q}}\right)$ durante um ciclo completo do andar. As setas indicam os sentidos de rotação - flexão plantar (FP) e dorsi-flexão (DF) para o tornozelo, flexão (Flex) e extensão (Ext) para o joelho e o quadril - e as barras de incerteza representam o desvio padrão.

condiz com o deslocamento angular apresentado na figura 3.3. Essa articulação inicia o ciclo com velocidade angular crescente no sentido de flexão plantar. Há, então, uma desaceleração e a primeira mudança de sentido, a qual ocorre antes dos primeiros $10 \%$ do ciclo. A segunda mudança ocorre na fase final do apoio e, novamente, o tornozelo se move no sentido de flexão plantar. Durante a fase de balanço ocorrem mais duas mudanças: uma nos instantes iniciais do balanço e a outra pouco antes de $90 \% T_{p}$. A velocidade máxima no sentido de flexão plantar é em média $85(21)^{\circ} / s$ no ambiente aquático e ocorre, na maioria das vezes, nos instantes finais do apoio, podendo ocorrer também no inicio e no fim do ciclo. Já em terra, a velocidade máxima de flexão plantar ocorre sempre nos instantes finais do apoio, em média em $59,7(13) \% T_{p}$. Sua magnitude é de $243(42)^{\circ} / s$, a qual é significativamente diferente daquela obtida em ambiente aquático. No sentido de dorsi-flexão, a magnitude máxima da velocidade ocorre, tanto em terra quanto em água, na primeira metade da fase de balanço ou após a primeira mudança no sentido no apoio. Em terra é em média $-160(50)^{\circ} / s$, aproximadamente duas vezes maior, em 
magnitude, do que aquela obtida em água: $-77(18)^{\circ} / \mathrm{s}$ (ver tabela 4.6 e gráfico 4.7 ).

Em ambiente aquático a articulação do joelho inicia o ciclo com velocidade articular decrescente no sentido de extensão, mudando o sentido do movimento logo nos primeiros instantes. Já em água, a velocidade angular no contato inicial é bem mais variável, com alguns indivíduos iniciando o ciclo com velocidade de extensão decrescente, assim como na água, e outros já com velocidade de flexão. Após esses primeiros instantes é possível identificar mais três mudanças no sentido da rotação, comuns aos dois ambientes. A primeira ocorre antes de $20 \% T_{p}$ e a partir daí o joelho passa a ter uma pequena velocidade de extensão. No final do apoio ocorre a outra, e o joelho inicia novo movimento de flexão atingindo a velocidade máxima neste sentido no inicio da fase de balanço: em média em $t=63,2(32) \% T_{p}$ no ambiente aquático e em $t=64,9(14) \% T_{p}$ (tabela 4.6). Aproximadamente no meio da fase de apoio ocorre uma nova mudança no sentido do movimento e o joelho começa a estender para se preparar para o início do novo ciclo. Também é nesta fase que o joelho atinge a velocidade máxima de extensão: em terra em $t=90,6(12) \% T_{p}$ e em água $t=91,2(18) \% T_{p}$. Na fase final do balanço a velocidade de extensão começa a diminuir à medida que a articulação do joelho se aproxima da posição neutra. Tanto a máxima velocidade de extensão quanto a máxima velocidade de flexão, se mostraram incompatíveis quando comparadas entre os ambientes, sendo maiores durante o andar em terra.

Tabela 4.6: Valores representativos da velocidade angular máxima, nos dois sentidos de rotação, para as articulações do membro inferior, com exceção do quadril para o qual esta reportada a velocidade média de extensão ao invés da máxima. Tais valores representativos consistem da média do grupo (desvio padrão) nos dois ambientes. Nas duas últimas colunas encontram-se os valores de $\mathrm{p}$ dos testes estatísticos e o ${ }^{*}$ indica diferença entre os ambientes.

\begin{tabular}{lllccc}
\hline \multirow{2}{*}{ Articulações } & $\begin{array}{l}\text { Direção de } \\
\text { Movimento }\end{array}$ & \multicolumn{2}{c}{$\omega(\% / s)$} & \multicolumn{2}{c}{ Testes Estatísticos } \\
\cline { 3 - 6 } Tornozelo & Flexão Plantar & $243(42)$ & $85(21)$ & 0,80 & $<0,0001 *$ \\
\cline { 2 - 6 } & Dorsi Flexão & $-160(50)$ & $-77(18)$ & 0,03 & $<0,001 *$ \\
\hline \multirow{2}{*}{ Joelho } & Extensão & $392(33)$ & $158(37)$ & 0,18 & $<0,0001 *$ \\
\cline { 2 - 6 } & Flexão & $-326(22)$ & $-145(25)$ & 0,62 & $<0,0001 *$ \\
\hline \multirow{2}{*}{ Quadril } & Extensão & $56,2(51)$ & $22,5(39)$ & 0,56 & $<0,0001 *$ \\
\cline { 2 - 6 } & Flexão & $-183(34)$ & $-73(12)$ & 0,32 & $<0,0001 *$ \\
\hline
\end{tabular}

O quadril, diferente das outras articulações, muda o sentido da sua rotação apenas duas vezes durante o ciclo. Ele apresenta uma velocidade aproximadamente constante de extensão durante quase toda a fase de apoio e, no final desta fase, inicia um movimento de flexão com 
velocidade crescente, visando erguer a coxa, a perna e o pé. Essa articulação atinge a velocidade máxima de flexão em média em $70,9(14) \% T_{p}$ em terra e em $70,6(51) \% T_{p}$ em água. No final do balanço ela muda novamente de sentido.

A velocidade média de extensão nos primeiros $50 \%$ do ciclo e a máxima velocidade de flexão do quadril estão descritas na tabela 4.6, assim como os resultados dos testes estatísticos, os quais indicam diferença significativa entre os ambientes.

No gráfico da figura 4.7 também podem ser vistas as velocidades angulares máximas (e média no caso do quadril) das três articulações, nos dois sentidos de rotação.

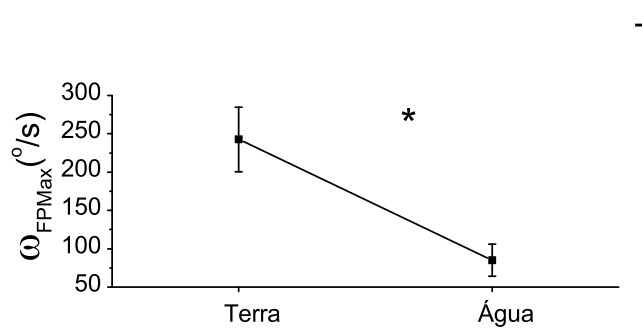

\section{Tornozelo}
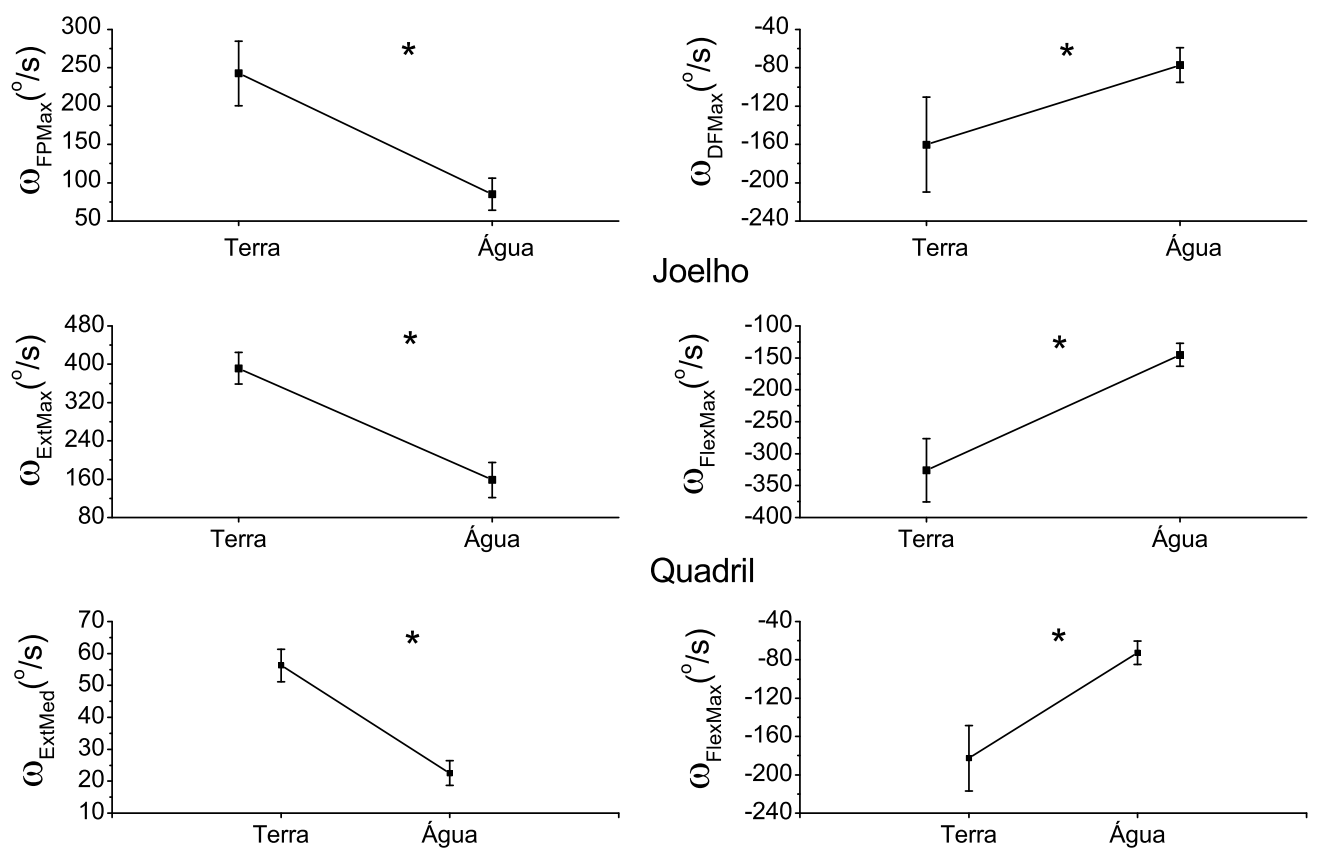

Figura 4.7: Comparação entre os ambientes dos valores representativos das velocidades angulares máximas do tornozelo e do joelho, nos dois sentidos de rotação, e da velocidade máxima de flexão e média (nos primeiros $50 \%$ do ciclo) de extensão para o quadril. $\mathrm{O}$ * indica diferença estatística significativa e as barras de incerteza representam o desvio padrão.

A velocidade de translação do centro de massa de cada segmento pode ser observada na figura 4.8. Na primeira coluna desta figura estão reportadas as curvas da componente horizontal $\left(V C M_{\mathrm{H}}\right)$. Podemos ver nesses gráficos que as componentes assumem valores positivos durante todo o ciclo, o que indica que, mesmo rodando em torno da articulação, os segmentos apresentam um movimento resultante progressivo. Os padrões da componente horizontal ao longo da passada são semelhantes entre os ambientes apesar das curvas diferirem em magnitude principalmente na fase de balanço. É nesta fase que ocorrem os valores máximos de $V C M_{\mathrm{H}}$, 

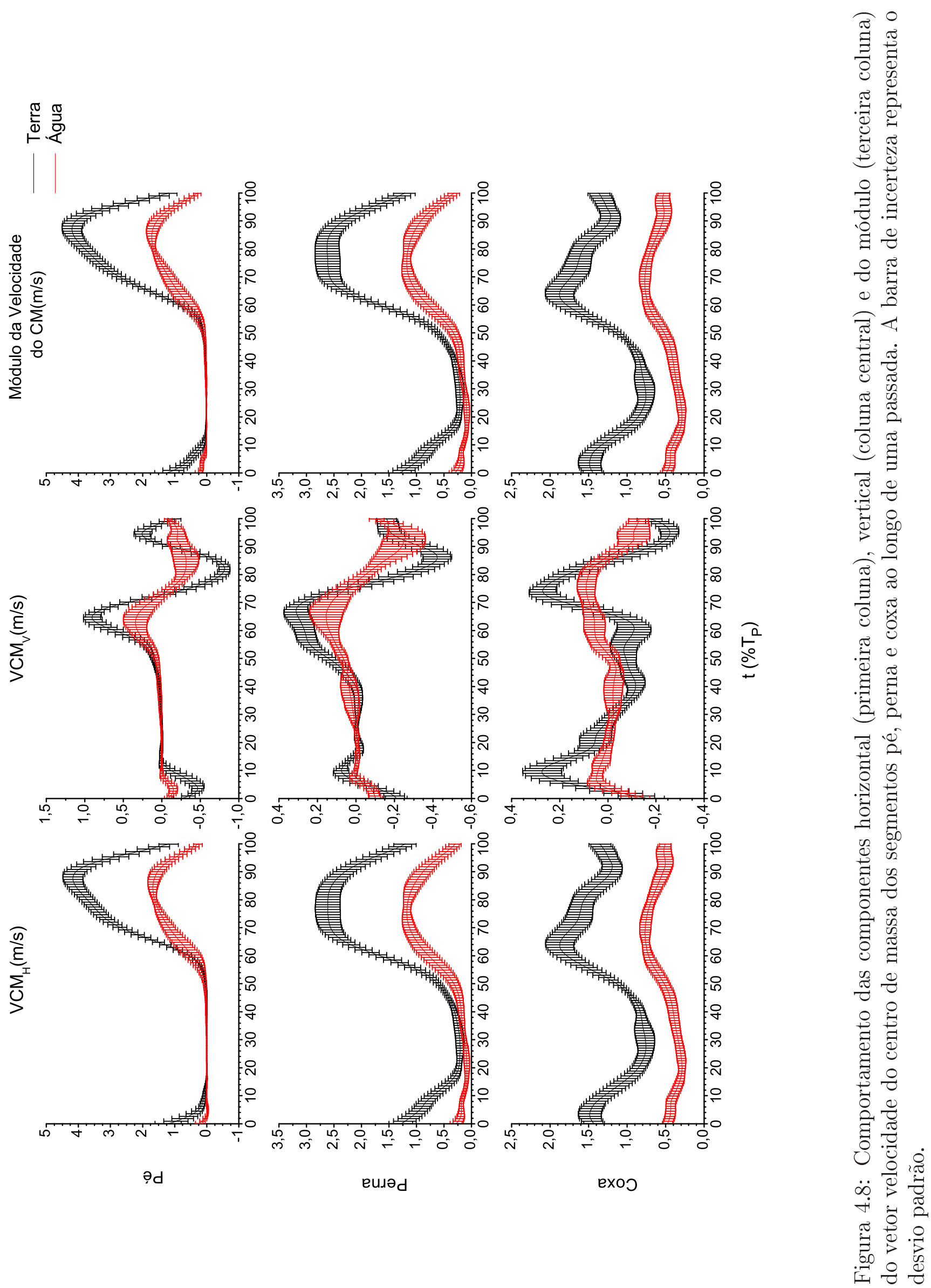
os quais são maiores em terra (ver tabela 4.7).

Tabela 4.7: Média do grupo (desvio padrão) dos valores máximos e mínimos alcançados pela componente horizontal da velocidade do centro de massa $\left(V C M_{\mathrm{H}}\right)$ de cada segmento, ao longo do ciclo, nos dois ambientes. As duas últimas colunas reportam o valor de p dos testes estatísticos e o $*$ indica diferença entre os valores obtidos nos dois ambientes.

\begin{tabular}{lccccc}
\hline \multirow{2}{*}{ Segmentos } & Evento & \multicolumn{2}{c}{$V C M_{\mathrm{H}}(\mathrm{m} / \mathrm{s})$} & \multicolumn{2}{c}{ Testes Estatísticos } \\
\cline { 2 - 6 } & & Terra & Água & Shapiro-Wilk & teste t \\
\hline Pé & Máximo & $4,21(30)$ & $1,77(11)$ & 0,64 & $<0,0001 *$ \\
\hline \multirow{2}{*}{ Perna } & Máximo & $2,64(22)$ & $1,238(93)$ & 0,26 & $<0,0001 *$ \\
\cline { 2 - 6 } & Mínimo & $0,175(51)$ & $0,039(34)$ & 0,72 & $<0,001 *$ \\
\hline \multirow{2}{*}{ Coxa } & Máximo & $1,90(18)$ & $0,807(54)$ & 0,30 & $<0,0001 *$ \\
\cline { 2 - 6 } & Mínimo & $0,704(83)$ & $0,250(46)$ & 0,72 & $<0,0001 *$ \\
\hline
\end{tabular}

Tabela 4.8: Média do grupo (desvio padrão) da magnitude máxima da componente vertical da velocidade do centro de massa $\left(\left|V C M_{\mathrm{V}}\right|\right)$ de cada segmento em terra e em água. Nas últimas colunas estão reportados os valores de $\mathrm{p}$ dos testes estatísticos, com o ${ }^{*}$ indicando diferença entre os valores obtidos nos dois ambientes.

\begin{tabular}{lcccc}
\hline \multirow{2}{*}{ Segmento } & \multicolumn{2}{c}{$\left|V C M_{\mathrm{V}}\right|(\mathrm{m} / \mathrm{s})$} & \multicolumn{2}{c}{ Testes Estatísticos } \\
\cline { 2 - 5 } & Terra & Água & Shapiro-Wilk & teste t \\
\hline Pé & $0,94(11)$ & $0,44(11)$ & 0,37 & $<0,0001 *$ \\
\hline Perna & $0,438(70)$ & $0,293(87)$ & 0,11 & $<0,001 *$ \\
\hline Coxa & $0,343(50)$ & $0,179(31)$ & 0,36 & $<0,0001 *$ \\
\hline
\end{tabular}

Os valores mínimos da componente horizontal dos três segmentos ocorrem na fase de apoio e também podem ser vistos na tabela 4.7. Especificamente para o pé, não é possível reportar um valor mínimo pois, devido aos erros intrínsecos do processo de medida, $V C M_{\mathrm{H}}$ oscila em torno do zero durante o intervalo aproximado de $10 \%$ a $50 \% T_{p}$, nos dois ambientes. Para os segmentos perna e coxa há diferença no valor de $V C M_{\mathrm{H}}$ mínimo que, assim como os valores máximos, são maiores no ambiente terrestre.

As componentes verticais, possuem intensidades menores em comparação às componentes horizontais e contribuem menos para as magnitudes dos respectivos vetores. As curvas destas componentes estão representadas nos gráficos da coluna central da figura 4.8. 
Tabela 4.9: Média (desvio padrão) dos valores máximos e mínimos do módulo da velocidade do CM de cada segmento, nos dois ambientes. Nas últimas colunas estão reportados os valores de $\mathrm{p}$ do teste de Shapiro-Wilk e do teste t. $\mathrm{O} *$ indica diferença significativa entre os ambientes.

\begin{tabular}{llcccc}
\hline \multirow{2}{*}{ Segmentos } & Evento & \multicolumn{2}{c}{$V_{\mathrm{CM}}(\mathrm{m} / \mathrm{s})$} & \multicolumn{2}{c}{ Testes Estatísticos } \\
\cline { 3 - 6 } Pé & Máximo & $4,23(29)$ & $1,81(11)$ & 0,82 & $<0,0001 *$ \\
\cline { 2 - 6 } & Mínimo & $0,0029(11)$ & $0,0020(11)$ & 0,72 & 0,11 \\
\hline \multirow{2}{*}{ Perna } & Máximo & $2,66(21)$ & $1,247(91)$ & 0,30 & $<0,0001 *$ \\
\cline { 2 - 6 } & Mínimo & $0,176(48)$ & $0,048(26)$ & 0,63 & $<0,001 *$ \\
\hline \multirow{2}{*}{ Coxa } & Máximo & $1,91(18)$ & $0,810(55)$ & 0,30 & $<0,0001 *$ \\
\cline { 2 - 6 } & Mínimo & $0,706(83)$ & $0,252(46)$ & 0,78 & $<0,0001 *$ \\
\hline
\end{tabular}

Os valores máximos, em módulo, das componentes verticais da velocidade do $\mathrm{CM}\left(\left|V C M_{\mathrm{V}}\right|\right)$ dos três segmentos, podem ser vistos na tabela 4.8. Os resultados do teste t mostram diferença significativa entre os ambientes nos valores de $\left|V C M_{\mathrm{V}}\right|$ para os três segmentos, apesar da diferença das velocidades entre os ambientes ser maior na componente horizontal.

O segmento pé é o que apresenta as maiores velocidades verticais dentre os três segmentos nos dois ambientes. Os maiores valores de $\left|V C M_{\mathrm{V}}\right|$ para o pé ocorrem no balanço, tanto durante a elevação do CM (no primeiro ponto de máximo), quanto durante seu movimento descendente (no ponto de mínimo). É possível identificar, a partir da curva de $V C M_{\mathrm{V}} \times t$ (figura 4.8) deste segmento, quatro mudanças no sentido do movimento vertical em terra, enquanto em água só é possível verificar duas. A fase de balanço é a responsável pela diferença entre os ambientes, pois nela ocorrem três mudanças de sentido no ambiente terrestre e uma no ambiente aquático. As curvas de $V C M_{\mathrm{V}}$ dos segmentos perna e coxa, no entanto, apresentam os mesmos padrões em terra e água, mas possuem uma forma mais "achatada" neste último.

A magnitude máxima da velocidade vertical da perna ocorre na fase de balanço, tanto durante a elevação quanto durante o abaixamento do CM. Já a coxa apresenta as maiores velocidades às vezes na fase de apoio (no primeiro pico no sentido de elevação), às vezes na fase de balanço (no último pico de elevação ou nos instantes finais do ciclo durante o abaixamento).

Na última coluna da figura 4.8 está reportado o comportamento da intensidade do vetor que representa a velocidade do $\mathrm{CM}\left(\left|\vec{V}_{\mathrm{CM}}\right|\right)$ de cada segmento durante uma passada.

Analisando o módulo deste vetor, vemos que os valores máximos desta curvas são muito próximos dos valores máximos de $V C M_{\mathrm{H}}$ e ocorrem, praticamente, nos mesmo instante (ver tabela 4.9 e gráfico 4.9). Em terra a velocidade máxima é 2,34(21), 2,13(23) e 2,25(27) vezes 


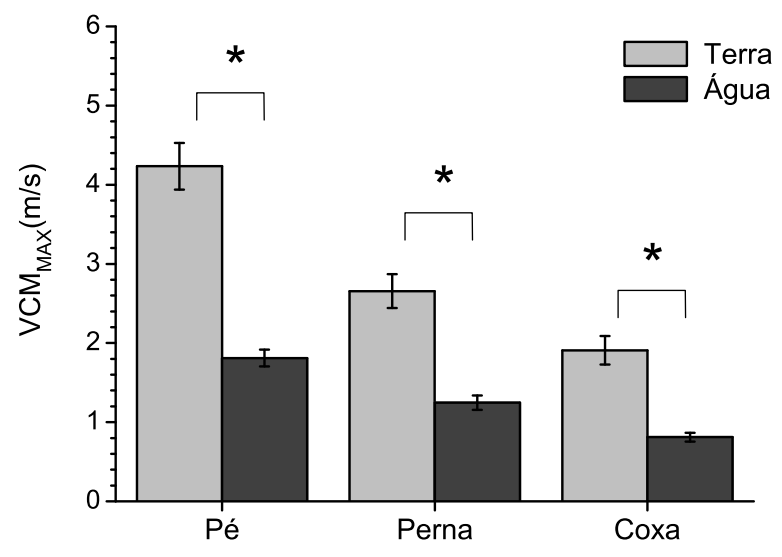

Figura 4.9: Valores máximos da velocidade do centro de massa para os três segmentos. O * indica diferença entre os ambientes e a barra de incerteza o desvio padrão.

maior do que em água, respectivamente para os segmentos pé, perna e coxa. Os valores mínimos atingidos pelo módulo do vetor também ocorrem em instantes semelhantes àqueles da componente horizontal e são maiores em terra do que em água (tabela 4.9).

O Número de Reynolds, estimado para os três segmentos através da equação 3.17, depende diretamente de $\left|\vec{V}_{\mathrm{CM}}\right|$ e por esta ser a única grandeza usada em seu cálculo que varia durante o ciclo, o comportamento do Número de Reynolds está associado ao comportamento da velocidade do CM. Na tabela 4.10 é mostrada, para cada segmento, a faixa de variação deste índice que, da mesma maneira que a velocidade dos CM's, atinge os maiores valores na fase de balanço e os menores na fase de apoio.

Tabela 4.10: Faixa de variação do Número de Reynolds de cada segmento nos dois ambientes.

\begin{tabular}{lcccc}
\hline \multirow{2}{*}{ Segmentos } & \multicolumn{4}{c}{ Número de Reynolds } \\
\cline { 2 - 5 } & \multicolumn{3}{c}{ Terra } & \multicolumn{2}{c}{ Água } \\
\cline { 2 - 5 } & $16,0(53)$ & $2,37(45) \times 10^{4}$ & $20(11) \times 10$ & $1,95(38) \times 10^{5}$ \\
\hline Pé & $1,37(47) \times 10^{3}$ & $2,04(23) \times 10^{4}$ & $7,0(37) \times 10^{3}$ & $1,83(16) \times 10^{5}$ \\
\hline Perna & $9,8(16) \times 10^{3}$ & $2,66(42) \times 10^{4}$ & $6,8(17) \times 10^{4}$ & $2,17(38) \times 10^{5}$ \\
\hline
\end{tabular}




\subsection{Variáveis Cinéticas}

\subsubsection{Forças e Torques Externos}

Para chegarmos a uma estimativa das forças e torques articulares, foi necessário quantificar as forças externas que agem sobre cada segmento. Das quatro forças externas que atuam sobre o corpo durante o andar apenas o empuxo e o peso de cada segmento são constantes durante o ciclo.

No ambiente terrestre o empuxo pode ser desprezado quando comparado ao peso corporal (é cerca de 1000 vezes menor). Entretanto, o mesmo não acontece no ambiente aquático, no qual a densidade da água é da mesma ordem de grandeza da densidade dos segmentos corporais (ver seção 3.1). A atuação do empuxo sobre os segmentos do membro inferior faz com que o peso aparente sentido pelo pé, pela perna e pela coxa, durante a caminhada no ambiente aquático, sejam, respectivamente, $0,12 \% P C, 0,38 \% P C$ e $0,68 \% P C$, aproximadamente.

Já a força de arrasto e a força de reação do solo, possuem magnitude variável ao longo do ciclo e portanto foi analisado o comportamento destas forças em função do tempo.

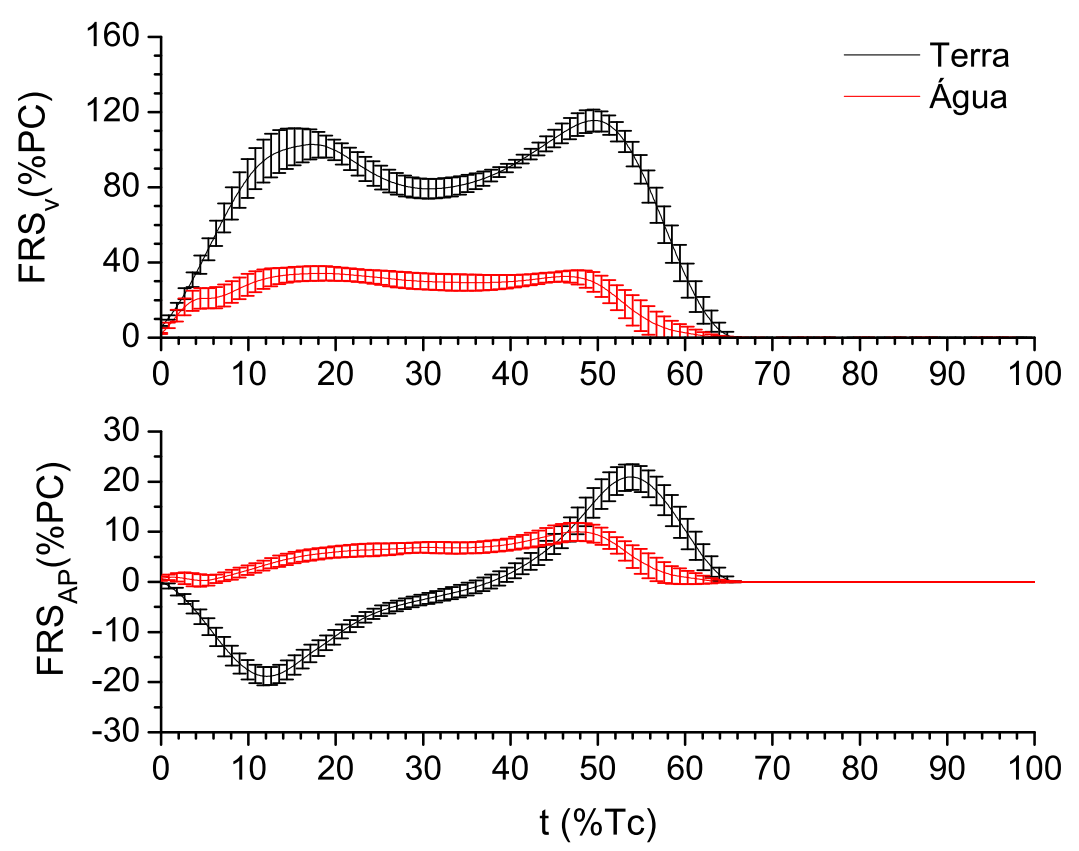

Figura 4.10: Componentes vertical $\left(F R S_{\mathrm{V}}\right)$ e ântero-posterior $\left(F R S_{\mathrm{AP}}\right)$ da força de reação do solo (FRS) para o andar em terra e água. As componentes de $F R S$ estão em porcentagem do peso corporal e as barras de incerteza representam o desvio padrão.

As componentes vertical e ântero-posterior da força de reação do solo ao longo da passada, tanto para o ambiente aquático quanto para o ambiente terrestre, são apresentadas na figura 4.10. A figura 4.11 mostra o comportamento, no ambiente aquático, das componentes hori- 
zontal e vertical, além da magnitude, do vetor força de arrasto que age em cada um dos três segmentos.

Não será reportada a curva da força de arrasto em função do tempo para o ambiente terrestre devido às baixas magnitudes atingidas por esta força ao longo do ciclo, como será discutido adiante.

Com relação à força de reação do solo, é possível notar, observando a curva da figura 4.10, que a componente ântero-posterior $\left(F R S_{\mathrm{AP}}\right)$, além de apresentar magnitude reduzida no ambiente aquático, não apresenta a fase negativa. Em terra, esta fase ocorre aproximadamente durante os primeiros $30 \%$ do ciclo. Já a componente vertical $\left(F R S_{\mathrm{V}}\right)$ apresenta padrão semelhante àquele obtido em ambiente terrestre. Contudo, seus valores são menores e os dois picos e o vale se apresentam pouco pronunciados.

Durante o andar, a $F R S_{\mathrm{v}}$ atinge seu máximo ou no primeiro ou no segundo pico apresentados pela curva. Os picos ocorrem na primeira e na segunda metade da fase de apoio em ambos os ambiente e o valor médio de cada um, assim como o instante em que eles ocorrem em terra e água, estão reportados na tabela 4.11 .

Tabela 4.11: Valor médio (desvio padrão) para o primeiro e para o segundo pico da componente vertical da força de reação do solo, para o valor máximo e o mínimo da componente ânteroposterior e para os respectivos instantes em que estes eventos ocorrem (IO). Nas duas últimas colunas estão reportados os valores de $\mathrm{p}$ dos testes estatísticos e o * indica diferença significativa entre os ambientes.

\begin{tabular}{|c|c|c|c|c|c|}
\hline \multirow{2}{*}{$\begin{array}{c}\text { Componentes } \\
\text { da FRS }\end{array}$} & \multirow[b]{2}{*}{ Variáveis } & \multirow[b]{2}{*}{ Terra } & \multirow[b]{2}{*}{ Água } & \multicolumn{2}{|c|}{ Testes Estatísticos } \\
\hline & & & & $\begin{array}{l}\text { Shapiro- } \\
\text { Wilk }\end{array}$ & teste $\mathrm{t}$ \\
\hline \multirow{4}{*}{ Vertical } & $1^{o} \operatorname{Pico}(\% P C)$ & $106,0(81)$ & $36,0(39)$ & 0,50 & $<0,0001 *$ \\
\hline & $I O_{1 \text { Рico }}\left(\% T_{p}\right)$ & $17,6(23)$ & $17,6(20)$ & 0,40 & 0,99 \\
\hline & $2^{\circ}$ Pico $(\% P C)$ & $116,5(59)$ & $35,2(36)$ & 0,41 & $<0,0001 *$ \\
\hline & $I O_{2^{\circ} \text { Pico }}\left(\% T_{p}\right)$ & $49,8(8)$ & $43,9(47)$ & 0,19 & $<0,01 *$ \\
\hline \multirow{4}{*}{ Ântero-Posterior } & Máximo $(\% P C)$ & $21,4(26)$ & $11,2(23)$ & 0,87 & $<0,0001 *$ \\
\hline & $I O_{\mathrm{MAx}}\left(\% T_{p}\right)$ & $53,8(9)$ & $47,6(20)$ & 0,24 & $<0,0001 *$ \\
\hline & Mínimo $(\% P C)$ & $-19,1(18)$ & $-0,43(89)$ & 0,37 & $<0,0001 *$ \\
\hline & $I O_{\mathrm{MIN}}\left(\% T_{p}\right)$ & $12,2(9)$ & $3,2(10)$ & 0,40 & $<0,0001 *$ \\
\hline
\end{tabular}

Comparando os resultados obtidos nos dois ambientes, podemos perceber diferença significativa na magnitude dos dois picos e no instante em que o segundo pico ocorre. Há tam- 
bém diferença entre os valores do primeiro e do segundo pico obtidos em terra (Shapiro-Wilk $p=0,88$; teste t: $p<0,01)$.

A componente ântero-posterior atinge seu valor máximo no final do apoio nos dois ambientes. Contudo, é possível perceber, ao confrontarmos os resultados obtidos em terra e água, diferença no valor e no instante em que o máximo ocorre (ver tabela 4.11).

Até aproximadamente a metade da fase de apoio, $F R S_{\mathrm{AP}}$ apresenta uma fase negativa, cujo mínimo é -19,1(18)\%PC. Este resultado é significativamente diferente daquele obtido, nessa mesma fase do ciclo, para o andar em água: $-0,4(9) \% P C$. Foi verificada também diferença no instante em que a curva atinge seus menores valores, como pode ser visto na tabela 4.11.

A força de arrasto resultante sobre cada segmento $\left(\vec{F}_{\mathrm{D}}\right)$ foi calculada a partir da equação 3.26. O comportamento das suas componentes horizontal e vertical para o ambiente aquático, bem como a magnitude do vetor, podem ser observados na figura 4.11.

Enquanto a magnitude do arrasto em água tem valor máximo de 3, 92(53)\% PC, 3, 47(66)\% PC e 3,93(72)\% PC respectivamente para os segmentos pé, perna e coxa, em terra os valores máximos para estes segmentos não chegam a $0,1 \% P C$ e são respectivamente: $0,023(4) \% P C$, 0, 024(4)\% PC e 0,025(7)\% PC, significativamente diferentes e muito menores do que os valores obtidos em água (Shapiro-Wilk: $p>0,01$; teste t: $\mathrm{p}<0,0001$ - para os três conjuntos).

Os gráficos da primeira coluna da figura 4.11 mostram que a componente horizontal da força de arrasto $\left(F_{\mathrm{DH}}\right)$ assume valores negativos durante todo o ciclo, se opondo ao movimento sempre progressivo dos segmentos (figura 4.8). A componente vertical do arrasto $\left(F_{\mathrm{DV}}\right)$, no entanto, apresenta valores positivos e negativos, já que os segmentos realizam movimentos ascendentes e descendentes durante o ciclo (principalmente na fase de balanço). Vemos também que a componente horizontal possui maiores magnitudes em relação à componente vertical, pois as velocidades na direção horizontal são maiores do que na vertical. Desta maneira, esta componente contribui mais para o valor do módulo do vetor força de arrasto.

No geral, a força de arrasto tem maior intensidade no balanço; é nesta fase que as duas componentes atingem seus valores máximos (ver tabela 4.12). Durante a fase de suporte a coxa é o segmento sobre o qual age o arrasto de maior intensidade 0,94(22)\%PC, valor que só é atingido pelas forças que agem no pé e na perna no início do balanço.

A atuação da força de arrasto sobre um segmento gera um torque em sua articulação mais proximal. Este torque é descrito pela equação 3.27 e está representado para o tornozelo $\left(\tau_{\text {DT }}\right)$, joelho $\left(\mathcal{T}_{\text {DJ }}\right)$ e quadril $\left(\mathcal{T}_{\text {DQ }}\right)$, para um ciclo do andar em água, nos gráficos da figura 4.12. Nestes gráficos o sinal positivo indica um torque no sentido anti-horário, que representa um torque dorsi-flexor para o tornozelo, extensor para o joelho e flexor para o quadril.

Os máximos torques gerados pela força de arrasto $\left(\tau_{\mathrm{D}}\right)$ em terra, são muito pequenos em comparação àqueles gerados em água, como pode ser observado através dos dados da tabela 4.13. Por isso a curva de $\tau_{\mathrm{D}}$ em função do tempo para o ambiente terrestre, também não será mostrada. 

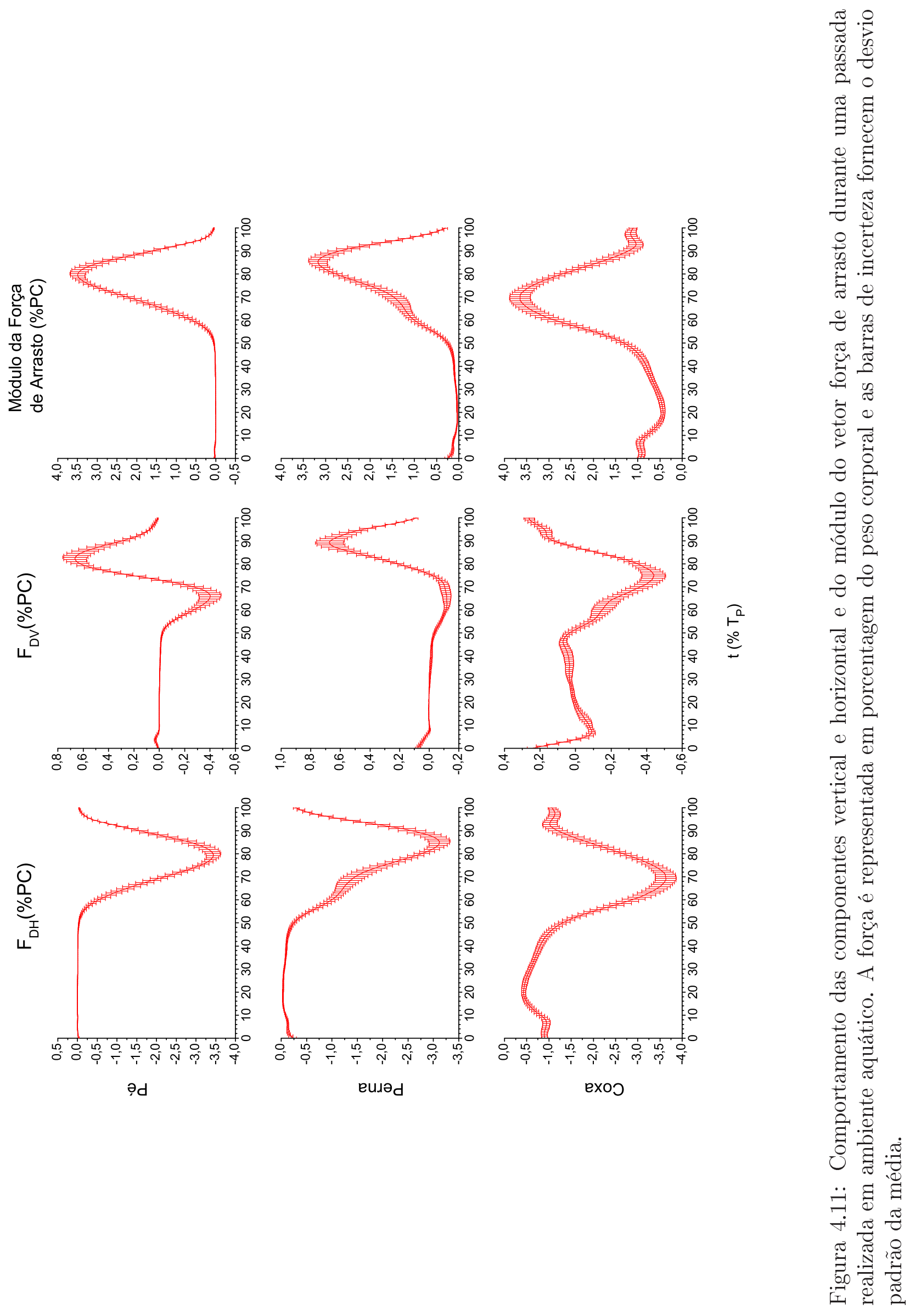
Tabela 4.12: Média (desvio padrão) do valor máximo, em módulo, da componente horizontal, da componente vertical e do vetor força de arrasto, que age nos segmentos pé, perna e coxa durante o andar em ambiente aquático. São também reportados os instantes de ocorrência destes eventos (IO) em porcentagem do período do ciclo.

\begin{tabular}{lcccc}
\hline \multirow{2}{*}{ Segmentos } & Eventos & \multicolumn{3}{c}{ Variáveis } \\
\cline { 2 - 5 } & & $\left|F_{\mathrm{DH}}\right|$ & $\left|F_{\mathrm{DV}}\right|$ & $\left|\vec{F}_{\mathrm{D}}\right|$ \\
\hline \multirow{2}{*}{ Pé } & Máximo $(\% P C)$ & $3,83(51)$ & $0,85(27)$ & $3,92(53)$ \\
\cline { 2 - 5 } & $I O_{\mathrm{MAx}}\left(\% T_{p}\right)$ & $79,3(31)$ & $79,7(54)$ & $79,5(32)$ \\
\hline \multirow{2}{*}{ Perna } & Máximo $(\% P C)$ & $3,41(67)$ & $0,77(28)$ & $3,47(66)$ \\
\hline \multirow{2}{*}{ Coxa } & $I O_{\mathrm{MAx}}\left(\% T_{p}\right)$ & $83,6(34)$ & $89,0(25)$ & $84,9(35)$ \\
\cline { 2 - 5 } & Máximo $(\% P C)$ & $3,92(71)$ & $0,59(20)$ & $3,93(72)$ \\
\hline
\end{tabular}

Tabela 4.13: Máximos torques da força de arrasto que atuam sobre as articulações do tornozelo, joelho e quadril durante o andar em terra e água. As duas últimas colunas mostram o valor de $\mathrm{p}$ dos testes estatísticos $\mathrm{e}^{*}$ indica diferença significativa entre os ambientes.

\begin{tabular}{lcccc}
\hline \multirow{2}{*}{ Articulações } & \multicolumn{2}{c}{$\tau_{\mathrm{D}} /\left(P C * L_{M}\right)$} & \multicolumn{2}{c}{ Testes Estatísticos } \\
\cline { 2 - 5 } & Terra & Água & Shapiro-Wilk & teste t \\
\hline Tornozelo & $-3,35(70) \times 10^{-5}$ & $-0,0054(10)$ & 0,82 & $<0,0001 *$ \\
\hline Joelho & $-6,38(86) \times 10^{-5}$ & $-0,0084(12)$ & 0,76 & $<0,0001 *$ \\
\hline Quadril & $-7,3(20) \times 10^{-5}$ & $-0,0117(22)$ & 0,35 & $<0,0001 *$ \\
\hline
\end{tabular}




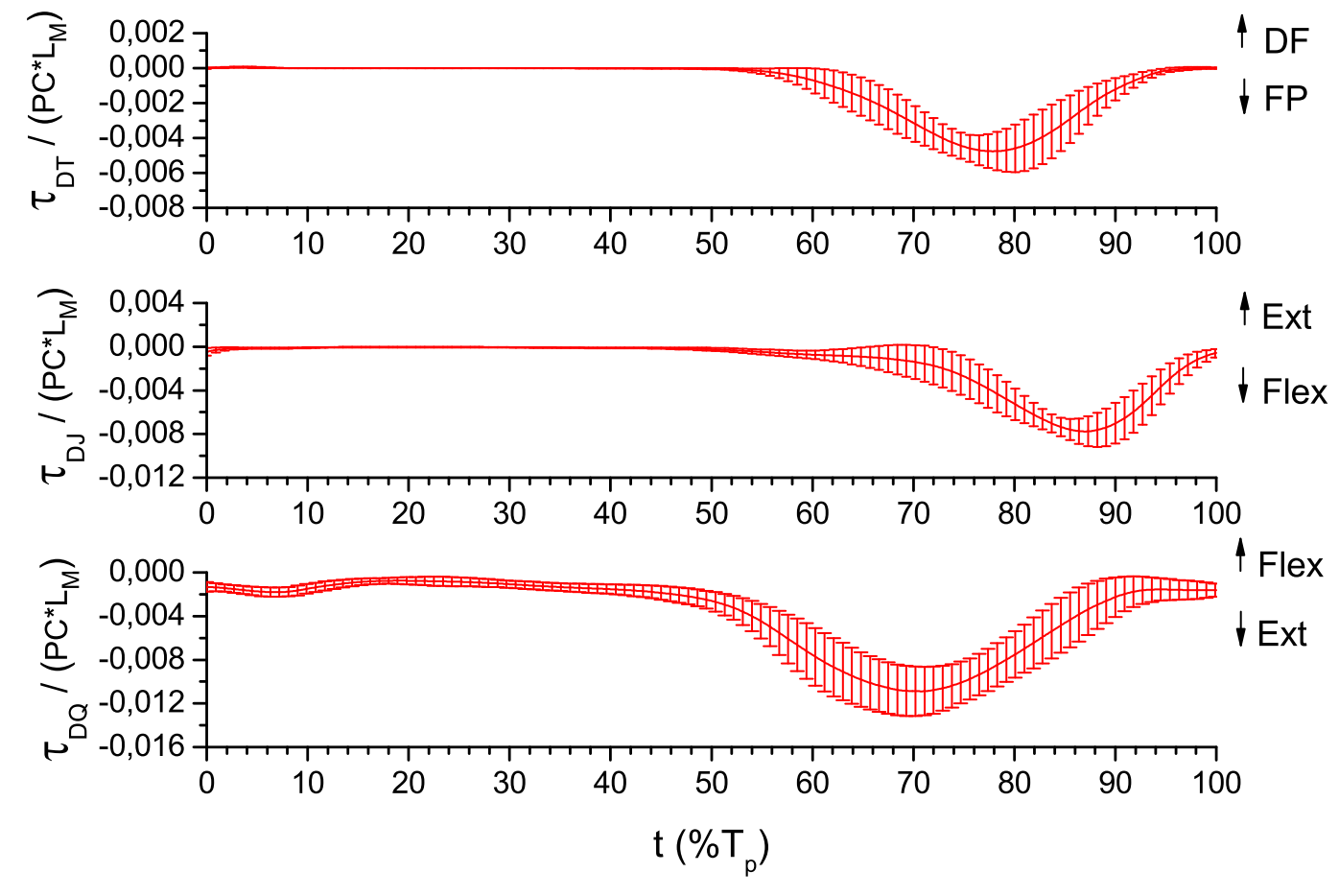

Figura 4.12: Torques produzidos pela força de arrasto no tornozelo, joelho e quadril durante um ciclo completo do andar em ambiente aquático. Os torques estão normalizados pelo produto entre o peso corporal e comprimento do membro inferior $\left(P C * L_{M}\right)$ e as barras de incerteza representam o desvio padrão.

Observando os gráficos da figura 4.12 vemos que os torques nas três articulações têm sentido negativo. Apenas o tornozelo apresenta uma pequena fase positiva nos instantes iniciais do ciclo. Este torque tem magnitude bem pequena, $8(6) \times 10^{-5} /\left(P C * L_{M}\right)$, porém incompatível com zero (Shapiro-Wilk: $p=0,10$; teste t: $p<=0,01$ ). Ele representa o torque dorsi-flexor, que ocorre após o contato inicial, à medida que o pé gira sobre o calcanhar para encostar no solo. No quadril, o torque da força de arrasto age de modo a estender a articulação e no joelho de modo a flexioná-la.

Os torques da força de arrasto de maior intensidade ocorrem na fase de balanço em média em $t=77,5(35) \% T_{p}$ para o tornozelo, em $t=86,2(23) \% T_{p}$ para o joelho e em $t=69,2(30) \% T_{p}$ para o quadril. Os torques de menor intensidade ocorrem na fase de suporte, na qual tanto as velocidades lineares quanto angulares são menores. No tornozelo o torque de menor intensidade é da ordem de $10^{-11}$, compatível com zero (Shapiro Wilk: $p=0,28$; teste t $p=0,85$ ) e ocorre nos instantes da fase de apoio em que o pé está parado. O torque de menor intensidade que age sobre o joelho também tem magnitude muito pequena, $-1(1) \times 10^{-5} /\left(P C * L_{M}\right)$. No entanto, é sistematicamente negativo e portanto incompatível com zero (Shapiro-Wilk $p=0$, 16; teste t: $p<0,01)$. O torque de menor intensidade que age sobre a coxa em água é uma ordem de 
grandeza maior do que os máximos torques que agem nos segmentos durante o andar em terra: $-4,3(20) \times 10^{-4} /\left(P C * L_{M}\right)$.

\subsubsection{Forças e Torques Internos}

Até o momento foram reportadas as variáveis que tem como finalidade ajudar na avaliação da coerência do modelo proposto para a força de arrasto e compreender melhor os padrões das forças e torques articulares. Nesta seção serão apresentados os torques, as forças e as potências articulares, cujas curvas, para um ciclo do andar, podem ser vistas respectivamente nos gráficos das figuras 4.13, 4.16 e 4.19 .

As componentes vertical $\left(F_{\mathrm{V}}\right)$ e horizontal $\left(F_{\mathrm{H}}\right)$ das forças articulares que atuam no tornozelo joelho e quadril, foram calculadas a partir das equações 3.11, 3.13 e 3.15. Elas estão representadas na figura 4.13 junto com o módulo do vetor força articular.

Na primeira coluna da figura 4.13 estão os gráficos referentes às componentes horizontais nos dois ambientes. É possível notar que há uma grande diferença nos padrões das curvas obtidas em terra e água. Em terra, na fase de apoio, para as três articulações, a componente horizontal apresenta uma grande fase em que a força age no sentido positivo (que se inicia em aproximadamente $5 \%$ e vai até por volta de 40\%) e outra grande fase em que ela age no sentido contrário (de aproximadamente $40 \%$ até o final da fase de apoio). No balanço, esse comportamento se repete, sendo a força horizontal positiva no início e negativa no final desta fase do ciclo. Em água, no entanto, a força horizontal é basicamente negativa durante todo o apoio e positiva durante o balanço, havendo pequenas mudanças no sentido apenas nos instantes iniciais e finais da passada.

A intensidade máxima atingida pelas componentes horizontais das forças articulares podem ser vistas no gráfico localizado na parte superior da figura 4.14. Os máximos de $F_{\mathrm{H}}$ são diferentes entre os ambientes e maiores no ambiente terrestre (tabela 4.14).

Para avaliar a intensidade média das forças articulares e suas componentes durante as fases de apoio e de balanço, foi calculada a raiz quadrática média (RQM) durante ambas as fases. A RQM para cada curva (j) de cada sujeito (k) é dada pela equação 4.1. Nesta equação $n$ é o número de dados existentes entre o instante inicial $\left(t_{1}\right)$ e o final $\left(t_{n}\right)$ das fases de apoio e balanço. Usando as equações 3.28 e 3.29, foram calculados valores representativos, respectivamente, para cada indivíduo e para o grupo.

$$
R Q M_{k j}=\sqrt{\sum_{i=1}^{n} \frac{F\left(t_{i}\right)^{2}}{n}}
$$

Apesar dos valores máximos das componentes horizontais das forças articulares serem atingidos em terra, a intensidade média desta componente durante cada fase $\left(R Q M_{\mathrm{FH}}\right)$ nem sempre é 
舜営
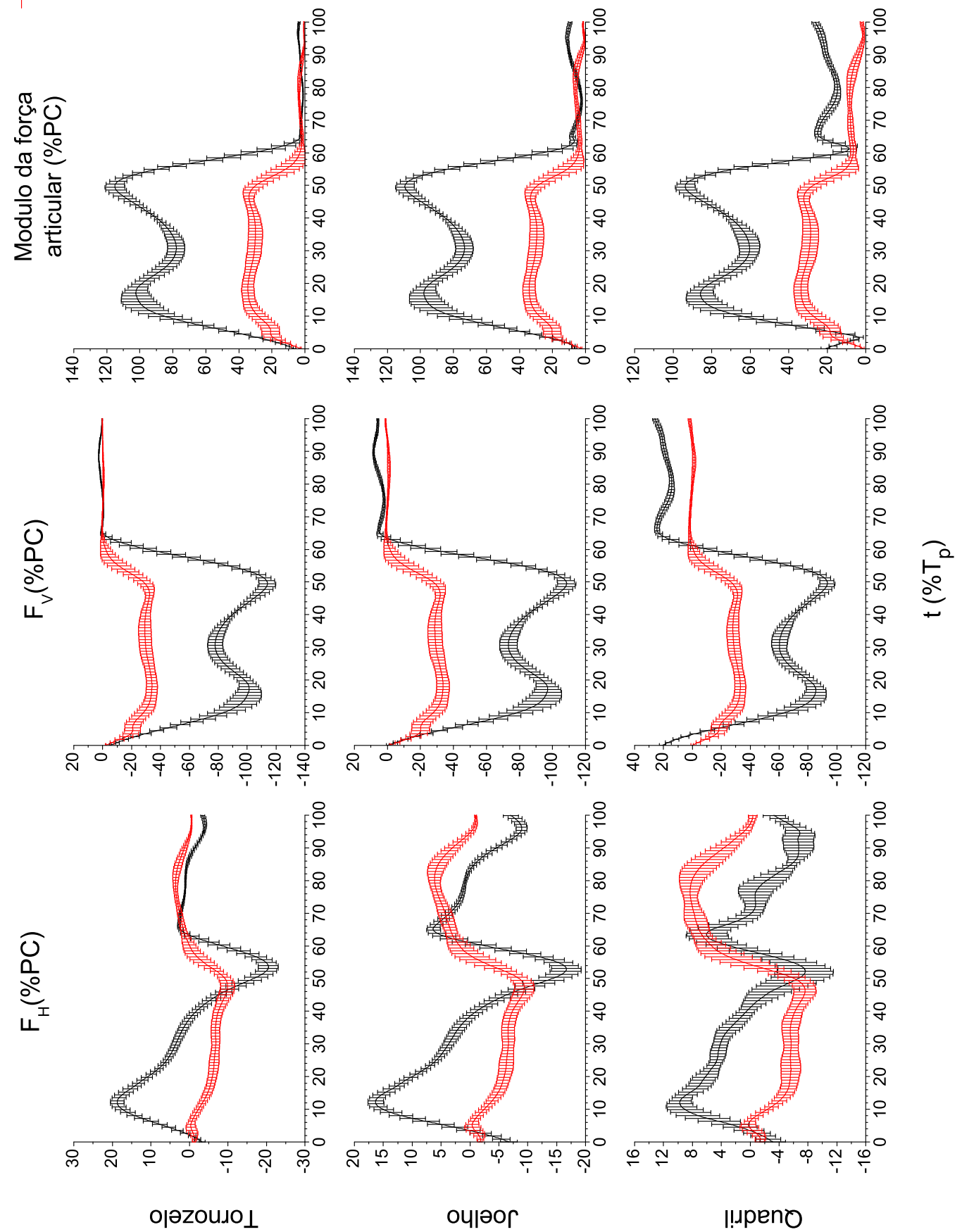
diferente entre os ambientes (ver tabela 4.15). Durante a fase de apoio $R Q M_{\mathrm{FH}}$ apresenta diferenças significativas apenas para o tornozelo e para o joelho. Já no balanço, não há diferença entre os ambientes em nenhuma das articulações (figura 4.15).

Tabela 4.14: Média (desvio padrão) do valor máximo atingido pelo módulo do vetor força articular e por suas componentes, para o tornozelo, joelho e quadril. Nas duas últimas colunas estão reportados os valores de $\mathrm{p}$ dos testes estatísticos. $\mathrm{O} *$ representa diferença significativa entre os valores encontrados em cada ambiente.

\begin{tabular}{lccccc}
\hline \multirow{2}{*}{ Articulações } & Variáveis & \multicolumn{2}{c}{ Máximo(\%PC) } & \multicolumn{2}{c}{ Testes Estatísticos } \\
\cline { 2 - 6 } & & Terra & Água & $\begin{array}{c}\text { Shapiro- } \\
\text { Wilk }\end{array}$ & teste t \\
\hline \multirow{2}{*}{ Tornozelo } & $|\vec{F}|$ & $116,7(58)$ & $37,7(40)$ & 0,21 & $<0,0001 *$ \\
\cline { 2 - 6 } & $\left|F_{\mathrm{H}}\right|$ & $21,3(24)$ & $11,1(23)$ & 0,62 & $<0,0001 *$ \\
\cline { 2 - 6 } & $\left|F_{\mathrm{V}}\right|$ & $115,5(56)$ & $36,6(38)$ & 0,24 & $<0,0001 *$ \\
\hline & $|\vec{F}|$ & $111,0(56)$ & $37,1(41)$ & 0,22 & $<0,0001 *$ \\
\hline \multirow{2}{*}{ Joelho } & $\left|F_{\mathrm{H}}\right|$ & $17,9(22)$ & $10,6(22)$ & 0,29 & $<0,0001 *$ \\
\hline$\left|F_{\mathrm{V}}\right|$ & $110,1(54)$ & $36,1(38)$ & 0,31 & $<0,0001 *$ \\
\hline & $|\vec{F}|$ & $95,6(50)$ & $36,0(40)$ & 0,59 & $<0,0001 *$ \\
\hline & $\left|F_{\mathrm{H}}\right|$ & $11,8(19)$ & $10,2(19)$ & 0,49 & $<0,01 *$ \\
\hline$\left|F_{\mathrm{V}}\right|$ & $95,3(50)$ & $35,3(39)$ & 0,73 & $<0,0001 *$ \\
\hline
\end{tabular}

A componente vertical, cujo comportamento está reportado nos gráficos da coluna central da figura 4.13, tem aparência semelhante à componente vertical da força de reação do solo na fase de apoio e é maior em terra do que em água. Nesta fase, $F_{\mathrm{V}}$ age no sentido negativo, ou seja, apontando para baixo, nos dois ambientes. No balanço, em terra, apresenta valores positivos e em água, oscila entre positivo e negativo, mas com magnitudes bem inferiores em relação ao ambiente terrestre.

Os valores máximos da componente vertical de cada articulação são também maiores em terra, como pode ser visto no gráfico central da figura 4.14 e na tabela 4.14 , e ocorrem sempre durante a fase de apoio. A intensidade média da componente vertical $\left(R Q M_{\mathrm{FV}}\right)$ durante o apoio é maior em terra do que em água. No balanço, no entanto, ela só é maior nas articulações do joelho e quadril (figura 4.15) não apresentando diferença significativa para o tornozelo (ver também tabela 4.15).

No que diz respeito a intensidade do vetor força articular em cada articulação, os resultados são semelhantes àqueles obtidos para a força vertical: os valores máximos são diferentes entre 
Tabela 4.15: Valores representativos (média (desvio padrão)) da raiz quadrática média da componente vertical $\left(F_{\mathrm{V}}\right)$, da componente horizontal $\left(F_{\mathrm{H}}\right)$ e do módulo do vetor força articular, calculados para o tornozelo, para o joelho e para o quadril, durante as fases de apoio e balanço. As duas últimas colunas reportam o valor de $\mathrm{p}$ dos testes estatísticos. O sinal $\sharp$ indica não normalidade da amostra, $†$ indica que foi usado o Teste de Wilcoxon (TW) ao invés do teste $t$ (TT) e o* indica diferença entre os valores encontrados em terra e água.

\begin{tabular}{|c|c|c|c|c|c|c|}
\hline \multirow{2}{*}{ Articulações } & \multirow{2}{*}{ Variáveis } & \multirow{2}{*}{$\begin{array}{c}\text { Fase do } \\
\text { Ciclo }\end{array}$} & \multicolumn{2}{|c|}{ RQM (\%PC) } & \multicolumn{2}{|c|}{ Testes Estatísticos } \\
\hline & & & Terra & Água & $\begin{array}{l}\text { Shapiro- } \\
\text { Wilk }\end{array}$ & teste $t$ \\
\hline \multirow{6}{*}{ Tornozelo } & \multirow{2}{*}{$|\vec{F}|$} & Apoio & $84,9(16)$ & $29,1(30)$ & 0,57 & $<0,0001 *$ \\
\hline & & Balanço & $3,00(38)$ & $2,92(90)$ & $<0.01^{\sharp}$ & $0,28 \dagger$ \\
\hline & \multirow{2}{*}{$F_{\mathrm{H}}$} & Apoio & $11,4(11)$ & $6,43(80)$ & 0,84 & $<0,0001 *$ \\
\hline & & Balanço & $2,26(21)$ & $2,45(36)$ & 0,07 & 0,28 \\
\hline & \multirow{2}{*}{$F_{\mathrm{V}}$} & Apoio & $84,1(15)$ & $28,4(30)$ & 0,71 & $<0,0001 *$ \\
\hline & & Balanço & $1,93(45)$ & $1,2(11)$ & 0,09 & $<0,0001 *$ \\
\hline \multirow{6}{*}{ Joelho } & \multirow{2}{*}{$|\vec{F}|$} & Apoio & $80,1(17)$ & $28,7(30)$ & 0,48 & $<0,0001 *$ \\
\hline & & Balanço & $7,47(46)$ & $4,7(10)$ & 0,81 & $<0,0001 *$ \\
\hline & \multirow{2}{*}{$F_{\mathrm{H}}$} & Apoio & $9,6(10)$ & $6,20(78)$ & 0,89 & $<0,0001 *$ \\
\hline & & Balanço & $4,94(57)$ & $4,28(66)$ & 0,63 & 0,07 \\
\hline & \multirow{2}{*}{$F_{\mathrm{V}}$} & Apoio & $79,5(16)$ & $28,0(31)$ & 0,62 & $<0,0001 *$ \\
\hline & & Balanço & $5,59(25)$ & $1,5(10)$ & 0,014 & $<0,0001 *$ \\
\hline \multirow{6}{*}{ Quadril } & \multirow{2}{*}{$|\vec{F}|$} & Apoio & $67,0(17)$ & $27,8(30)$ & 0,52 & $<0,0001 *$ \\
\hline & & Balanço & $20,39(76)$ & $6,8(12)$ & 0,94 & $<0,0001 *$ \\
\hline & \multirow{2}{*}{$F_{\mathrm{H}}$} & Apoio & $5,8(10)$ & $5,40(74)$ & 0,16 & 0,22 \\
\hline & & Balanço & $5,06(75)$ & $6,4(10)$ & 0,012 & 0,013 \\
\hline & \multirow{2}{*}{$F_{\mathrm{V}}$} & Apoio & $66,7(17)$ & $27,2(31)$ & 0,63 & $<0,0001 *$ \\
\hline & & Balanço & $19,73(70)$ & $2,03(75)$ & 0,91 & $<0,0001 *$ \\
\hline
\end{tabular}



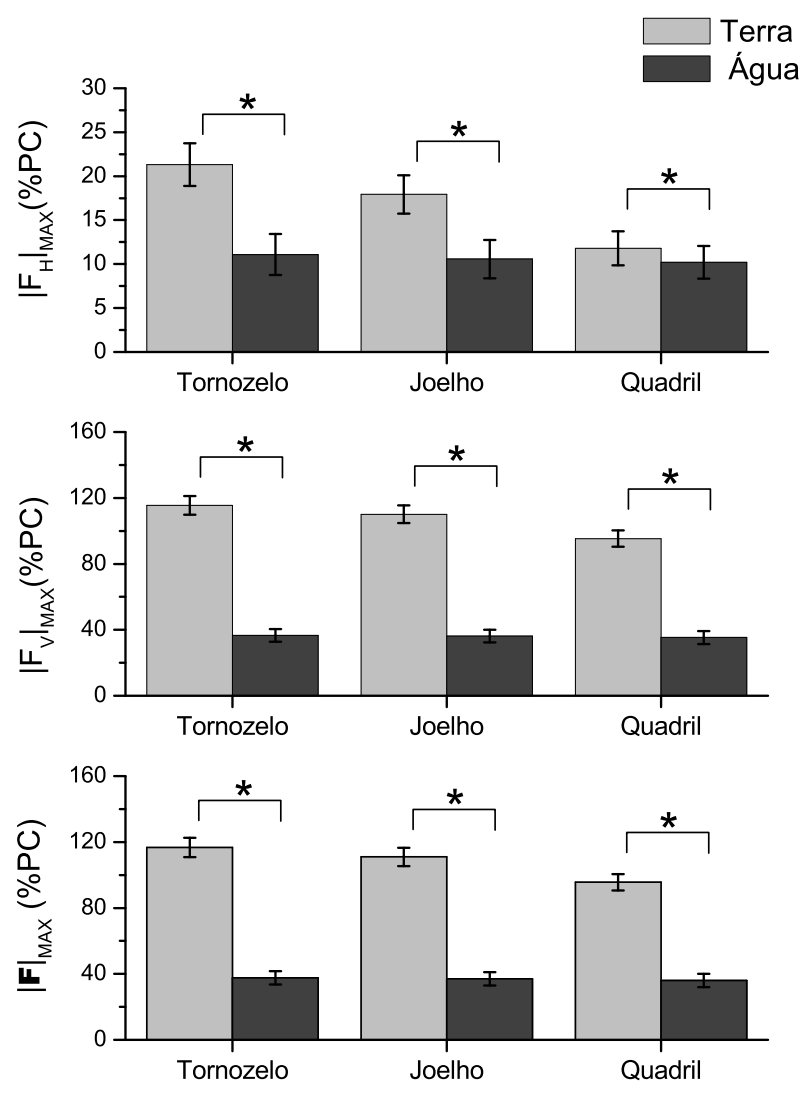

Figura 4.14: Valor máximo atingido pela força articular e suas componentes para as articulações do tornozelo joelho e quadril. $\mathrm{O} *$ indica diferença entre os valores encontrados para os dois ambientes e as barras de incerteza representam o desvio padrão.

os ambientes (tabela 4.14) e maiores em terra, como pode ser visualizado no gráfico inferior da figura 4.14. A intensidade média $\left(R Q M_{\mathbf{F}}\right)$ durante a fase de apoio também é maior durante o andar em terra e, no balanço só não vemos diferenças significativas para $R Q M_{\mathbf{F}}$ do tornozelo (ver figura 4.15 e tabela 4.15).

Os momentos articulares, calculados através das equações 3.12, 3.14 e 3.16, estão representados, para um ciclo do andar, na figura 4.16. Neste gráfico a convenção de sinais é a mesma reportada para a figura 4.12 .

O gráfico superior da figura 4.16 mostra o torque interno resultante que age sobre a articulação do tornozelo, durante a marcha em terra e em água. Analisando o comportamento das duas curvas, é possível verificar entre elas um padrão semelhante ao longo do ciclo. No instante do contato inicial não há diferença entre os momentos nos dois ambientes, o que pode ser visto na tabela 4.16. Durante a fase de apoio, age sobre o tornozelo, um torque predominantemente flexor plantar em ambas as situações. Porém, as curvas atingem o valor mínimo, que corresponde ao máximo torque flexor plantar, em instantes diferentes: $t=49,7(8) \% P C$ em terra e $t=42(7) \% P C$ em água (Shapiro-Wilk: $p=0,18$; teste t: $p<0,01$ ). Além disso, 

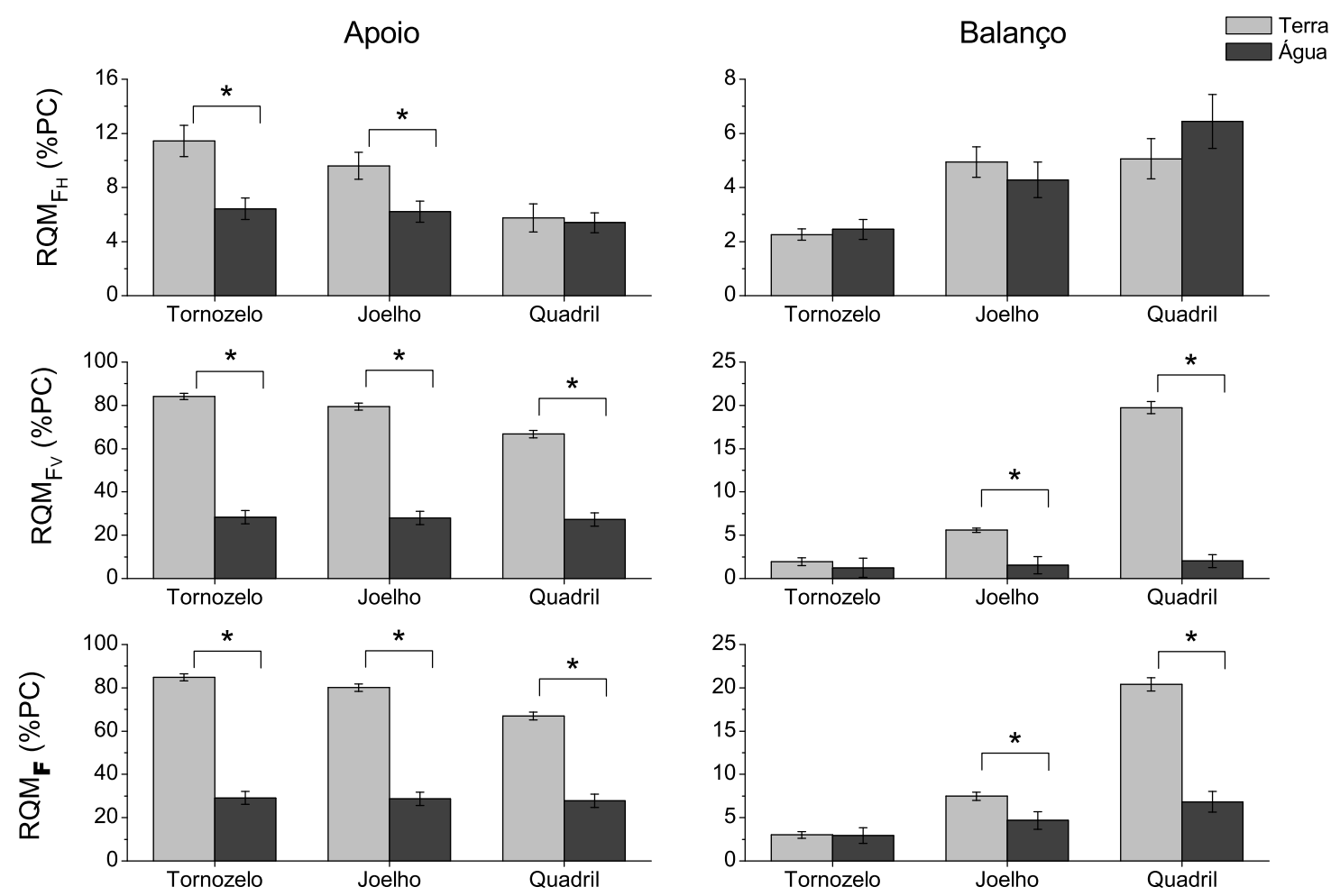

Figura 4.15: Intensidade média, dada pela raiz quadrática média (RQM), da força de arrasto e de suas componentes durante a fase de apoio e balanço para as articulações do tornozelo, joelho e quadril. $\mathrm{O} *$ indica diferença estatística entre os valores encontrados para os dois ambientes e as barras de incerteza representam o desvio padrão.

a magnitude deste torque difere entre os ambientes, como está apresentado na tabela 4.17 e no gráfico da figura 4.17. Já na fase de balanço, o momento articular sobre o tornozelo é bem próximo de zero. Entretanto, existe nesta fase, tanto no ambiente terrestre quanto no aquático, um instante onde há um pico de torque dorsi-flexor. As magnitudes destes picos são diferentes entre os ambientes, com o maior valor ocorrendo no ambiente aquático, como pode ser visto também na figura 4.17 e na tabela 4.17. Os instantes de ocorrência destes eventos também são diferentes: $65(11) \% T_{p}$ e $77,4(35) \% T_{p}$, respectivamente para o ambiente terrestre e para o ambiente aquático.

A articulação do joelho é aquela que apresenta maior diferença entre os ambientes com relação ao comportamento do torque articular (gráfico central da figura 4.16). Sua curva em terra apresenta dois picos na direção de extensão (o primeiro em média em $t=16,3(23) \% T_{p}$ e o segundo em $t=63,7(45) \% T_{p}$ ) e três na direção de flexão (em $t=2,1(11) \% T_{p}$, em $t=$ $43,1(30) \% T_{p}$ e em $\left.t=97,0(10) \% T_{p}\right)$. Em água, há apenas um pico flexor e um extensor: o primeiro ocorre na fase de apoio, na qual o torque é exclusivamente flexor, e o segundo ocorre 

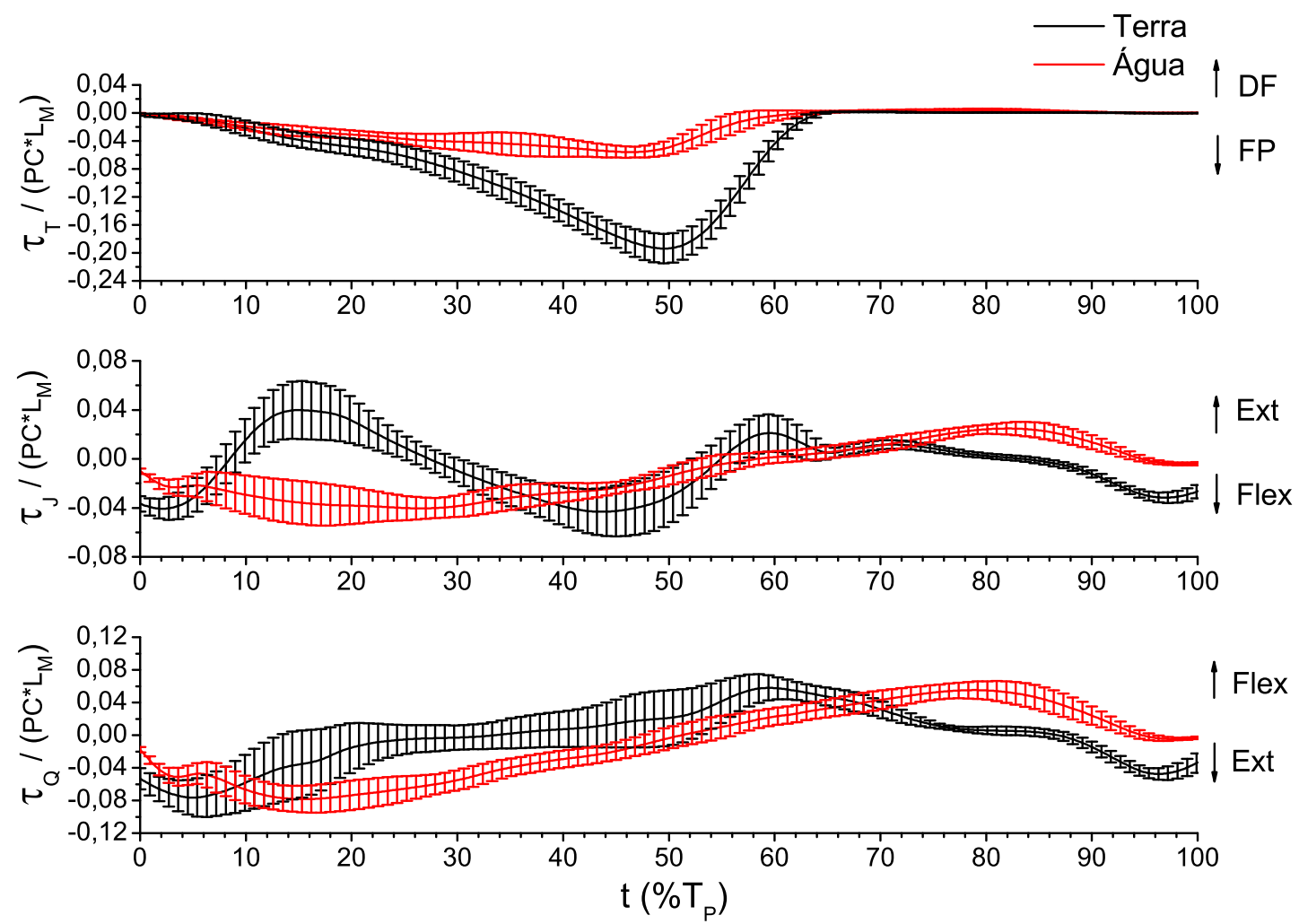

Figura 4.16: Torques internos resultantes que atuam nas articulações do tornozelo (gráfico superior), joelho (gráfico central) e quadril (gráfico inferior) durante um ciclo completo da marcha, para os dois ambientes. Os torques estão normalizados pelo produto entre o peso corporal e o comprimento do membro inferior $\left(P C * L_{m}\right)$ e as barras de incerteza representam o desvio padrão.

na fase balanço, na qual o torque é predominantemente extensor.

Para esta articulação, foi verificada diferença entre os momentos articulares no contato inicial (tabela 4.16). Neste instante, o torque possui o mesmo sentido em ambos os ambientes, é flexor. Porém, sua magnitude em terra é maior do que em água. O máximo torque extensor, em terra, pode ocorrer tanto no primeiro quanto no segundo pico (inicio e final da fase de apoio) e em água, ocorre no meio da fase de balanço, em média em $t=81,0(32) \% T_{p}$. Mesmo ocorrendo em instantes diferentes, não foi possível perceber diferença nas magnitudes destes torques máximos, como pode ser visto tanto na tabela 4.17 quanto no gráfico 4.17. O mesmo ocorre para o valor máximo do torque flexor: não há correspondência nos instantes de ocorrência - em terra pode ocorrer na fase de apoio (no primeiro ou no segundo pico) ou nos instantes finais da fase de balanço e em água ocorre na fase de apoio (em média em $t=24,9(50) \% T_{p}$ ) - mas também, não é possível verificar diferença nas magnitudes dos máximos torques flexores (ver tabela 4.17). 
Tabela 4.16: Média (desvio padrão) dos torques articulares no instante de contato inicial $\left(\mathcal{T}_{\mathrm{CI}}\right)$, para o tornozelo, o joelho e o quadril. As duas últimas colunas reportam o valor de p dos testes estatísticos e o ${ }^{*}$ indica diferença significativa entre os ambientes.

\begin{tabular}{lcccc}
\hline \multirow{2}{*}{ Articulações } & \multicolumn{2}{c}{$\tau_{\mathrm{CI}} /\left(P C * L_{M}\right)$} & \multicolumn{2}{c}{ Testes Estatísticos } \\
\cline { 2 - 5 } & Terra & Água & Shapiro-Wilk & teste t \\
\hline Tornozelo & $-0,0024(19)$ & $-0,0011(13)$ & 0,76 & 0,12 \\
\hline Joelho & $-0,0367(63)$ & $-0,0100(22)$ & 0,06 & $<0,0001 *$ \\
\hline Quadril & $-0,053(13)$ & $-0,0178(32)$ & 0,34 & $<0,0001 *$ \\
\hline
\end{tabular}

Ao observarmos o comportamento do torque articular do quadril (gráfico inferior da figura 4.16) vemos que, tanto em terra quanto em água, age sobre ele um torque extensor, que inverte de sentido duas vezes antes do final do ciclo. O que diferencia as curvas em cada ambientes é o instante em que estas inversões ocorrem. Durante a marcha em terra, o torque que age sobre o quadril é extensor no início da fase de suporte e flexor durante os instantes finais. Ele atinge o valor máximo (máximo torque flexor) no final da fase de apoio, em média em $t=60,4(27) \% T_{p}$, e, aproximadamente no meio da fase de balanço, inverte novamente o sentido. Em água, o torque sobre o quadril é extensor praticamente durante toda a fase de apoio. Apenas um pouco antes do fim desta fase ocorre a mudança no sentido do torque articular, que passa

Tabela 4.17: Valores representativos (média(desvio padrão)) do máximo torque articular $\left(\tau_{\text {MAX }}\right)$ dorsi-flexor e flexor plantar, que atua sobre o tornozelo, e do máximo torque flexor e extensor que atuam sobre o joelho e sobre o quadril. Nas duas últimas colunas estão reportados os valores de $\mathrm{p}$ dos testes estatísticos e $\mathrm{o}^{*}$ indica diferença significativa entre os ambientes.

\begin{tabular}{|c|c|c|c|c|c|}
\hline \multirow{2}{*}{ Articulações } & \multirow{2}{*}{$\begin{array}{l}\text { Direção de } \\
\text { Rotação }\end{array}$} & \multicolumn{2}{|c|}{$\tau_{\mathrm{MAx}} /\left(P C * L_{M}\right)$} & \multicolumn{2}{|c|}{ Testes Estatísticos } \\
\hline & & Terra & Água & $\begin{array}{l}\text { Shapiro- } \\
\text { Wilk }\end{array}$ & teste $\mathrm{t}$ \\
\hline \multirow{2}{*}{ Tornozelo } & Dorsi Flexão & $0,0020(6)$ & $0,0055(10)$ & 0,63 & $<0,0001 *$ \\
\hline & Flexão Plantar & $-0,195(21)$ & $-0,0637(76)$ & 0,41 & $<0,0001 *$ \\
\hline \multirow{2}{*}{ Joelho } & Extensão & $0,047(18)$ & $0,0280(42)$ & 0,80 & 0,011 \\
\hline & Flexor & $-0,052(11)$ & $-0,050(11)$ & 0,77 & 0,67 \\
\hline \multirow{2}{*}{ Quadril } & Flexão & $0,064(18)$ & $0,061(12)$ & 0,95 & 0,71 \\
\hline & Extensão & $-0,085(21)$ & $-0,084(17)$ & 0,28 & 0,91 \\
\hline
\end{tabular}


a ser flexor. O torque age sobre o quadril neste sentido durante aproximadamente $3 / 4$ da fase de balanço, quando novamente se torna extensor. $O$ valor máximo do torque flexor no ambiente aquático ocorre na fase de balanço, em média em $t=78,8(29) \% T_{p}$, diferente do ambiente terrestre, no qual o máximo ocorre no fim do apoio (Shapiro-Wilk: $p=0$, 19; teste t: $p<0.0001)$. O máximo torque extensor ocorre em média em $t=16,4(21) \% T_{p}$ em água, enquanto em terra ocorre ou bem no início do ciclo (antes dos primeiros 10\%) ou no final (nos últimos 10\%).

Assim como na articulação do joelho, não há diferenças significativas entre os ambientes nas magnitudes máximas de torque extensor e de torque flexor (ver figura 4.17 e tabela 4.17). Porém, há diferença na magnitude do torque no contato inicial (ver tabela 4.16).

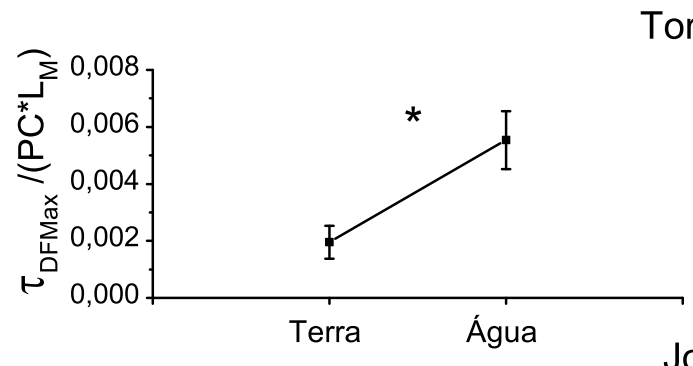

Tornozelo
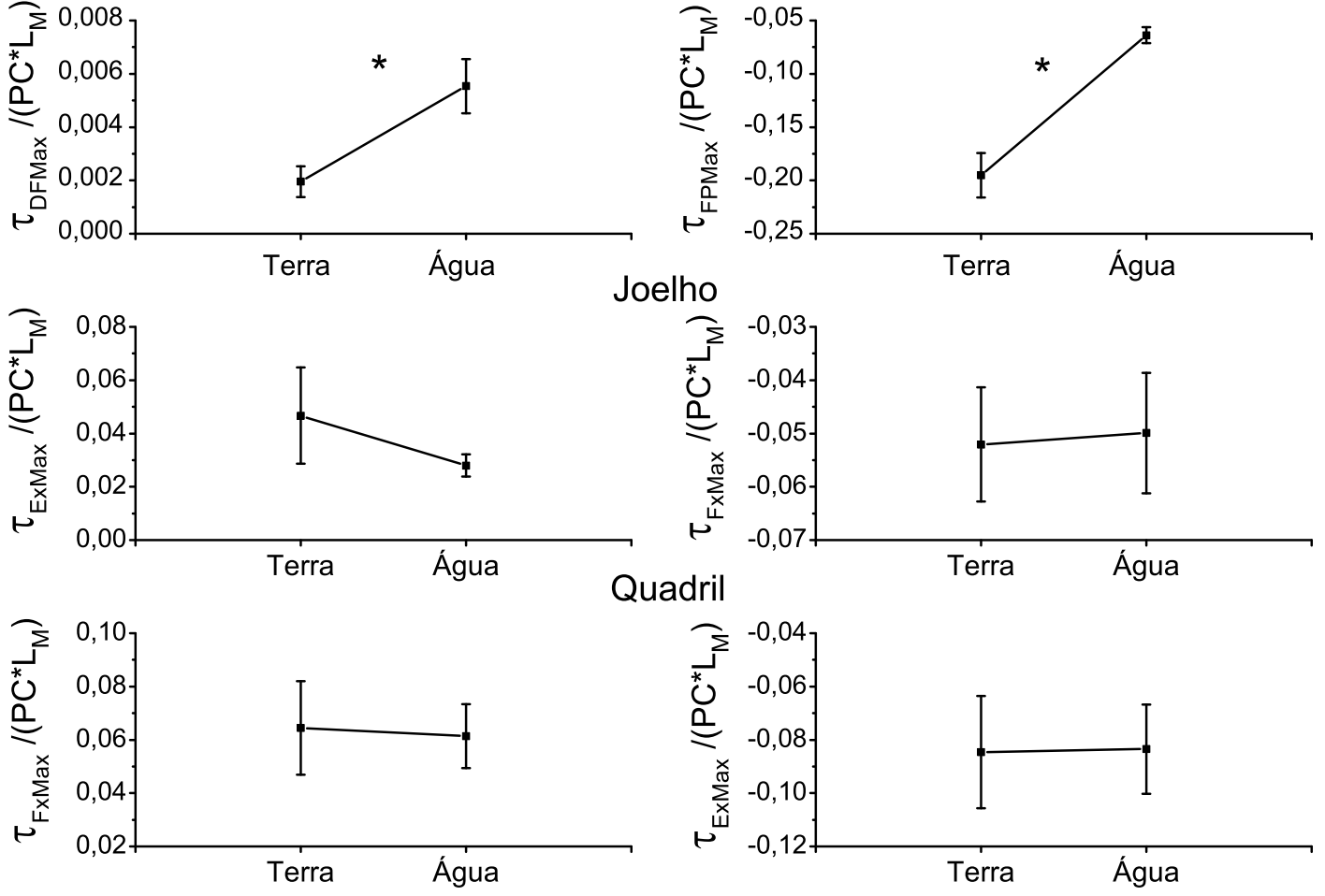

Figura 4.17: Máximo torque articular dorsi-flexor $\left(\mathcal{T}_{\text {DFMax }}\right)$ e flexor plantar $\left(\tau_{\text {FPMax }}\right)$ para o tornozelo e máximos torques flexores $\left(\mathcal{T}_{\text {FxMax }}\right)$ e extensores $\left(\mathcal{T}_{\text {ExMax }}\right)$ para o joelho e para o quadril. Os torques estão normalizados pelo produto entre o peso corporal e o comprimento do membro inferior $\left(P C * L_{m}\right)$ e as barras de incerteza representam o desvio padrão. $\mathrm{O} *$ indica diferença entre os valores obtidos nos dois ambientes.

A contribuição do torque da força de arrasto para os torques articulares em água pode ser vista nos gráficos da figura 4.18. Neles estão sendo mostrados, para cada articulação, o torque articular e o inverso do torque da força de arrasto, o qual representa o torque muscular 


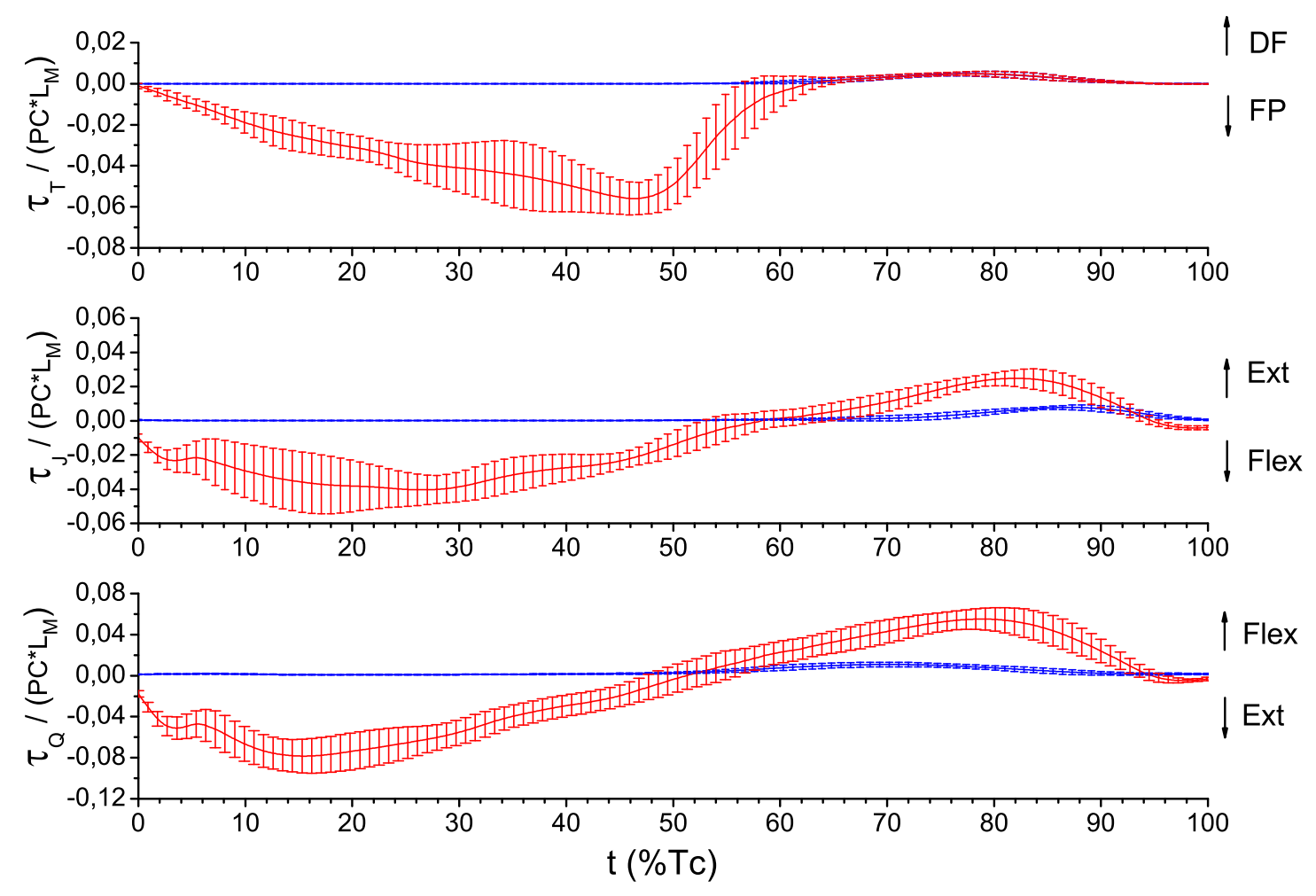

Figura 4.18: Contribuição do torque da força de arrasto para o torque articular resultante no ambiente aquático. A curva em azul representa o inverso do torque da força de arrasto e a curva em vermelho o torque interno resultante. As barras de incerteza indicam o desvio padrão.

que deve ser feito sobre cada articulação para contrabalancear o torque realizado pela força de arrasto.

A potência articular auxilia na compreensão do papel dos torques no movimento, uma vez que ajuda a identificar se ele está agindo de modo a gerar movimento ou "impedi-lo". A figura 4.19 mostra a potência para as três articulações nos dois ambientes.

No tornozelo, tanto em terra quanto em água, a potência apresenta uma fase negativa, ou seja, de absorção de energia, durante o apoio. Em terra, este período termina perto de $40 \%$ do ciclo e em água perto de 30\%. A fase positiva é iniciada em seguida e termina apenas no fim do ciclo. Para o tornozelo, ela atinge seu valor máximo na fase de apoio em instantes diferentes nos dois ambientes (Shapiro Wilk: $\mathrm{p}=0,80$, teste $\mathrm{t}$ :, $\mathrm{p}<0.01$ ): em $t=55,6(9) \% T_{p}$, em terra, e em $t=50,0(40) \% T_{p}$, em água. Na fase de balanço ela assume valores mais próximos de zero.

O joelho apresenta a potência oscilando entre positiva e negativa durante o apoio. Em terra, há três fases em que a potência é positiva e três fases em que é negativa. Já em água existem apenas duas fases positivas e uma negativa. Durante o apoio as potências são maiores em ambiente terrestre. Contudo, a maior diferença entre os ambientes está na fase de balanço. 

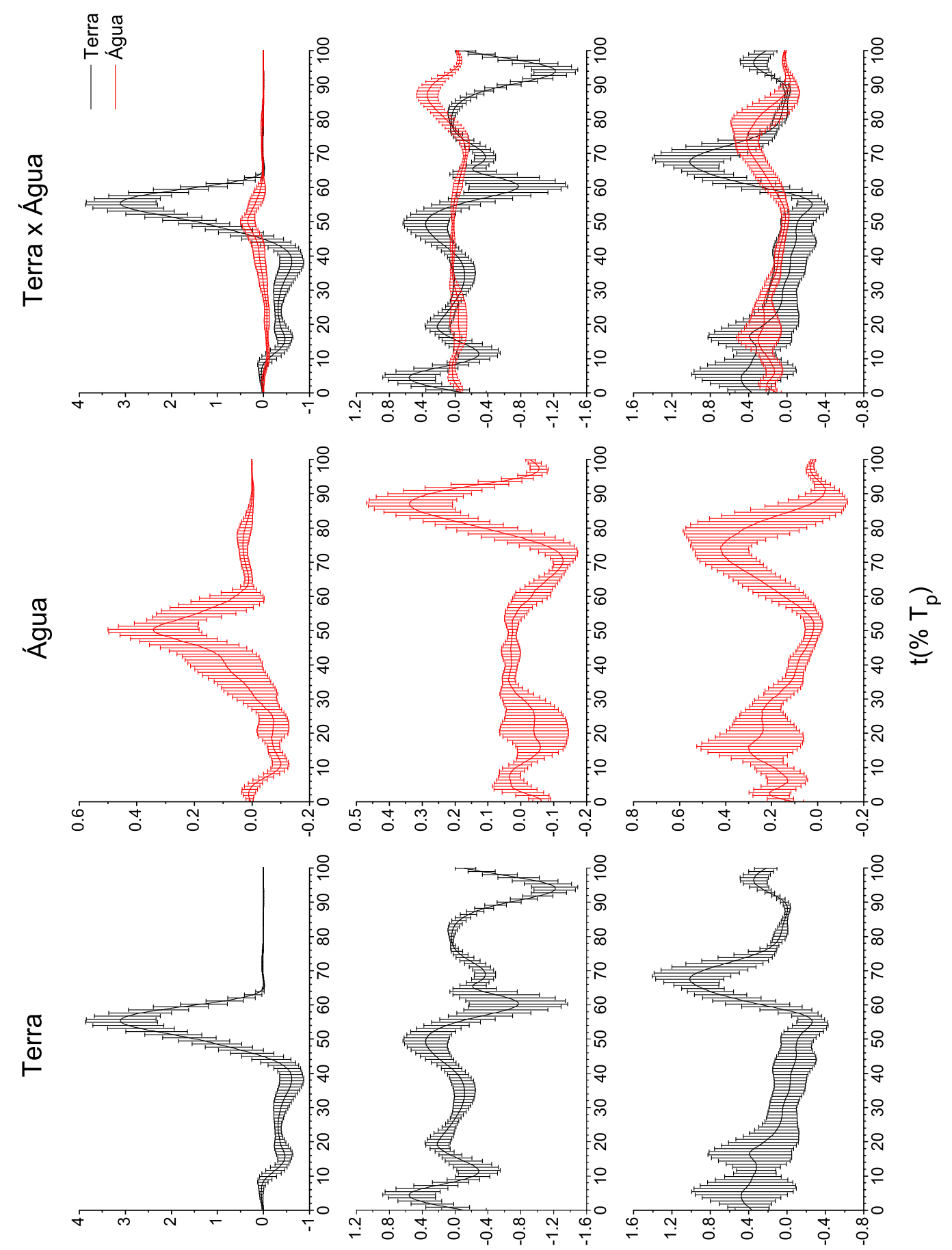

$(6 y / M)^{\perp} d$

$(6 y / M)^{r} d$

$(6 y / M)^{0} d$

룽 중

莫过

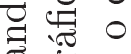

० 50

0 学

需寄苟

$\theta \vec{g}$

중

苛竎

Fं

ส용

Ex क क

$8 \stackrel{0=}{\pi}$

可年

\%

。

웡 흉

웜

嗐

워

의 윰

สํㅠㄹ

ธี

ㅎํ의

0

苛

0

ब

즐

웅

สี ซ

등

纪

㑒

की

党

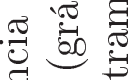

过

$\circ$ प

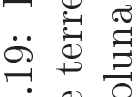

$+\circ 8$

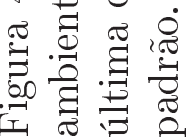


Enquanto em terra a potência é basicamente negativa, em água a potência é negativa durante o início do balanço mas, aproximadamente no meio desta fase, passa a ser positiva, atingindo seu valor máximo em média em $t=85,1(47) \% T_{p}$.

O quadril, em ambiente terrestre, inicia o ciclo com potência positiva. Aproximadamente no meio do apoio ela muda para negativa e volta a ser positiva no início do balanço, mantendose assim até o fim do ciclo. Em água, entretanto, a potência é positiva praticamente durante todo o ciclo.

A tabela 4.18, mostra a comparação entre os valores máximos e mínimos da potência articular nos dois ambientes. As magnitudes máximas das potências, tanto de "geração" (máximos dos gráficos) quanto de "absorção" (mínimos dos gráficos) do movimento, são maiores em ambiente terrestre do que em ambiente aquático para as três articulações.

Tabela 4.18: Valores representativos (média(desvio padrão)) para a potência articular máxima e mínima do tornozelo, do joelho e do quadril nos dois ambientes. As duas últimas colunas reportam o valor de $\mathrm{p}$ dos testes estatísticos. O sinal ${ }^{\sharp}$ indica a não normalidade da amostra, $\dagger$ indica que foi usado o Teste de Wilcoxon (TW) ao invés do teste t (TT) e o * indica diferença significante entre os valores encontrados em terra e água.

\begin{tabular}{lccccc}
\hline \multirow{2}{*}{ Articulações } & Evento & \multicolumn{2}{c}{$\mathbf{P}(W / k g)$} & \multicolumn{2}{c}{ Testes Estatísticos } \\
\cline { 2 - 5 } & & Terra & Água & Shapiro-Wilk & teste t \\
\hline \multirow{2}{*}{ Tornozelo } & Máximo & $3,22(80)$ & $0,49(17)$ & $<0,01 *$ & $<0,01 *$ \\
\cline { 2 - 6 } & Mínimo & $-0,82(13)$ & $-0,156(30)$ & $<0,01 \sharp$ & $<0,01 * \dagger$ \\
\hline \multirow{2}{*}{ Joelho } & Máximo & $0,72(27)$ & $0,41(13)$ & 0,15 & $<0,01 *$ \\
\hline \multirow{2}{*}{ Quadril } & Mínimo & $-1,43(28)$ & $-0,206(49)$ & 0,75 & $<0,0001 *$ \\
\cline { 2 - 6 } & Máximo & $1,22(35)$ & $0,57(21)$ & 0,77 & $<0,001 *$ \\
\hline
\end{tabular}

\subsection{Relação entre a Força de Arrasto a Força de Reação do Solo Durante o Andar em Água}

Barela e colaboradores [3, 4], com a finalidade de discutir o motivo da mudança de padrões da componente ântero-posterior de $F R S$, verificaram uma alta correlação linear entre esta componente e a componente horizontal da força de arrasto. Sugeriram, então, que a mudança nos padrões de $F R S_{\mathrm{H}}$ estaria relacionada à necessidade de gerar um impulso para superar o impulso horizontal força de arrasto. 
Para analisar mais profundamente esta relação e, ainda, fornecer um parâmetro para avaliar a qualidade da estimativa da força de arrasto, realizamos a análise que será descrita a seguir.

A componente horizontal da força resultante que atua sobre o indivíduo durante o andar em água é obtida a partir da soma da componente ântero-posterior da força de reação do solo e da componente horizontal do arrasto total. Esta resultante é responsável pelo movimento progressivo do CM do indivíduo. Portanto, ela está relacionada às variações da quantidade de movimento linear nessa direção.

Sabe-se que a variação da quantidade de movimento do centro de massa de um corpo, ou sistema, entre dois instantes consecutivos, é igual ao impulso da força resultante que age sobre o corpo durante este intervalo de tempo. Portanto, para o andar, podemos associar a variação da quantidade de movimento horizontal entre dois instantes à somatória do impulso de $F R S_{\mathrm{AP}}$ $\left(I_{\mathrm{FRS}}\right)$ e de $F_{\mathrm{DH}}\left(I_{\mathrm{D}}\right)$, como na equação abaixo:

$$
\int_{t_{i}}^{t_{f}} F R S_{\mathrm{AP}} d t+\int_{t_{i}}^{t_{f}} F_{\mathrm{DH}} d t=m\left(V C M_{\mathrm{H}}\left(t_{f}\right)-V C M_{\mathrm{H}}\left(t_{i}\right)\right)
$$

na qual $m$ representa a massa do indivíduo e $t_{i}$ e $t_{f}$ os instantes inicial e final do intervalo de tempo considerado.

Espera-se, então, que a relação entre $I_{\mathrm{FRS}}$ e $I_{\mathrm{D}}$ seja linear, com o coeficiente angular igual a -1 e com o coeficiente linear igual à variação da quantidade de movimento entre os instantes considerados $(\Delta p)$ :

$$
I_{\mathrm{FRS}}=-I_{\mathrm{D}}+\Delta p
$$

As análises foram feitas de modo a verificar se a relação proposta pela equação 4.3 era válida para a fase de suporte simples do andar. Esta fase foi escolhida pois a $F R S$ só foi medida para o membro inferior direito.

Como os eventos de toque do calcanhar do membro inferior esquerdo não foram identificados neste estudo, realizamos aproximações para determinar a fase de apoio simples. Para isso, levamos em conta o fato de que a fase de apoio simples da perna direita corresponde a fase de balanço da perna esquerda e que, portanto, a duração das duas é a mesma. Consideramos, ainda, que as fases de apoio duplo tem duração semelhante. Desta maneira, parece razoável a aproximação de que as fases de apoio duplo teriam duração de $10 \% T_{p}$.

Para calcular o impulso resultante da força de arrasto foi necessário estimar a força de arrasto no membro inferior esquerdo. Consideramos, então, as propriedades de simetria entre os lados direito e esquerdo, do andar de adultos saudáveis. Para o membro esquerdo, extrapolamos o valor da força de arrasto a partir dos dados obtidos para a fase de balanço do membro inferior direito. Determinamos, também,o arrasto para os segmentos do tronco (tronco inferior e médio $[25,23])$, os quais estão representadas nos gráficos da figura 4.20. 

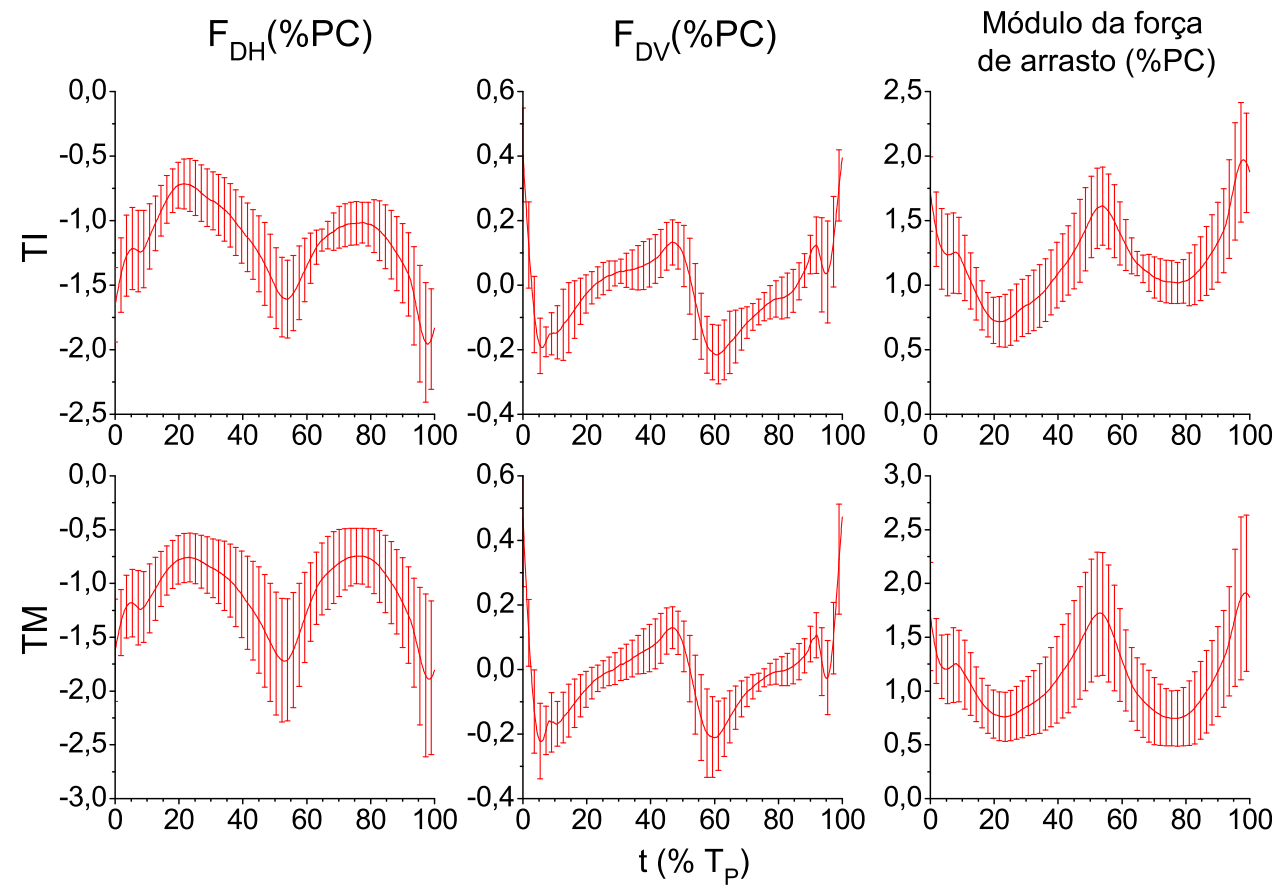

Figura 4.20: Componentes horizontal e vertical e módulo da força de arrasto que age sobre o tronco inferior (TI) e sobre o tronco médio (TM) durante um ciclo da marcha em ambiente aquático.

Tanto $I_{\mathrm{FRS}}$ quanto $I_{\mathrm{D}}$ foram obtidos a partir da integração das curvas das forças em função do tempo pelo método do trapézio, através de função fornecida pelo software MATLAB. Assim como as outras variáveis, o valor representativo dos impulsos para cada indivíduo foi obtido da média das cinco tentativas.

Para verificar se a relação dada pela equação 4.3 era satisfeita calculamos, inicialmente, o coeficiente de correlação linear $(\mathrm{R})$ entre $I_{\mathrm{FRS}}$ e $I_{\mathrm{D}}$ e a probabilidade desta correlação ser nula. Obtivemos para este coeficiente o valor de $-0,98$ com $p<0,0001$, indicando correlação significativa.

Em seguida, foi feito um ajuste linear, através do método dos mínimos quadrados, no qual o impulso da força de arrasto era a variável independente e o impulso de $F R S$ a variável dependente.

Tanto no cálculo da correlação quanto do ajuste foram considerados apenas os dados de 9 sujeitos, pois um dos participantes realizou o experimento sem a marca posicionada ao nível do processo xifóide, o que impediu o cálculo da força de arrasto para o tronco médio.

Os gráficos da figura 4.21 representam o ajuste da reta aos pontos experimentais e o respectivo gráfico de resíduo. O valor de $\chi^{2}$ para o ajuste foi de 5,5. Este valor não é inferior, nem excede os valores críticos, que são respectivamente 1,2 e 18, 5 para o nível de significância 
de $1 \%$ e 7 graus de liberdade [49]. A relação linear dada pelo ajuste foi:

$$
I_{F R S}=-0,67(17) * I_{D}+5(9)
$$

Neste ajuste o valor do coeficiente angular foi compatível com -1 com $p>0.05$ [49].

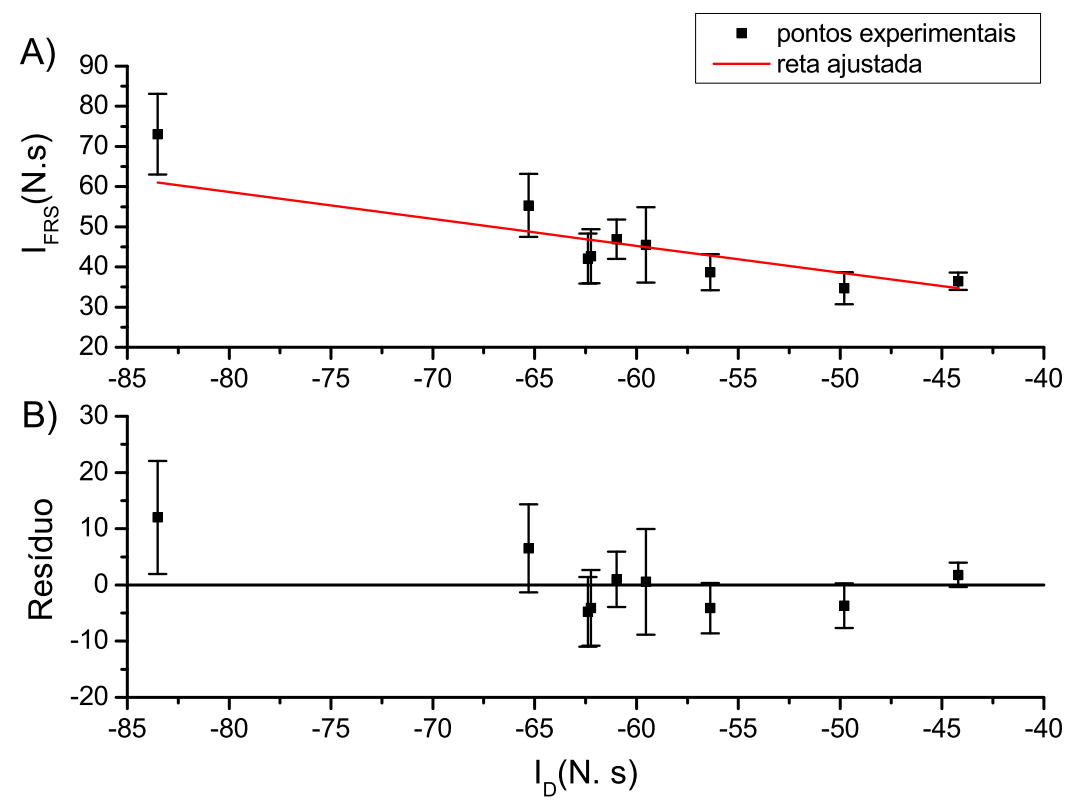

Figura 4.21: A)Gráfico do impulso da componente horizontal de $F R S$ em função do impulso da componente horizontal do arrasto durante a fase de apoio único. A reta em vermelho representa o ajuste linear feito através do método dos mínimos quadrados. B) Gráfico de resíduo referente ao ajuste.

Para fins de comparação, estimamos também o valor médio da variação da quantidade de movimento linear do CM dos indivíduos durante a fase de apoio simples. Novamente realizamos uma extrapolação, a partir dos dado obtidos para o membro inferior direito, para determinar as velocidades dos centros de massa dos segmentos do membro inferior esquerdo.

O valor médio do grupo para a variação da quantidade de movimento do $\mathrm{CM}$, determinada a partir da estimativa da velocidade do CM e das massas dos indivíduos, foi de $6(3) \mathrm{kg} . \mathrm{m} / \mathrm{s}$ que é compatível com o valor do coeficiente linear obtido no ajuste $(5(9) \mathrm{kg} \cdot \mathrm{m} / \mathrm{s}) \operatorname{com} p>0,05$ [49]. 


\section{Capítulo 5}

\section{Discussão}

O presente estudo teve como principal objetivo avaliar as carga mecânicas sobre o aparelho locomotor durante o andar em ambiente aquático, além de fornecer uma estimativa para a força de arrasto e seus respectivos torques durante esta tarefa.

Para tanto, determinamos as forças e torques articulares no tornozelo, joelho e quadril. Analisamos, também, as forças externas que atuam sobre o corpo e a cinemáticas do movimento, visando compreender melhor as diferenças entre as forças e torques internos durante o andar em terra e água. Os resultados foram comparados entre os ambientes e com as informações fornecidas por estudos anteriores.

No geral, os resultados referentes ao ambiente terrestre, assim como os padrões cinemáticos e da força de reação do solo em ambiente aquático, foram condizentes com os estudos reportados na literatura.

Com relação a cinemática do andar em ambiente aquático, não houve mudanças na coordenação dos movimentos articulares, nem re-organização temporal significativa da passada durante o andar em água. Entretanto, pudemos perceber mudanças nos sentidos dos torques articulares para o joelho e o quadril. Isso sugere que, para manter a mesma coordenação articular sob a ação do empuxo e do arrasto, é necessário promover modificações nos padrões dos torque internos nestas articulações.

Houve também diminuição nas magnitudes das forças articulares durante o andar em ambiente aquático, principalmente na fase de apoio, sugerindo que ao caminhar em água os indivíduos estão sujeitos a uma menor carga compressiva nas articulações do membro inferior.

A estimativa das forças de arrasto se mostrou adequada para descrever a situação experimental. Isto foi verificado através da relação linear entre o impulso das componentes horizontal da força de arrasto e o da força de reação do solo, a qual apresentou o comportamento esperado, e também pelos valores dos Números de Reynolds dos segmentos, que confirmaram a predominância do arrasto de pressão. Os resultados sugerem, então, que os valores apresentados neste estudo são adequados para descrever a carga mecânica no aparelho locomotor durante o andar em piscina com água rasa. 
Com a finalidade de esclarecer as mudanças descritas acima, discutiremos a seguir os principais resultados obtidos neste estudo. Será dado maior enfoque aos resultados referentes ao ambiente aquático, pois a marcha em ambiente terrestre é bem descrita na literatura.

\subsection{Cinemática do Andar em Ambiente Aquático}

\subsubsection{Cinemática Descritiva}

As variáveis descritivas obtidas neste estudo (tabela 4.1) além de serem comparadas entre os ambientes, foram comparadas com aquelas obtidas no estudo de Barela e colaboradores [3] (ver tabela 2.1), o qual foi realizado em condições semelhantes e com os mesmos equipamentos.

Ao confrontarmos os valores médios obtidos para $L_{p}$ e $T_{p}$, reportados na tabela 4.1 , com os reportados na tabela 2.1, podemos notar que os valores obtidos neste estudo são superiores aos encontrados por Barela e colaboradores [3]. Entretanto, como as diferenças entre as médias são da mesma ordem do desvio padrão da medida, podemos considerar essas grandezas semelhantes frente à variabilidade da amostra.

Os participantes adotaram a velocidade mais confortável ao caminhar tanto em ambiente aquático quanto em ambiente terrestre. A velocidade média neste estudo foi igual à reportada por Barela e colaboradores [3] e bastante próxima àquela adotada pelos participantes do estudo de Miyoshi e colaboradores [29] na condição em que eles caminharam com velocidade confortável.

A velocidade adotada em terra é compatível aos valores descritos na literatura para o andar de adultos normais [45] e próxima ao valor da tabela 2.1 .

Comparando os resultados entre os ambientes é possível ver que há diferença na duração e na velocidade da passada, porém, não há diferença em $L_{p}$ nos dois ambientes, o que concorda com os resultados apresentados em [3].

A duração da fase de balanço $\left(T_{a_{\text {NORM }}}\right)$, ao contrário do estudo de Barela e colaboradores [3], foi diferente entre os ambientes (tabela 4.1). A diferença foi de aproximadamente 5\%, e é pequena em comparação ao desvio padrão das medidas (3, $3 \%$ em água e $1 \%$ em terra). Isso faz com que ao observamos a curva referente à componente vertical de $F R S$ (gráfico superior da figura 4.10), não possamos ver tal diferença.

A diminuição na fase de apoio em ambiente aquático indicaria que há uma re-organização temporal das fases que compõem o ciclo do andar neste ambiente. No entanto, o fato da diferença entre as médias ser pequena em comparação às incertezas envolvidas, torna este resultado inconclusivo. Além disso, seria esperado um aumento na duração da fase de apoio, ao invés de uma redução, devido à diminuição da velocidade da passada [3]. 


\subsubsection{Cinemática Articular e Segmentar}

As curvas dos ângulos articulares do tornozelo, joelho e quadril em função do tempo, em uma análise qualitativa, se mostraram similares às apresentadas na literatura [3, 28, 29, 52]. Os padrões destas curvas, assim como descrito em outros estudos [3, 28], foram semelhantes entre os ambientes e não foi possível verificar diferenças nas amplitudes das articulações em água e em terra (figura 4.2B). Tais resultados estão em acordo com resultados anteriores inclusive no que diz respeito aos valores médios das amplitudes [3].

Uma análise especifica de cada articulação, mostrou que não há diferença entre os ambientes no ângulo do tornozelo no instante de contato inicial e que, nas duas condições, esta articulação inicia o ciclo em flexão plantar (ver figura 4.2A).

Tanto Barela [1] (numericamente) quanto Miyoshi [28, 29] (em seus gráficos do ângulo articular em função do tempo) mostraram que o tornozelo inicia o ciclo em flexão plantar no ambiente aquático.

Para o ambiente terrestre, entretanto Barela [1] verificou que o tornozelo iniciava o ciclo em dorsi-flexão e com um ângulo diferente do ângulo adotado no meio aquático. Segundo Whittle [52], em terra, a articulação geralmente inicia o ciclo próximo da posição neutra, algumas vezes em flexão plantar outras em dorsi-flexão, o que explica a diferença nos resultados para o ambiente terrestre.

Com relação ao ambiente aquático, apesar de todos os estudos [1, 28, 29] indicarem que a articulação do tornozelo inicia o ciclo em posição de flexão plantar, em todos eles os ângulos foram próximos ao da posição neutra e apresentaram desvios padrões tão grandes quanto o valor da média. Além disso, foi possível observar através da análise dos dados individuais de cada participante, que alguns iniciaram o ciclo com com o tornozelo em poucos graus de dorsiflexão. Estes fatos podem indicar que em água ocorre o mesmo que em terra: a articulação fica próxima da posição neutra.

Para o tornozelo também foram comparados os ângulos máximos de dorsi-flexão e flexão plantar atingidos nas fases de apoio e balanço. Não foi possível perceber diferença entre os ambientes na fase de apoio. Na fase de balanço, porém, o tornozelo atingiu valores de dorsi-flexão significativamente maiores em ambiente aquático (gráfico 4.3) e se manteve nesta posição durante mais tempo, enquanto em terra, ficou próximo da posição neutra a partir da segunda metade do balanço. Contudo, o mesmo não pôde ser visto no gráfico da figura 2.2A, ao contrário, a curva reporta maiores ângulos de dorsi flexão em terra. Novamente há uma contradição entre os resultados que pode ser explicada por outra afirmação de Whittle [52]. Segundo ele, no ambiente terrestre, no final da fase de balanço, a posição do tornozelo não é muito importante e pode variar entre alguns graus de dorsi-flexão e a posição neutra. É possível então inferir que o mesmo acontece em ambiente aquático.

Uma análise qualitativa do gráfico superior da figura 4.1 mostra que pode haver diferenças 
entre os ambientes nos instantes de ocorrência dos picos, tanto de dorsi-flexão quanto de flexão plantar, porém, os teste estatísticos não foram capazes de identificá-las (ver tabela 4.4). Se analisarmos a curva da velocidade angular desta articulação em função do tempo, podemos ver que as mudanças nos sentidos de rotação $\left(\omega_{\mathrm{T}}=0\right)$ ocorrem antecipadamente em ambiente aquático, indicando que podem haver diferenças nos instantes de ocorrência de tais eventos. Em adição, três fatos reforçam essa hipótese: Miyoshi e colaboradores [28, 29] reportaram em seus estudos a antecipação do pico de dorsi-flexão na fase de apoio em ambiente aquático; se observarmos com cuidado o gráfico obtido por Barela [1] para o ângulo articular do tornozelo (figura 2.2), podemos ver esta mesma antecipação; e, além disso, os valores de $\mathrm{p}$ do teste t reportados na tabela 4.4 são próximos do nível de significância, principalmente para a flexão plantar máxima no apoio e a dorsi-flexão máxima no balanço.

Os resultados ainda são inconclusivos, porém, a existência da antecipação dos picos de flexão plantar e dorsi-flexão em ambiente aquático poderia estar associada a uma estratégia para enfrentar fases de maior velocidade linear com as articulações mais flexionadas. Isso faria com que a área dos segmento perpendicular ao vetor velocidade $\left(A_{\perp}\right)$ fosse menor, reduzindo o arrasto.

A análise dos deslocamentos angulares do joelho mostrou não haver diferença, entre os ambientes, no ângulo máximo de flexão da articulação e nem no instante em que este pico ocorre (tabela 4.5 e figura 4.4). No apoio, entretanto, não é possível identificar na curva obtida para o ambiente aquático (figura 4.1), o primeiro pico de flexão do joelho.

Em terra este primeiro pico ocorre próximo ao início da fase de apoio simples [52] (balanço do membro contralateral), em aproximadamente $10 \% T_{p}$ e pode ser visto no gráfico da figura 2.2A. Já em água, o joelho inicia o ciclo mais flexionado e, durante a primeira metade do apoio, vai reduzindo este ângulo, o que também foi visto em estudos anteriores [3, 28, 29]. Além disso Miyoshi e colaboradores [28, 29] constataram uma menor amplitude de deslocamento do joelho na fase de apoio em água.

Segundo Whittle [52] o pico de flexão, acima referido, ocorre em terra ao mesmo tempo em que há uma contração excêntrica do quadriceps, que resulta em um torque articular extensor (ver gráfico central da figura 4.16) com absorção de energia (potência negativa na figura 4.19). Este mecanismo é adotado para absorver energia e impedir que a componente vertical da força de reação do solo cresça bruscamente (fase de desaceleração do movimento descendente do centro de massa). O desaparecimento deste pico em água pode estar associado à redução da velocidade do andar (assim como em terra [52]) e à sustentação proporcionada pelo empuxo, a qual resulta numa necessidade menor de absorção de energia para desacelerar o centro de massa (como pode ser visto pela redução dos valores da potência nos primeiros instantes do ciclo - figura 4.19).

Outra diferença entre as curvas do joelho obtidas em terra e em água está no ângulo apresentado pela articulação no contato inicial (figura 4.2). Em água o joelho encontra-se, em 
média, flexionado durante o início do ciclo, enquanto em terra, encontra-se próximo à posição neutra. Este resultado não foi verificado por Barela [1], contudo tanto a autora quanto Miyoshi e colaboradores $[28,29]$ reportaram em seus gráficos curvas cujos ângulos no contato inicial eram superiores em água. Também podemos notar que o joelho se encontra mais flexionado em água nos instantes finais da fase de apoio (ver figuras 4.1 e $2.2 \mathrm{~A}$ ).

Em terra a extensão do joelho, que ocorre no final do balanço, inicia-se devido à inércia do segmento e ao torque extensor da força peso e se mantém devido apenas à inércia (não há forças externas para frear o movimento). Em oposição, age um torque flexor sobre a articulação para evitar que o joelho estenda muito rapidamente e atinja uma posição de hiper-extensão [52]. Assim, no final do ciclo, a perna está bem próxima da posição neutra.

No ambiente aquático a extensão do joelho não pode ocorrer por inércia, pois há forças externas desacelerando o movimento e ainda, o torque extensor da força peso é contraposto por um torque flexor do empuxo. Portanto, é necessária a ação dos músculos agonistas, como pode ser visto pela inversão da curva da potência articular do joelho, na figura 4.19. A força de arrasto, ao se opor ao movimento, faz com que a extensão seja realizada com velocidade angular menor (figura 4.6), o que pode explicar o fato do joelho se manter mais flexionado durante o apoio e não atingir a posição articular neutra no contato inicial.

O quadril foi a articulação cujas curvas dos ângulos articulares nos dois ambientes foram mais semelhantes (figura 4.1). Tanto o ângulo de extensão máxima, quanto o ângulo de flexão máxima na fase de apoio, foram similares nos dois ambientes (tabela 4.5). Também não foi possível verificar diferenças significativas nos instantes em que esses eventos ocorreram. Podemos notar, entretanto, uma pequena diferença (5\%) no instante de ocorrência do pico de flexão, a qual foi verificada também na análise da velocidade angular do quadril por uma antecipação na mudança de sentido de $\omega_{\mathrm{Q}}$, que ocorre um pouco antes do início da fase de balanço (figura 4.6).

No que diz respeito às velocidades angulares articulares (figura 4.6), podemos observar que o padrão das curvas se mostrou semelhante entre os ambientes. As magnitudes, porém, foram menores em água devido à ação da força de arrasto.

Tanto no ambiente aquático quanto no terrestre, as velocidades angulares foram superiores na fase de balanço e o joelho foi a articulação que apresentou maiores velocidades nos dois ambientes (tabela 4.6). Estes padrões semelhantes para as velocidades articulares reforçam a idéia de que a coordenação das articulações é mantida, mesmo com a presença do empuxo e com a resistência imposta pelo arrasto.

As curvas para o módulo do vetor velocidade linear do CM do pé, da perna e da coxa, também apresentaram comportamento semelhante em terra e água (figura 4.8). Os padrões destas curvas são similares aos de suas componentes horizontais, pois as velocidades nessa direção são maiores em comparação às velocidades na direção vertical (ver tabelas 4.7, $4.8 \mathrm{e}$ $4.9)$. 
Assim como o módulo do vetor, $V C M_{\mathrm{H}}$ também apresenta comportamento bastante parecido entre os ambientes. O fato de seu sentido ser sempre positivo mostra que, apesar das rotações em torno das articulações, os segmentos do membro inferior apresentam um movimento resultante progressivo. Por esse motivo, a componente horizontal da força de arrasto tem sempre sentido negativo (figura 4.11).

As curvas da velocidade vertical do centro de massa da perna e da coxa apresentam comportamento semelhantes entre os ambientes, com magnitudes menores em água (tabela 4.8). Já $V C M_{\mathrm{v}}$ do pé indica uma mudança a menos no sentido do movimento vertical no final da fase de balanço, em ambiente aquático.

Como não foi possível perceber mudanças nos padrões dos deslocamentos articulares, uma mudança na trajetória do CM do pé só poderia ser explicada por mudanças nos ângulos segmentares do pé e/ou da perna.

Barela e colaboradores [3] mostraram que há diferenças significativas entre terra e água nas amplitudes do deslocamento segmentar para o pé, para a perna e para o tronco. Também é possível perceber, através dos gráficos reportados pelos autores, que o pé e a perna apresentam ângulos diferentes em água no final da fase de balanço [3]. As mudanças apontada por Barela e colaboradores [3] são capazes de explicar a não elevação do centro de massa do pé e, ao mesmo tempo, a manutenção dos padrões articulares.

As maiores velocidades lineares são atingidas pelo pé, tanto no meio aquático quanto no terrestre. O centro de massa deste segmento adquire uma velocidade máxima aproximadamente duas vezes maior que a da perna e a da coxa (figura 4.9). Como o arrasto depende do quadrado da velocidade, o pé esta sujeito a forças da ordem das que atuam na perna e na coxa, mesmo possuindo uma área frontal menor (figura 4.11 e 4.12).

Para as velocidades adotadas nos dois ambientes pelos participantes deste estudo, a estimativa da faixa de variação do número de Reynolds (ver tabela 4.10), indica que as hipóteses propostas para o escoamento estão de acordo com as observações experimentais, pois os valores para o ambiente aquático são similares àqueles reportados por D. Newman [32].

\subsection{Cinética do Andar em Ambiente Aquático}

\subsubsection{Forças e Torques Externos}

As curvas de $F R S_{\mathrm{V}}$ e $F R S_{\mathrm{AP}}$ em ambiente aquático apresentam os mesmos padrões descritos em estudos anteriores [3, 43, 29], o que pode ser visto ao compararmos as figuras 4.10 e 2.2B.

Em terra, tanto o comportamento das componentes de $F R S$ quanto os valores apresentados por ela estão de acordo com a literatura [52].

Analisando o gráfico da componente vertical e os valores apresentados na tabelas 4.11 para os picos de $F R S_{\mathrm{v}}$ em ambiente aquático, vemos que eles são semelhantes àqueles obtidos a 
partir do trabalho de Barela e colaboradores [3] (ver valores ajustados na tabela 2.2) e aos valores obtidos em outros estudos [19, 29, 43].

Em ambiente terrestre as médias para o primeiro e segundo pico foram aproximadamente $11 \%$ PC e $4 \% P C$ menores em relação aos valores apresentados por Barela e colaboradores [3]. Além disso, foi possível perceber diferença significativa entre eles (o primeiro pico foi $10 \% P C$ menor em comparação ao segundo). A diferença elevada no valor do primeiro em relação ao segundo e em relação ao valor médio do primeiro pico obtido por Barela e colaboradores [3], sugere que alguns sujeitos ainda estavam acelerando quando tocaram na plataforma de força. Portanto, na fase final do balanço, o centro de massa desses indivíduos possuía velocidade maior, o que poderia ter provocado a diferença entre os dois picos. Para o andar em água isso não ocorreu, ou seja, o arranjo experimental em ambiente aquático permitiu que os indivíduos alcançassem uma velocidade da passada aproximadamente constante antes de atingir a plataforma de força.

Ao compararmos os ambientes é interessante enfocar que a redução apresentada em $F R S_{\mathrm{V}}$ no ambiente aquático, se deve ao empuxo. Esta força age no sentido oposto do peso corporal proporcionando uma redução na força de compressão que o individuo faz sobre o solo. A característica mais plana da curva (com os dois picos e vale menos acentuados), se deve, no entanto, à resistência imposta pelo arrasto [3]. O arrasto reduz a magnitude da velocidade do centro de massa do indivíduo, o que faz com que sejam necessárias desacelerações menores para inverter os movimentos ascendentes e descendentes do CM.

Como foi verificado em estudos anteriores [3, 29, 43], a componente ântero-posterior da força de reação do solo no meio aquático, não apresenta a fase negativa, que, em terra, é responsável por frear o movimento progressivo do membro inferior.

Miyoshi e colaboradores [29] apenas atribuíram isso à resistência imposta pela água. Roesler e colaboradores [43] sugeriram que o indivíduo modifica a fase de suporte da marcha de modo a ganhar velocidade e para isso só realiza a fase de propulsão.

Já Barela e colaboradores [3] mostraram que durante a fase de suporte em terra o impulso de $F R S_{\mathrm{AP}}$ é zero, o que indica que não há variação da quantidade de movimento horizontal entre os dois instantes. Sugeriram, então, que, em água, mesmo para manter a variação nula de velocidade entre os dois instantes, seria necessário gerar um impulso que se opusesse ao impulso da força de arrasto. Para reforçar essa hipótese mostraram que havia correlação entre a magnitude da força de arrasto e a magnitude da componente horizontal da força de reação do solo $[3,4]$.

Os nossos resultados confirmam a hipótese de Barela e colaboradores [3, 4] pois mostram uma alta correlação linear $(R=-0.98)$ entre o impulso da componente horizontal da força de arrasto e o impulso da componente horizontal da força de reação do solo, durante a fase de apoio simples da marcha. O sinal negativo de $\mathrm{R}$ indica que os sentidos dos dois impulsos são opostos. 
A relação entre $I_{\mathrm{D}}$ e $I_{\mathrm{FRS}}$ é linear e dada pela equação 4.2. Com o objetivo de verificar se os dados obtidos experimentalmente satisfaziam esta equação, realizamos um ajuste linear através do método dos mínimos quadrados. O gráfico 4.21A mostra o ajuste e o gráfico $4.21 \mathrm{~B}$ o respectivo resíduo.

Uma análise qualitativa da reta ajustada mostra que a relação linear é adequada para descrever os dados. Além disso, o gráfico de resíduo possui uma distribuição aleatória dos pontos em torno do zero e o valor de $\chi^{2}$ ficou dentro dos limites críticos, o que garante a qualidade do ajuste.

Ao compararmos os coeficientes angular e linear obtidos (ver equação 4.4) com os valores esperados pela equação 4.3, pudemos perceber que, dentro do nível de significância adotado, o coeficiente angular $(-0.67(17))$ foi compatível com -1. O coeficiente linear $(5(9) \mathrm{kg} . \mathrm{m} / \mathrm{s})$, que corresponde à variação da quantidade de movimento horizontal durante a fase de apoio simples, foi compatível com o valor calculado a partir da massa dos indivíduos e da estimativa da velocidade de seu centro de massa nos instantes iniciais e finais do apoio simples $(6(3) \mathrm{kg} . \mathrm{m} / \mathrm{s})$.

Tais resultados não só explicam a característica sempre positiva de $F R S_{\mathrm{AP}}$, como sugerem que o modelo proposto para a força de arrasto foi adequado para descrever a situação experimental dentro das incertezas apresentadas. Entretanto, observando o gráfico da figura 4.21A, é possível verificar que o módulo de $I_{\mathrm{D}}$ é sistematicamente maior do que $I_{\mathrm{FRS}}$. Isso faz com que o coeficiente angular seja menor do que -1, apesar de ser compatível com este valor, sem, no entanto, interferir no coeficiente linear. Isso sugere que o arrasto pode estar ligeiramente superestimado, e uma hipótese é que isto ocorra devido ao valor adotado para o coeficiente de arrasto. Estudos futuros, devem verificar a influência desta grandeza no valor da força resultante, além de determinar valores mais acurados para os segmentos corporais.

$\mathrm{O}$ valor máximo para $F R S_{\mathrm{AP}}$ (figura 4.10) foi semelhante ao observado na figura 2.2B (em torno de $10 \% P C$ ). Entretanto a média reportada por Miyoshi e colaboradores [29] para o pico de $F R S_{\mathrm{AP}}$ é próxima de $20 \% P C$ na condição de velocidade confortável, duas vezes maior que os valores apresentados acima. Mesmo ao compararmos este resultado àquele obtido por Roesler e colaboradores [43] em uma condição de caminhada semelhante ${ }^{1}$, vemos que os valores apresentados por Miyoshi e colaboradores [29] são ainda superiores. A única explicação para isso seria que os participantes do estudo de Miyoshi e colaboradores [29] teriam caminhado com velocidade maior. O fato das velocidades serem parecidas com os valores aqui obtidos sugere que o método utilizado pelos autores para calcular $V_{p}$ (estimar a velocidade a partir de uma marca posicionada no tronco) estaria subestimando a velocidade da passada em relação ao método aqui utilizado (equação 2.1).

No ambiente aquático as forças de arrasto de maior magnitude são atingidas na fase de

\footnotetext{
${ }^{1}$ Roesler e colaboradores [43] mostraram que com água entre o manúbrio e o processo xifóide, na situação em que os participantes caminharam com velocidade de $0,55(6) \mathrm{m} / \mathrm{s}$, a média para o pico de $F R S_{\mathrm{AP}}$ foi próxima de $13 \% P C$
} 
balanço, na qual tanto as velocidades de rotação quanto de translação são maiores para os três segmentos. Nesta o arrasto atinge valores máximos de e 3,92(53)\%PC, 3,47(66)\%PC e $3,93(72) \% P C$, respectivamente para o pé, a perna e a coxa.

Os torques gerados por essas forças nas articulações do membro inferior são pequenos em relação aos torques articulares resultantes. Especificamente na fase de apoio, são tão pequenos que poderiam ser desprezados (ver figuras 4.12 e 4.18).

Apesar de individualmente as forças de arrasto parecerem pequenas quando comparadas às outras forças que agem sobre o segmento (como por exemplo as forças articulares - figura 4.13), a força de arrasto resultante (somatória do arrasto que age sobre todos os segmentos submersos) pode chegar a valores próximos a $15 \% \mathrm{PC}^{2}$ nas fases de apoio simples. Esse valor corresponde a aproximadamente metade da magnitude máxima da força de reação do solo.

Como discutido anteriormente, a força de arrasto máxima no pé é semelhante à que age na perna e na coxa, apesar de sua área frontal ser menor. Este resultado sugere que os movimentos do pé são importantes e não devem ser desconsiderados, como fizeram D. Newman [32] e Biscarini e Cerulli [7] ao modelarem, em seu estudos, a perna e o pé como um segmento único.

\subsubsection{Forças e Torques Internos}

Os gráficos para o módulo da força articular e suas componentes estão apresentados na figura 4.13. Para o ambiente terrestre as curvas referentes às duas componentes da força articular foram comparadas aos gráficos construídos a partir dos dados publicados por Winter em [53]. Tanto as forças verticais quanto as horizontais apresentaram comportamento e magnitudes semelhantes. Ao comparar os dois ambientes foi verificado que as forças articulares em água apresentaram intensidades inferiores na fase de apoio em comparação ao ambiente terrestre, devido à atuação do empuxo sobre o corpo do indivíduo. Para o tornozelo e o joelho, em alguns instantes do balanço, as forças em terra e água se assemelham (figura 4.13).

Além dos picos de força serem superiores em ambiente terrestre para as três articulações (gráfico inferior da figura 4.14), as forças articulares médias que agem sobre o tornozelo, o joelho e o quadril na fase de apoio também o são (gráfico inferior da 4.15). Na fase de balanço, porém, a força média que age sobre o tornozelo é equivalente nos dois ambientes.

Analisando individualmente cada componente vemos que, ao caminhar em ambiente aquático, os indivíduos estão sujeitos a ação de forças articulares verticais inferiores, tanto na fase de apoio quanto na fase de balanço (figuras 4.13, 4.14 e 4.15). O empuxo é o responsável por essa redução nas duas fases do ciclo. No apoio, a conseqüência da ação do empuxo é a redução da força vertical de reação do solo, responsável pela maior carga sobre o corpo dos indivíduos. No balanço, esta força contrapõe o peso de cada segmento, fazendo com que a tração resultante sobre as articulações seja menor. Além da contribuição do empuxo para a redução da com-

\footnotetext{
${ }^{2}$ Valor obtido por inspeção visual dos gráficos das figuras 4.11 e 4.20
} 
ponente vertical, vimos também uma contribuição da força de arrasto, pois, durante a maior parte desta fase, a força no pé e na perna também "apontam" para cima e sua ação se soma à do empuxo (ver figura 4.11).

A força articular média, que age sobre o tornozelo em água na fase de balanço, é semelhante a força média que age em terra, mesmo com a ação "sustentadora" do empuxo e da força de arrasto. Uma explicação possível é que existe a necessidade de uma força muscular maior e/ou mais constante para mover os segmentos (pé e perna) contra a resistência imposta pela força de arrasto. A hipótese é reforçada pelo aumento do torque dorsi-flexor sobre tornozelo (que ocorre na fase de balanço), reportado na tabela 4.17.

$\mathrm{Na}$ maior parte do ciclo, a componente horizontal atua em sentidos opostos no ambiente aquático e no ambiente terrestre. Este fato pode ser atribuído a ação da força de arrasto que, na fase de apoio, torna necessária a realização de modificação nas forças articulares para gerar sobre o solo, a impulsão necessária à manutenção do movimento. Durante o balanço o arrasto é a única força externa que tem ação na direção horizontal, portanto, para gerar um movimento progressivo, as forças internas devem ser tais que vençam a componente horizontal (sempre negativa) do arrasto.

Os resultados mostram diferenças significativas nas magnitudes máximas atingidas pela componente horizontal das forças internas das três articulações: todas elas são maiores em ambiente terrestre (figura 4.14). Contudo, para o quadril a diferença entre os valores médios obtidos nos dois ambientes é menor do que a incerteza nas medidas. Ou seja, mesmo o resultado do teste estatístico indicando diferença, ela não é relevante.

Apesar das máximas forças articulares horizontais serem atingidas durante o andar em terra, a força horizontal média que atua sobre cada articulação não é diferente entre os ambientes na fase de balanço (figura 4.15). Isso pode ser explicado pelo fato da componente horizontal da força articular em água mudar menos de sentido e, portanto, variar menos em magnitude. Na fase de apoio a RQM da componente horizontal se mostrou diferente entre os ambientes para o tornozelo e para o joelho, pois, nesta fase, a intensidade atingida pelas forças internas que agem sobre essas articulações são muito maiores durante o andar em terra.

Na fase de suporte, as modificações verificadas para as forças internas resultantes implicam claramente em uma redução das forças compressivas sobre as articulações. Também é possível que existam mudanças tanto nos sentido de atuação quanto nas magnitudes das forças de cisalhamento, devido à inversão da componente horizontal da FRS em água. No balanço, também devem ser observadas reduções tanto nas forças de tração quanto cisalhamento, além de mudanças no sentido da componente de cisalhamento, principalmente no joelho e no quadril.

As curvas referentes aos torque articulares durante a fase de apoio foram parecidas, em comportamento, com as curvas reportadas por Miyoshi e colaboradores [28] (ver figuras 2.3 e 4.16). Entretanto, as magnitudes dos torques aqui obtidos são maiores do que as reportadas no estudo supracitados. A diferença nos valores pode estar relacionada ao fato de que os par- 
ticipantes do estudo de Miyoshi e colaboradores [28] caminharam com água ao nível das axilas e com os braços dentro da água. Como foi visto em estudo desses mesmos autores [30], os torques no tornozelo na fase de apoio são bastante sensíveis a variações no peso aparente.

Fazendo uma análise individual de cada articulação, vemos que os torques internos que atuam sobre o tornozelo apresentam comportamento similar em terra e em água (figura 4.16). Entretanto, a magnitude do torque flexor plantar, durante a fase de apoio, é significativamente menor em água, enquanto o torque dorsi-flexor na fase de balanço é significativamente maior (figura 4.17).

A redução do pico de torque flexor plantar no ambiente aquático, se deve tanto à ação do empuxo, quanto à redução de velocidade do andar [30]. Já o aumento do torque dorsi-flexor no balanço se deve principalmente ao torque exercido pela força de arrasto como pode ser visto na figura 4.18, na qual o torque articular se sobrepõe, no final do ciclo, ao torque da força de arrasto.

O torque interno do tornozelo, no instante de contato inicial, também é reduzido em água (tabela 4.16), o que pode ser atribuído à diminuição do impacto (tabela 2.2), provocada pelo empuxo e também pela menor velocidade de movimento.

As curvas dos torques articulares do joelho foram bastante diferentes em terra e água, tanto no apoio, como já havia sido constatado anteriormente [28, 29], quanto na fase de balanço.

A principal modificação na fase de apoio é a não existência do primeiro pico de torque extensor (início da fase de apoio), também reportada por Miyoshi e colaboradores [28, 29].

Em terra, o torque extensor sobre o joelho ocorre na mesma fase do ciclo em que esta articulação atinge o primeiro pico de flexão (ver figura 4.1). Esse torque corresponde a uma atividade excêntrica e depois concêntrica (figura 4.19) dos músculos extensores do joelho de modo a desacelerar o centro de massa, que está em movimento descendente, e impedir que $F R S_{\mathrm{V}}$ cresça rapidamente [52].

Segundo Miyoshi e colaboradores [29, 30], a não existência deste pico em água está relacionado exclusivamente à redução do impacto proporcionada pelo empuxo, o que faria com que o joelho não tivesse o papel de absorver o impacto em água. Contudo, ao observarmos o torque que as forças internas do tornozelo exercem sobre o joelho (torque de $F_{\mathrm{T}}$ na equação 3.8), vemos que este se trata de um torque extensor, enquanto em terra, se trata de um torque flexor. Essa mudança esta associada à inversão do sentido da componente horizontal da força articular, que por sua vez ocorrem devido à necessidade de gerar um impulso oposto ao impulso da força de arrasto para que o movimento progressivo seja mantido. Ou seja, isto sugere que existe uma mudança na coordenação muscular para gerar a propulsão necessária a superar a resistência imposta pelo arrasto, culminando na mudança dos padrões da $F R S_{\mathrm{AP}}$.

Portanto, a mudança do torque articular, de extensor para flexor, no joelho durante o andar em água, não estaria só associada à ação do empuxo, mas sim a uma ação conjunta do efeito sustentador do empuxo e da resistência imposta pelo arrasto. 
$\mathrm{Na}$ fase de balanço, o torque interno do joelho, em água, é extensor durante praticamente toda esta fase, enquanto em terra é flexor na metade final. Tal mudança pode ser atribuída à atuação da força de arrasto em conjunto com o empuxo.

Em terra a extensão do joelho na fase de balanço ocorre em grande parte pela ação da força peso e por inércia (já que não atuam forças externas capazes de frear o movimento da perna). Em água a ação do empuxo é contrária ao peso e o arrasto freia o movimento da perna, cujas velocidades são bem menores em comparação as do andar em terra. Desta maneira é necessária a ação concêntrica dos extensores do joelho (figura 4.19) para gerar o movimento que antes acontecia, em grande parte, pela ação de elementos passivos.

Ao contrário do que foi observado por Miyoshi e colaboradores [28], não foi possível perceber para o joelho uma redução dos torques articulares em água (ver figura 4.16). Tanto o máximo torque flexor, quanto o máximo torque extensor foram semelhantes nos dois ambientes (ver figura 4.17).

Para o quadril podemos verificar que o pico de torque flexor, que em terra ocorre na transição da fase de apoio para a fase de balanço, passa a ocorrer, em água, aproximadamente no meio da fase de balanço. Desta forma, o torque na fase de apoio é predominantemente extensor (como foi visto por Miyoshi e colaboradores $[28,29]$ ) e na fase de balanço predominantemente flexor. O torque interno flexor, em terra, tem primeiro a função de frear o movimento extensor do quadril [52] e prevenir que o membro inferior "colapse" sob a ação da gravidade [30] (ação excêntrica), para depois elevar o membro inferior para o balanço e mantê-lo flexionado (ação concêntrica), como pode ser visto na figura 4.19.

Entretanto, na primeira metade da fase de suporte, pode haver uma modificação nos torques articulares para gerar, sobre o solo, a força adequada para vencer a ação resistiva do arrasto. Isso pode explicar o fato do torque extensor ser crescente e não decrescente nos primeiros $20 \%$ do ciclo. Essa hipótese surge da análise das componentes da força articular, que mostra um torque flexor sobre o quadril devido à ação da força articular do joelho sobre a coxa (torque de $F_{\mathrm{J}}$ na equação 3.10$)$.

Já na segunda metade, assim que a perna contra lateral passa a frente da perna de apoio, a extensão do quadril ocorre em grande parte pela inércia do movimento do tronco [52]. Contudo, em água, existe a força de arrasto que freia esse movimento, podendo ser esta a explicação para a ação concêntrica do torque interno sobre o quadril (ver figuras 4.16 e 4.19).

Estes resultados estão em acordo com o que foi proposto por Miyoshi e colaboradores [30], e reforça a hipótese proposta por eles de que a função principal dos torques dessa articulação na fase de apoio seria a de gerar propulsão.

Em água, ainda no final do apoio, o torque passa a ser flexor, também em uma atitude concêntrica, para elevar o membro inferior para o balanço. Ele é mantido nesta direção durante quase toda fase final do ciclo. Isso pode ocorer devido a ação extensora da força de arrasto (ela age no tronco e na coxa de modo a extender a articulação do quadril - ver figuras 4.12 e 
4.20), e também pelo efeito de diminuição global da velocidade da marcha.

Assim como acontece na articulação do joelho, apesar da mudança na coordenação muscular e redução das forças articulares, não foi possível perceber diferenças entre os máximos torques flexores e extensores do quadril nos dois ambientes (figura 4.17).

No que diz respeito ao instante de contato inicial, não foi possível perceber diferença, entre os ambientes, no torque articular que age sobre o tornozelo, apesar disso, ele apresenta valores menores em água. Já os torques sobre o quadril e joelho foram maiores no ambiente terrestre (ver tabela 4.16).

O fato de não haver mudança no sentido dos torques neste instante, aliado ao fato de que as componentes das forças articulares tem o mesmo sentido nos dois ambientes, sugere que a redução, em água, dos momentos no quadril e joelho se deva principalmente à ação do empuxo e diminuição da velocidade de movimento, o que provoca a redução do impacto do contato do membro inferior com o solo.

Com relação às potências articulares, podemos perceber através dos gráficos da figura 4.19 e da tabela 4.18, que há uma redução dos valores dessa grandeza em ambiente aquático. Como não há redução nos torques para o joelho e para o quadril, supõe-se que a diminuição nas velocidades angulares articulares é responsável por isso. Já no tornozelo, a redução da potência se deve tanto a redução dos torques articulares quanto à redução da velocidade.

As principais modificações ocorrida nas "trocas de energia" nas articulações podem ser vistas no joelho e quadril. O quadril apresenta uma contração resultante concêntrica na maioria do ciclo, sugerindo que a ação muscular vai no sentido de gerar o movimento durante quase toda a passada. As mudanças ocorrem principalmente na fase de balanço, quando o quadril atua de modo a propulsionar o corpo contra a força de arrasto.

No joelho, a potência é bem pequena na fase de apoio, devido às baixas velocidades articulares. É possível verificar também que ela oscila menos em água, principalmente na primeira metade do apoio, quando esta variação está associada à absorção de impacto. Na fase final do balanço, há uma grande modificação na curva da potência em ambiente aquático com relação ao ambiente terrestre: ela atinge, em água, o maior valor positivo, indicando contração concêntrica dos extensores do joelho, quando em terra atinge valor máximo negativo, indicando contração excêntrica. Como discutido anteriormente, isso sugere que os músculos do joelho agem de modo a fornecer energia para o movimento da articulação, ao contrário do que é feito em terra.

O movimento concêntrico do joelho durante a extensão, foi visto também por Pöyhönen ao investigar a atividade eletromiográfica dos extensores e flexores do joelho durante o exercício de extensão realizado em água [39].

Os resultados, aqui apresentados, sobre as potências e torques articulares parecem ir no mesmo sentido que os resultados apresentados por Barela e colaboradores [3] para a atividade elétrica dos músculos que movimentam as articulações do membro inferior. Os autores constataram uma mudança nos padrões de ativação muscular em ambiente aquático em com- 
paração com o ambiente terrestre. A exceção foi o músculo gastrocnêmio medial, o qual atua como flexor plantar do tornozelo. Os autores verificaram também, aumento na ativação das cabeças longa e curta do Biceps, que age como flexor do joelho, durante a fase de apoio. Quanto ao eretor espinhal, extensor do quadril, verificaram que ele era mais ativado no início da fase de suporte e se mantinha assim até o final do ciclo.

No geral, os autores reportam uma ação mais tônica (mais contínua) dos músculos em ambiente aquático, em contraposição aos picos mais definidos de ativação em ambiente terrestre [3], e atribuem isso a necessidade de ativação constante da musculatura para vencer a resistência do arrasto. Isso parece estar em acordo com as menores variações no sentido de atuação tanto das forças quanto dos torques articulares, em ambiente aquático.

\subsubsection{O Papel da Força de Arrasto e do Empuxo nas Adaptações Realizadas Durante o Andar em Água}

Observando os gráficos das figuras 4.18, 4.11 e 4.20, ou mesmo os valores máximos atingidos pela força de arrasto que age sobre cada segmento (tabela 4.12), podemos concluir que a força de arrasto, que age individualmente em cada segmento, é menor que outras forças envolvidas no movimento (como por exemplo as forças articulares - figura 4.13 - e a força de reação do solo - figura 4.10) e que a contribuição dos torques da força de arrasto para o torque interno resultante é bem pequena.

Contudo, a mudança provocada pela presença do arrasto é uma mudança mais global do que local, pois, como dito anteriormente, o arrasto resultante sobro o corpo imerso pode chegar a valores próximo a $15 \%$ PC nas fases de apoio simples, o que corresponde a aproximadamente metade do módulo da força de reação do solo.

A atuação da força de arrasto diminui a velocidade dos movimentos, reduzindo significativamente os efeito da inércia em algumas fases do ciclo, mas não modificando os padrões de movimentação articular. Entretanto, os resultados de estudos anteriores [3] mostram que o posicionamento dos segmentos é alterado, o que modifica, por exemplo, a trajetória do centro de massa do pé (figura 4.8), ou o ângulo do joelho durante o início e o fim do balanço (figura $4.1)$.

Estas modificações nas posições segmentares podem estar associadas a estratégias para diminuir a força de arrasto (diminuindo $A_{\perp}$ ), principalmente no balanço, onde as velocidades são maiores. Tais modificações também podem ser devido à necessidade de gerar, sobre o solo, uma força cujo impulso seja maior ou igual ao da força de arrasto, para manter o movimento, durante a fase de apoio.

A necessidade de impulsionar o corpo contra a força de arrasto, é provavelmente, a maior responsável pela modificação nos torques e forças articulares na fase inicial do apoio. Isso porque a tarefa de se movimentar para frente em ambiente aquático não é fácil: além do 
arrasto que se opõe ao movimento, há também uma redução do atrito, pois este é proporcional à força vertical aplicada sobre o solo,que é menor em ambiente aquático.

A diminuição dos efeitos da inércia, aliada à desaceleração provocadas pela força de arrasto (principalmente da fase de balanço), também é responsável por modificar os torques e forças articulares, exigindo uma ação concêntrica maior nas articulações do joelho e quadril.

Apesar das alterações na coordenação muscular das articulações não é possível verificar uma diminuição significativa nos torque articulares do joelho e do quadril (ver figuras 4.16 e 4.17), o que sugere que, caso não ocorra co-contração muscular em ambiente aquático, a força muscular necessária para mover estas articulações é similar em terra e água.

O empuxo tem um papel bastante importante na redução das forças internas na fase de apoio e balanço. Ele age se opondo ao peso corporal, o que diminui a força de reação do solo vertical na fase de apoio e a tração sobre as articulações na fase de balanço. Ele também é responsável pela redução dos torques articulares sobre o tornozelo no apoio e por "minimizar" o efeito do torque da força peso sobre o joelho e o quadril (principalmente na fase de balanço), contribuindo também para a modificação nos padrões destes torques.

\subsubsection{Implicações e Estudos Futuros}

A principal implicação dos resultados deste estudo está em fornecer parâmetros, que permitam aos profissionais da área de saúde, prescrever mais corretamente a atividade de andar em seus protocolos de treinamento e reabilitação. As variáveis aqui reportadas fornecem informações não só quanto a carga sobre as articulações, mas também quanto ao papel dos torques durante este movimento, o que pode ajudar o profissional a aproveitar melhor os benefícios oferecidos pelo meio aquático.

A redução das forças internas, devido à ação do empuxo, comprova que caminhar no ambiente aquático é uma maneira de se exercitar adequada a pacientes com problemas articulares, que apresentem dor quando sujeitos a forças compressivas. A existência da dor nesse tipo de paciente pode reduzir a amplitude de movimento articular. Assim, ao caminhar em água, o paciente estaria sujeito a forças inferiores, o que diminuiria a dor e auxiliaria na recuperação da amplitude de movimento, pois, como foi mostrado anteriormente, caminhar em água não altera os limites de deslocamento articular.

As mudanças na coordenação muscular do joelho e do quadril, provocadas pela ação do empuxo e do arrasto, fazem com que durante a fase de apoio do andar em água, sejam trabalhados mais os músculos flexores do joelho e os extensores do quadril. Já na fase de balanço são trabalhados mais os extensores do joelho e os flexores do quadril.

Apesar da alteração na coordenação muscular, os resultados indicam que os torques, necessários para realizar os movimentos destas articulações, são semelhantes nos dois ambientes. Isso implica que, caso não haja co-contração em ambiente aquático, a magnitude da força 
muscular que gera esses torques é semelhante nos dois ambientes; caso a co-contração exista, as forças musculares no joelho e no quadril seriam maiores em ambiente aquático (pois sabe-se que em terra a existência de co-contração é muito pequena [52]).

Percebe-se também, com o auxilio das curvas de potência articular, que, em ambiente aquático, há uma ação concêntrica dos extensores do joelho no final da fase de balanço, enquanto em terra essa ação é excêntrica. Com relação ao quadril, a análise da potência sugere que a ação concêntrica prevalece durante todo o ciclo, não existindo a fase de contração excêntrica no final do apoio, como em ambiente terrestre.

No que diz respeito ao tornozelo, os resultados mostram que, durante o apoio, há uma redução no torque necessário para gerar a flexão plantar e, durante a fase de balanço, há um aumento no torque necessário para gerar a dorsi-flexão. Para esta articulação, não foi possível verificar alterações nem nos padrões de coordenação muscular nem nos padrões da potência.

As diferenças apresentadas pelos indivíduos nos torques e potências articulares durante o andar em água, em relação ao andar em terra, devem ser consideradas na reabilitação da marcha, que em diversos casos é iniciada neste ambiente.

Estudos futuros devem verificar o comportamento das forças e torques articulares à medida em que é modificada a intensidade do exercício, variando, por exemplo, a profundidade de imersão e a velocidade do andar. Além disso, como diversas populações se beneficiam do exercício em água, este estudo pode ser reproduzido para grupos como idosos ou pacientes com hemiplegia.

O método, aqui utilizado, também pode ser adaptado para ser empregado no cálculo das forças e torques articulares durante outras atividades, como exercícios executados em hidroterapia e hidroginástica, corrida em águas rasas e corrida em águas profundas ("deep running"). Entretanto, para tornar o método mais acurado, estudos devem determinar os valores específicos do coeficiente de arrasto para cada segmento corporal e, principalmente, os termos não inerciais (massa adicional) que contribuem para a força de arrasto. 


\section{Capítulo 6}

\section{Conclusão}

Os resultados deste estudo mostraram que há uma redução significativa na magnitude das forças articulares durante o andar em água. Isso nos permite afirmar que há diminuição nas forças compressivas, que agem nas articulações do membro inferior, durante a fase de apoio. A inversão no sentido da componente horizontal das forças articulares, indica que devem haver modificações, também, nos sentido das forças de cisalhamento em relação ao ambiente terrestre.

No que diz respeito aos torques articulares houve mudanças significativas nos padrões de coordenação muscular para as articulações do joelho e do quadril. Na primeira metade do apoio, estas mudanças parecem estar ligada à necessidade de gerar sobre o solo uma força adequada para vencer a resistência do arrasto. Especificamente no joelho, há o desaparecimento do primeiro pico de torque extensor que, em terra, tem a função de impedir o crescimento demasiado da força de reação do solo (absorção do impacto). Em água, o torque flexor que aparece nesta fase do ciclo sugere que o joelho também tem função de auxiliar na propulsão em água. No balanço a ação do empuxo contrária ao peso, a desaceleração dos movimentos provocadas pelo arrasto e as baixas velocidades, parecem estar associadas às modificações nos padrões dos torques articulares do joelho e quadril.

Apesar da mudança na coordenação muscular, não foi possível verificar mudanças nas intensidades máximas atingidas pelos torques flexores e extensores no ambiente aquático. Estes resultados sugerem que, caso não ocorra co-contração muscular, a magnitude das forças musculares que geram estes torques são semelhantes.

Com relação ao tornozelo, os resultados mostram que há redução na força muscular necessária para gerar a flexão plantar durante o apoio e aumento na força necessária para gerar a dorsiflexão no balanço. Não é possível verificar, no entanto, alterações nos padrões de solicitação muscular nem nos padrões da potência articular.

$\mathrm{Na}$ análise dos ângulos articulares, apesar de, no geral, haver concordância entre os dados apresentados neste estudo e os reportados em estudos anteriores, alguns resultados foram inconclusivos e/ou conflitantes. Demonstra-se, assim, a necessidade de uma melhor investigação desses parâmetros. Também parece ser necessária uma investigação cuidadosa dos ângulos 
segmentares, o que poderia auxiliar na interpretação dos torques articulares.

As forças de arrasto em ambiente terrestre, assim como seus respectivos torques sobre as articulações do membro inferior, foram pequenas, podendo ser desprezadas. Em água, o arrasto atingiu em cada segmento valores próximos a $4 \% P C$ e os torques destas forças contribuíram pouco para os torques articulares, o que sugere que, analisar apenas localmente a influência do arrasto, não é adequado para interpretar o movimento em água. As modificações mais significativas causadas por essa força consistem na redução global da velocidade do andar e na mudança do padrão da componente ântero-posterior da força de reação do solo. Tanto a redução da velocidade quanto a necessidade de gerar sobre o solo uma força horizontal sempre positiva, implicam em um padrão de ativação muscular diferenciado em ambiente aquático.

Os números de Reynolds apresentaram valores próximos aos reportados em estudo anterior, indicando que as hipóteses com relação ao escoamento são adequadas para descrever a situação experimental. Além disso a alta correlação linear entre o impulso da componente ânteroposterior da FRS e o impulso da componente horizontal da força de arrasto, bem como os resultados do ajuste linear, feito sobre estas duas grandezas na fase de apoio simples da marcha, mostraram que o método usado para a estimativa da força de arrasto também foi adequado dentro das incertezas das grandezas envolvidas em seu cálculo. Entretanto, o fato dos impulsos da componente horizontal do arrasto terem sido sistematicamente maior que os impulsos da componente horizontal da força de reação do solo, para todos indivíduos, sugere que a força de arrasto pode estar ligeiramente super-estimada. Isto pode estar relacionado ao valor atribuído ao coeficiente de arrasto, que se trata de uma grandeza pouco investigada para os segmentos corporais.

É reforçada, assim, a necessidade de se conduzir estudos que estimem de forma mais acurada os coeficientes de arrasto para os segmentos corporais. Uma melhor estimativa desses coeficientes, aliado ao cálculo dos termos não inerciais (massa adicional) que contribuem para o arrasto, devem tornar o método de estimativa desta força mais acurado.

Os dados fornecidos por este estudo serão capazes de orientar melhor os profissionais da área de saúde na prescrição de atividades físicas dentro da piscina. Contudo, foram reportadas as forças e torques articulares para uma única velocidade e um único nível de imersão. Além disso, foi considerada apenas a população de adultos jovens e saudáveis. Estudos futuros devem considerar, então, diversas velocidades de caminhada e profundidades de imersão, visando obter uma compreensão mais completa das cargas sobre o aparelho locomotor durante a tarefa do andar. Eles também devem considerar as diferentes populações que podem se beneficiar da prática de atividades físicas em ambiente aquático, como por exemplo idosos.

Finalmente, o método apresentado para cálculo da força de arrasto se mostrou adequado podendo também ser aplicado em uma primeira investigação das forças e torques articulares durante outras atividades, como exercícios executados em hidroterapia e hidroginástica, corrida em águas rasas e corrida em águas profundas ("deep running"). Entretanto, para tornar os 
resultados mais acurados, as implementações, propostas acima, no método de cálculo da força de arrasto devem ser realizadas. 


\section{Anexo A}

\section{Questionário de Anamnese Clínica}

Nome

Data de Nascimento:

No

Massa:

Estatura

\section{ANAMNESE CLÍNICA}

1. Possui problemas musculares ou tendinite?

() Sim. Quais?

() Não

2. Sofreu fraturas ou sente algum tipo de dor nos membros inferiores ou em suas articulaçōes?

() Sim. Especifique

() Não

3. Possui doenças neurológicas?

() Sim. Quais?

() Nâo

4. Possui alguma deficiência física?

() Sim. Qual?

() Não 
5. Sente algum tipo de tontura ou fraqueza?

( ) Sim. Especifique

() Não

6. Usa medicamentos regularmente?

() Sim. Quais?

() Não

7. Já fez alguma cirurgia?

() Sim. Qual?

() Não

\section{INFORMAÇŌES ADICIONAIS}
Pratica atividade(s) física(s) ?
() Sim
() Não

Se sim:

Qual (is)?

Com que freqüência?

Há quanto tempo? 


\title{
Anexo B
}

\section{Termo de Consentimento Esclarecido}

\author{
ESCOLA DE EDUCAÇĀO FÍSICA E ESPORTE \\ DA \\ UNIVERSIDADE DE SĀO PAULO
}

TERMO DE CONSENTIMENTO LIVRE E ESCLARECIDO

I - DADOS DE IDENTIFICAÇÃO DO SUJEITO DA PESQUISA

1. NOME DO INDIVÍDUO:

DOCUMENTO DE IDENTIDADE N²: SEXO: M $\mathrm{F}$ DATA NASCIMENTO: .......................

ENDEREÇO:

$N^{2}$ APTO

BAIRRO:

CIDADE:

CEP:

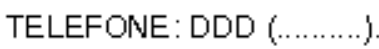

\section{II - DADOS SOBRE A PESQUISA CIENTÍFICA}

1. TÍTULO DO PROJETO DE PESQUISA: "ESTIMATIVA DE FORÇAS E TORQUES ARTICULARES EM SERES HUMANOS DUR ANTE O ANDAR EM PISCINA COM ÁGUA RASA"

2. PESQUISADOR RESPONSÁvEL: Prof. Dr. Marcos Duarte 
3. CARGO/FUNÇÃO: Professor da Escola de Educaçāo Fisica e Esportes -USP

4. AVALIAÇÃO DO RISCO DA PESQUISA:

$\begin{array}{ll}\text { RISCO MÍNIMO } \mathbf{X} & \text { RISCO MÉDIO } \\ \text { RISCO BAIXO } & \text { RISCO MAIOR }\end{array}$

(probabilidade de que o individuo sofra algum dano como consequência imediata ou tardia do estudo)

5. DURAÇÂO DA PESQUISA : A pesquisa consiste em dois experimentos de 30 min que serāo agendados conforme disponibilidade do participante.

\section{III - EXPLICAÇÕES DO PESQUISADOR AO INDIVÍDUO OU SEU REPRESENTANTE LEGAL SOBRE A PESQUISA:}

1. Esperamos com esse estudo ter uma compreensāo melhor da carga mecánlca sobre o corpo humano e a consequiente sollcltaçäo mecánlca que o corpo deve desenvolver para se locomover na água. Desta manelra esses resultados poderāo ser útels para prescrever mals adequadamente atlvldades físicas na água.

2. Durante $\circ$ experImemt $\infty$ o particlpante Irá andar, prlmelramemte, em um amblente aproprlado dentro do Laboratórlo de Blofísica da EEFE-USP e posterlormente em uma plscina aquecida locallzada na mesma Insthulçāo. Pequenas marcas serāo aflxadas em sua pele, com flta adesiva, para reglstrar os deslocamentos de sua perna e pé. Estas marcas nāo serāo conectadas a nenhum cabo elétrlco. Serāo, também, tomadas medldas dos dlâmetros e comprlmentos desses membros. Os movimentos de bcomoçāo, tanto na água, quanto em terra, serāo fllmados para posterlor anállse, mas a Imagem do partic|pante nāo será utIllzada para outros flns que nāo esse estudo.

3. O exper Imento nāo será Invasıvo e nāo envolve qualquer rlsco à saúde física e mental do particlpante, além dos rlscos encomtrados nas atlvidades normals da vida clárla.

4. Esperamos com esse experlmento compreender melhor a carga mecânlca, sobre as artlculaçōes estudadas, durante a locomoçāo na água; podenco aludar numa melhor prescrlçāo de atlvidades físlcas na água. Porém o partlclpante nāo terá nenhum benefíclo dlreto.

\section{IV - ESCLARECIMENTOS DADOS PELO PESQUISADOR SOBRE GARANTIAS DO SUJEITO DA PESQUISA:}

1. O particlpante tem dlrelto a fazer perguntas a qualquer momento sobre os objetlvos do experimento, o procedimento experlmemal, rlscos envolvidos e beneflclo relaclonado à pesqulsa, de modo que suas dúvidas sobre o experlmento sejam esclarecidas pelos pesqulsadores.

2. A particlpaçāo nesse estudo é volumtárla e $\circ$ sujelto da pesqulsa tem $\circ$ dlrelto tenho cllrelto Imterromper a sua particlpaçāo a qualquer momento sem prejuízo próprlo.

3. A Idemtldade do partıclpante nāo será revelada em qualquer momento, bem como seus dados pessoals e sua Imagem, a qual será usada apenas para os flns desse estudo.

4. O particlpante tem dlrelto a asslsténcla médlca no Hospltal Unlversltárlo (HU) e no Hospltal das CIInlcas, da Faculdade de Mediclna da USP, caso ocorram eventuals danos à saúde, decorrentes da partlc/paçāo na pesqulsa. 


\section{V- INFORHAÇÕES DE NOMES, ENDEREÇOS E TELEFONES DOS RESPONSÁVEIS PELO ACOMPANHAMENTO DA PESQUISA, PARA CONTATO EHA CASO DE INTERCORRÉNCIAS CLINICAS E REAÇÕES ADVERSAS.}

Para questónes associadas com esse experimento, por lavor, entrar em conlato com Maria Isabel $\mathrm{V}$. Orselli, pesquisadora gerente elou Prot. Dr. Marcos Duarle, pesquisador responsável e coordenador do Laboralório de Biolísica.

O Laboralório de Biolísica fica na Escola de Educação Física e Esporle, Universidaded de São Paulo, na Rua Prolessor Melo Moraes, 65 - Cidade Uniwersilária - CEP: 05508-030 - lone/lax: 3812-6123

\section{VI. - OBSERVAÇÕES COMPLEMENTARES:}

É direilo do participante manter uma cópia desse consenimento.

\section{VII - CONSENTIHENTO PÓS-ESCLARECIDO}

Declaro que, após convenientemente esclarecido pelo pesquisador e ler entendido o que me foi explicado, consinto em participar do presente Projeto de Pesquisa.

São Paulo, de de 20 


\section{Referências Bibliográficas}

[1] A. M. F. Barela. Análise Biomecâncica do Andar de Adultos e Idosos nos Ambientes Aquático e Terrestre. Tese de doutorado, Escola de Educação Física e Esportes - Universidade de São Paulo, 2005.

[2] A. M. F. Barela and M. Duarte. Biomechanical characteristics of elderly individuals walking on land and in water. Journal of Electromyography and Kinesiology, 2006.

[3] A. M. F. Barela, S. F. Stolf, and M. Duarte. Biomechanical characteristics of adults walking in shallow water and on land. Journal of Electromyography and Kinesiology, $16(3): 250-256,2006$.

[4] A. M. F. Barela, S. F. Stolf, and M. Duarte. Supplementary material to "Biomechanical characteristics of adults walking in shallow water and on land". http://lob.incubadora.fapesp.br/portal/p, 2006.

[5] M. A. M. Berger, G. de Groot, and A. P. Hollander. Hydrodynamic drag and lift forces on human hand/arm models. Journal of Biomechanics, 28(2):125-133, 1995.

[6] M. A. M. Berger, A. P. Hollander, and G. de Groot. Determining propulsive forces in front crawl swimming: a comparison of two methods. Journal of Sports Sciences, 17:97-105, 1999.

[7] A. Biscarini and G. Cerulli. Modeling of the knee joint load in rehabilitative knee extension exercise under water. Journal of Biomechanics, 40(2):345-355, 2007.

[8] C. E. Brennen. A review of added mass and fluid inertial forces. Monografia, Departamento da Marinha, Port Hueneme, California, EUA, 1982. http://resolver.caltech.edu/CaltechAUTHORS:BREncel82.

[9] M. R. Campion, editor. Hidroterapia. Manole, 2000.

[10] P. de Leva. Adjustment to Zatsyorsky-Seluyanov's segment inertia parameters. Journal of Biomechanics, 29(9):1223-1230, 1996. 
[11] P. Douris, V. Southard, et al. Effect of land and aquatic exercise on balance scores in older adults. Journal of Geriatric Physical Therapy, 26(1):3-6, 2003.

[12] M. Duarte. Princípios Físicos da Interação entre Ser Humano e Ambiente Aquático. http://lob.incubadora.fapesp.br/portal/t, 2004.

[13] R. F. Edlich, M. A. Towler, et al. Bioengineering principles of hydrotherapy. The Journal of Burn Care \& Rehabilitation, 8(6):580-584, 1987.

[14] A. Erdemir, S. McLean, et al. Model-based estimation of muscle forces exerted during movements. Clinical Biomechanics, 22(2):131-154, 2007.

[15] R. W. Fox, A. McDonald, and P. J.Pritchard. Introdução à Mecânica dos Fluidos. LTC, 6th edition, 2006.

[16] P. Gardano and P. Dabnichki. On hydrodynamics of drag and lift of the human arm. Journal of Biomechanics, 39(15):2767-2773, 2006.

[17] A. Goland. Basic hydrotherapy. Physiotherapy, 67(9):258-262, 1981.

[18] S. J. Hall. Biomecânica Básica. Guanabara Koogan, 2005.

[19] R. Harrison, M. Hillman, and S. Bulstrode. Loading of the lower limb when whalking partially immersed: implications for clinical practice. Physiotherapy, 78(3):164-166, 1992.

[20] C. Kirtley. Clinical Gait Analysis: Theory and Practice. Elsevier, 2006.

[21] J. M. Klauck. Man's water resistance in acelerated motion: an experimental evaluation of the added mass concept. In K. L. Keskinen, P. V. Komi, and A. P. Hollander, editors, Biomechanics and Medicine in Swimming VIII - Procedings of the VII International Symposium on Biomechanics and Medicine in Swimming, pages 83-88, 1999.

[22] P. V. Komi. Relevance of in vivo force measurements to human biomechanics. Journal of Biomechanics, 23(Sup.1):23-34, 1990.

[23] Y.-H. Kwon. BSP equations. http://www.kwon3d.com/theory/bspeq/bspeq.html\#es, Janeiro 2008. Último acesso.

[24] Y.-H. Kwon. DLT Method. http://www.kwon3d.com/theory/dlt/dlt.html, Janeiro 2008. Último acesso.

[25] Y.-H. Kwon. Modified Hanavan Model. http://www.kwon3d.com/theory/bspeq/hanavan.html, Janeiro 2008. Último acesso. 
[26] K. Masumoto, T. Shono, et al. Muscle activation, caridorespiratory response, and rating of perceived exercion in older subjects while walking in water and on dry land. Journal of Electromyography and Kinesiology, doi:10.1016/j.jelekin.2006.12.009, 2007.

[27] K. Masuumoto, S.-I. Takasugi, et al. Electromyographic analysis of walking in water in healthy humans. Journal of Physiological Anthropology and Applied Human Scince, 23:119-127, 2004.

[28] T. Miyoshi, T. Shirota, et al. Lower limb joint moment during walking in water. Disability and Rehabilitation, 25(21):1219-1223, 2003.

[29] T. Miyoshi, T. Shirota, et al. Effect of the walking speed to the lower limb joint angular displacement, joint moments and ground reaction forces during walking in water. Disability and Rehabilitation, 26(12):724-732, 2004.

[30] T. Miyoshi, T. Shirota, et al. Function roles of lower-limb joint moments while walking in water. Clinical Biomechanics, 20(2):194-201, 2005.

[31] M. Nakashima, K. Satou, and Y. Miura. Development of swimming human simulation model considering rigid body dynamics and unstedy fluid force for the whole body. Journal of Fluid Science and Technology, 2(1), 2007.

[32] D. J. Newman. Human locomotion and energetics in simulated partial gravity. Tese de doutorado, Massachusetts Institute of Technology, 1992.

[33] J. N. Newman. Marine Hidrodynamics. The Massashusetts Institute of Technology Press, 1977.

[34] S. Oda, T. Matsumoto, et al. Relaxation effects in humans of underwater exercises of moderate intensity. European Journal of Applied Physiology, 80(4):253-259, 1999.

[35] C. J. Payton and R. M. Barlett. Estimating propulsive forces in swimming from threedimensional kinematic data. Journal of Sports Sciences, 13:447-454, 1995.

[36] J. Perry. Análise de Marcha: Marcha Normal, volume 1. Manole, 2004.

[37] J. Prins and D. Cutner. Aquatic therapy in the rehabilitation of athletic injuries. Clinics in Sports Medicine, 18(2):447-461, 1999.

[38] T. Pöyhönen, K. L. Keskinen, et al. Determination of hydrodynamic drag forces and drag coefficients on human leg/foot model during knee exercise. Clinical Biomechanics, $15(4): 256-260,2000$. 
[39] T. Pöyhönen, H. Kyröläinen, et al. Eletromyographic and kinematics analysis of therapeutic knee exercises under water. Clinical Biomechanics, 16(6):496-504, 2001.

[40] T. Pöyhönen, S. Spilä, et al. Effects of aquatic resistance training on neuromuscular performance in health women. Medicine $\mathscr{G}$ Science in Sports $\mathscr{G}$ Exercise, 26(1):21032109, 2002.

[41] J. G. Reid and R. K. Jensen. Human body segment inertia parametres: A survey and status report. Exercise and Sport Sciences Reviews, 18:225-241, 1990.

[42] D. Robertson, G. Caldwell, et al. Reserch Methods in Biomechanics. Human Kinetics, 2004.

[43] H. Roesler, A. Haupenthal, et al. Dynamometric analysis of the maximum force applied in aquatic human gait at $1.3 m$ of immersion. Gait $\mathscr{E}$ Posture, 24(4):412-417, 2006.

[44] A. Savitzky and M. J. E. Golay. Smothing and differentiation of data by simplified least squares procedures. Analytical Chemistry, 36(8):1627-1639, 1964.

[45] G. G. Simoneau. Cinesiologia do Aparelho Músculoesquelético: Fundamentos para Reabilitação Física, chapter Cinesiologia da Caminhada, pages 525-573. Guanabara Koogan, 2006.

[46] N. Takeshima, M. E. Rogers, et al. Water-based exercise improves health-related aspects of fitness in older women. Medicine $\mathscr{E}$ Science in Sports $\mathscr{G}$ Exercise, 34(3):544-551, 2002.

[47] H. Toussaint. The "fast-skin"body suit: hip, hype but does it reduce drag during front crawl swimming? Coaches' Information Service, 2005.

[48] B. J. Tovin, S. L. Wolf, et al. Comparison of the effects of exercise in water and on land on the rehabilitation of pacientes with intra-articular anterior cruciate ligament reconstructions. Physical Therapy, 74(8):710-719, 1994.

[49] V. Vanin, P. Gouffon, and O. Helene. Tópicos Avançados em Tratamento Estatístico de Dados em Física Experimental. Notas de Aula, 1998.

[50] A. R. Vorontsov and V. A. Rumyantsev. Biomechanics in Sport: Performance Enhancement and Injury Prevention, chapter Resistive forces in swimming, pages 184-204. Blackwell Publishing, 2000.

[51] M. D. White. Water Exercise. Human Kinetics, 1995.

[52] M. W. Whittle. Gait Analysis. Butterworth Heinemann, 2nd edition, 1996. 
[53] D. A. Winter. Biomechanics and Motor Control of Human Movement. John Wiley \& Sons, 2nd edition, 1990.

[54] M. Yeadon. The simulation of aerial movement - II. A mathematical inertia model of the human body. Journal of Biomechanics, 23(1):67-74, 1990.

[55] F. E. Zajac, R. R. Neptune, and S. A. Kautz. Biomechanics and muscle coordination of human walking. Part I: introduction to concepts, power transfer, dynamics and simulations. Gait \& Posture, 16:215-232, 2002.

[56] V. M. Zatsiorsky. Kinetics of Human Motion. Human Kinetics, 2002. 